


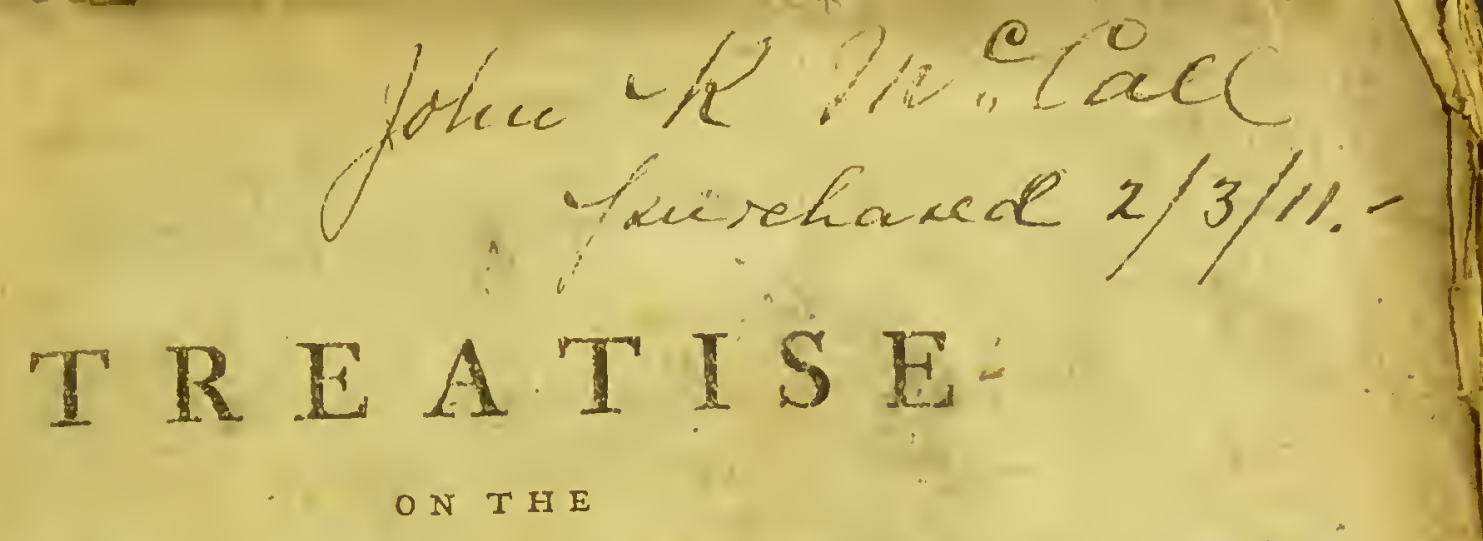

PREVENTIONOF DISEASES I N I D E TAL TO

II 0 क जि FROM BAD MANAGEMENT IN REGARD TO S T A B L S $\mathrm{FOO}$, W A T E R, AIR, AND EXERCISE.

TO WHICH ARE SUBJOINED

\section{O B S E R V A T I O N}

On fome, of the Surgical and Medical Branches

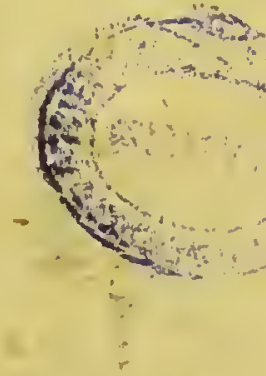

$$
\text { of FARRIERY. }
$$

B Y J. C L. A $R$ K, FARRIER TO HIS MAJESTY FOR SCOTLAND.

L_Lern are modum, finemque tenere,

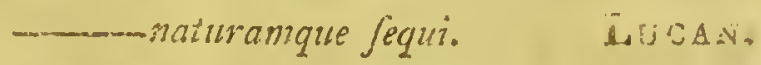

E D I N 3 U R G H:

SRINTED BY W. SMELLIE FOR THE $\triangle U$ THOK; AND SOLD BY THE BOOKSELLERS.
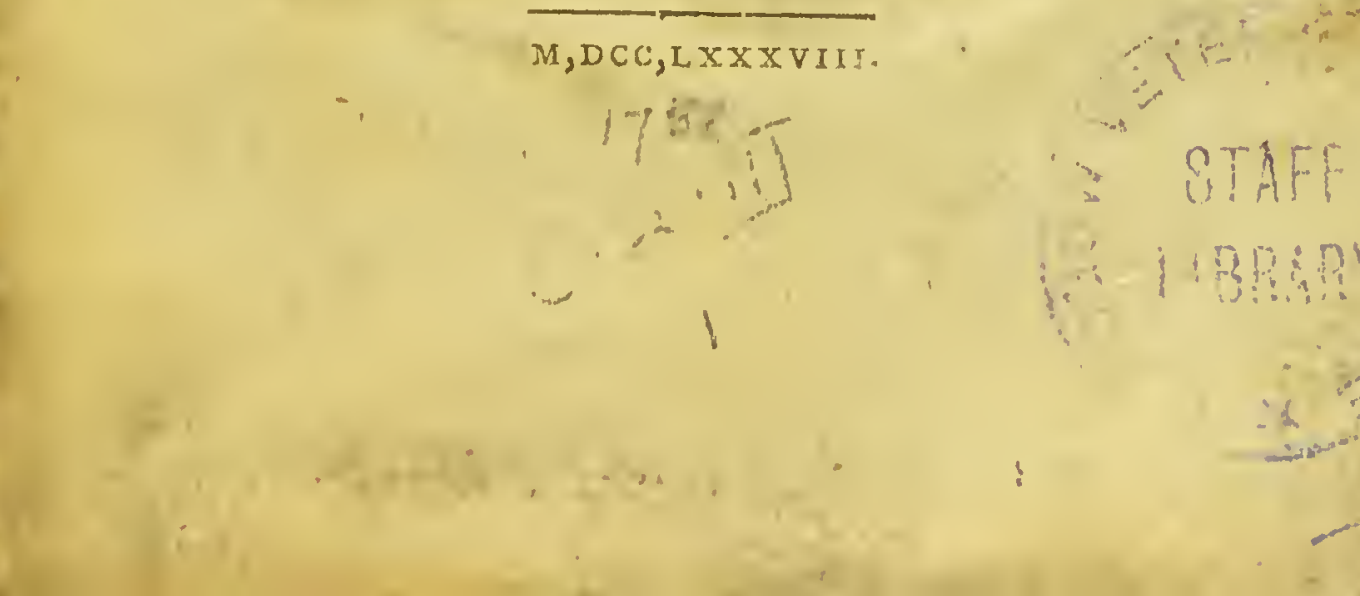

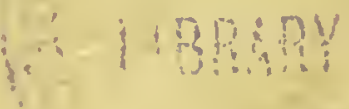





\section{( vii )}

Page.

horfes-improper treatment of horfes in cafes of gripes or colick pains-in cafes of a fwelled throat-the danger of forcing food or medicine on them in fuch cafes

\section{G. $\mathrm{H}$ A P. VI.}

Of blood-letting-the different inftruments ufed for this purpore-the danger of a ligature or bandage applied round the neck before blooding-the neceffity of meafuring the quantity of blood that is taken away-the proper place for making the orifice in the jugular veins-the advantages in curing difeafes from blood-letting appearances of the blood when cold, the uncertainty of - a greater quantity of blood to be drawn away in certain cafes than ufual-quality of the blood-circulation through the body-a defcription of the arteries-veins-the pulfe of a horfe in health-in difeafes-a due attention to the pulfe, the advantages that may be derived from it in the practice of farriery-the cafes which may require blood-letting

\section{H A P. VII.}

Of rowels-the operation defcribed-their ufewhere they ought to be placed-improper in fome cafes 


\section{( viii ) \\ C H A P. VIII. .}

Page.

Of fetons-their ufe-the proper method of introducing them-the form of the needle neceffary - cafes in cureing tumours on the upper part of the neck, as the pole-evil and withersand likewife neceffary to cure deep-feated abfceffes, \&rc.

\section{H A P. IX.}

Of purging-the intention of purging horfes in certain cafes-anatomical defcription of the ftomach and alimentary canal-animal oeconomy in the formation of the chyle-improper treatment of horfes during the operation of purging medicines cenfured-humours falling down explained-purging medicines not always neceffary for preparing horfes that are to run or hunt-the ufe of purging medicines in dif eares, \&c. \&x.

\section{G H A P. X.}

Of clyfters-more general ufe of them recommended-nourihment may be conveyed into the fyftem by clyfters-the compofition of clyfters thould be fimple-defects of too thort clyfter-pipes with fmall bags-a defcription of a proper clyfter-pipe and bag - the ufe of fy- 


\section{( ix )}

Page.

ringes for giving clyfters condemned-forms of clyfters-cafes where clyfters may be given with fuccers

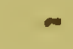

\section{G H A P, XI.}

Of drinks or drenches-the bad confequences of having them titled cures for difeafes-neceflity of having them properly compoundedthe proper time of adminiftering them of importance in certain difeafes-fhould be made palatable

\section{G H A P. XII.}

Of balls-the confequences of having them titled cures for difeafes-proper method of giving them -cautions concerning the compounding of them

\section{H A P. XIII.}

Of diuretics-their ufe in difeafes-preferable to purging medicines in many cafes-the cafes which require diuretic medicines-in what form they may be given

\section{G II A P. XIV.}

Of giving medicines as prefervatives or preventatives-the cuftom of giving horfes medicines 


\section{$(x)$}

Pagé.

whilft they are in health cenfured-aiteratives, their effects when properly prepared, and prefribed with judgment-the coarfer kind of antimony fhould be rejected-falts the fafert alterative, efpecially nitre $\quad-\quad \quad-\cdot$

\section{C $\mathrm{H}$ A P. XV.}

Of moulting or cafting the hair-horfes more fubject to faintnefs or weaknefs during that feafon than any other time of the year-manner in which horfes are kept and treated increafes this weaknefs, \&c. - the end of autumin the feafon when horfes may be faid to moult - the coldnefs and chillinefs of the weather, at this period, increafes the diforders of horfes-evacuations by medicines, \&c. hurtful, in many cafes, at this period-this feafon peculiarly fevere on old horfes-aged horfes fubject to difeafes in the teeth-a cafe-horfes are differently affected during the moulting-their feeding ought to be increafed at this period-frequent drefling or currying of horfes of great benefit to them at this time

\section{II $\wedge$ P. XVI.}

Of lamenefs-the caufes which may produce lamenefswa complication of them may take 


\section{( $\mathrm{xi}$ )}

Page.

place in the fame limb, and at the fame time - houlder-lip, remark on-bonny excrefcences, on the fhoulder or leg-bones, frequently the caufe of lamenefs, \&rc. \&c.-the difficulty of difcovering the true feat or caufe of a horfe's lamenefs in many cafes-caution recommended to practitioners in fuch cafes-illfitted faddles frequently caufe lamenefs

\section{H A P. XVII.}

Of beating or ill-treating horfes-the effects it produces on horfes in rendering them vicious - gentle ufage preferable to force or chaftifement-the practice of the Arabians recommended-horfes have their peculiarities of temper as well as the human fpecies-ill-ufage in breaking, \&c. the caufe of horfes fcaring or bogling at objects they meet on the road-the fenfe of hearing very acute in horfes-an advite to bad riders-chaftifing horfes on their tripping or ftumbling, its effects on them-the different caufes that may occafion horfes ftumbling, sic.

\section{G H A P. XXIII.}

Of trimming horfes ears-the bad effects it produces on them in many cafes-cropping their cars too thort produces the fame effects 395

$\mathrm{CH}$ A P. 


\section{( xii )}

\section{H A P. XIA.}

Of friction or drefling horfes-the effects it produces on the circclating fluids-promotes the natural fecretions-the advantages of it when horfes turn cold and chilly after exercife-to be avoided in the legs in cafes of fome difeafes -wahhing horfes bodies with cold water when over-heated, in order to clean them, remark on 408

\section{C $\mathrm{H}$ A P. XX.}

Of the management of horfes when travellingneceffary preliminaries confidered before taking a journey on horfeback-on watering, feeding, and drefling horfes, on a journey-remarks on fteel points for the fhoes when the roads are covered with ice - . . - 418 


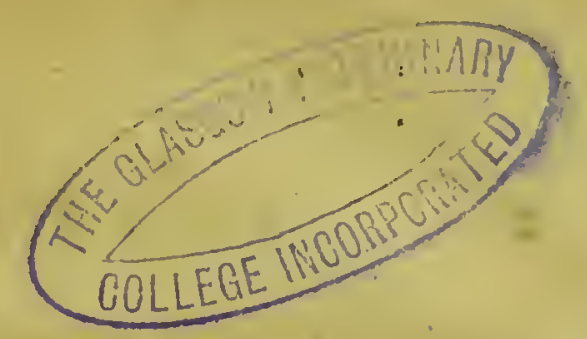

$\begin{array}{lllllll}\dot{P} & \mathbb{R} & \mathrm{E} & \ddot{\mathrm{F}} & \mathrm{A} & \mathrm{C} & \mathrm{E}\end{array}$

NN profecuting the plan which I formerly 1 propofed, in the introduction to my obfervations upon the Shoeing of Horfes, and the difeafes of their feet, which was to communicate my obfervations on the difeafes of horfes, I found that a number of repetitions and digreffions would occur fo frequently upon the proper management of horfes, in a variety of refpects, and which could not be avoided, without a manifeft injury to the work. In order to avoid this inconvenience, and to render the plan more complete and intelligible, I concluded that it would be of more utility to write a A feparate 
Separate treatife on the Management of Horfes in general, in which I have endeavoured to point out the Caufes of Difeares, and particularly of the acute kind, which generally prove moft deftructive to horfes. As immediately connecied with the fubject, I have fubjoined fome obfervations on the Medical and Surgical Branches of Farricry, becaufe they are abfolutely necefiary to be underftood by the young practition$\mathrm{er}$, before he enters upon the ftudy of the difeafes of horfes. It is not my intention to compile a Syftem of Farriery, but only to make fuch remarks and obfervations upon the moft practical branches of this ufeful art, as may contribute towards its improvement.

I am but too fenfible of the many difadvantages, in the prefent mode of a Farrier's education, the young practitioner labours under, and the difficulties he has to furmount, before he can attain, even in theory, a tolerable knowledge of the leading principles 
principles of this art. For that of Anatomy, the Materia Medica, and the Practice of Phyfic, fo far as may be neceffary for horfes, ought to be laid open to young Farriers, in a regular and fcientific manner, by Profeffors in different parts of the kingdom. At prefent, all the opportunities the young practitioner can have, for improving: himfelf in thefe branches, are only from reading; and reading alone is not fufficient to qualify a man, either for the profeffion of a Phyfician, "or a Farrier. All the affiftance that poffibly can be derived from theory, from demonftration, from practice and obfervation, are neceffary to qualify the Farrier for his profeffion. But, whilft this neceffary piece of education is neglected, and totally overlooked, the Farrier's art muft forever remain in darknefs and obfcurity. The fubject is of importance ; and it is furprifing that, whilft the arts and fciences are cultivated in a high degree, this ufeful art fhould be fo entirely neglected, more efpecially in Britain, which, 
at the fame time, is poffeffed of the fineft horfes perhaps in the world.

The laudable attempts that have been made by different authors, who have written on the fubject of Farriery, can only be attended with a partial improvement, while a regular mode of education is not to be attained on any terms, at leaft in this country. In France, a regular academy for the inftruction of young Farriers has been inftituted. The attempt is laudable, and worthy of imitation. The Phyfician and Surgeon enjoy the greateft opportunities for receiving inftruction in their proferfions, by a regular education. The analogy between the difeafes of the human body and thofe to which a horfe is liable, is very great. Hence it mult be obvious that the cure of thofe difeafes which affect the latter, muft depend upon the fame principles as that of the former : from which it is likewife evident that a regular education is neceffary to a Farrier. 
In handling the following fubjects, I have not extended them all the length they might have been carried; confining myfelf chiefly to the practical branches, and carefully hunning whatever might tend to perplex the reader, by avoiding technical terms as much as poffible, and at the fame time fudying the utmoft brevity the fubjecls would admit of.

The very favourable reception which my former Treatife on the Shoeing of Horfes, and on the Difeares of their Feet, met with from the public, encourages me to proceed in profecuting the plan I have propofed. In hopes of the fame kind indulgence, I now fubmit the following theets to the candour of the public, and earneftly wifh it may tend to the improvement of that art on which it treats. 



\section{IN T R O D UCTIO N.}

To hold the golden mean,

To keep the end in view, and follow nature.

$7 \mathrm{HE}$ propriety of this excellent ma-

1 xim is perhaps in. few cafes more applicable than in the following fubject, relating to the management of horfes. Every judicious obferver muft have had an opportunity of feeing the many abfurdities daily committed in the treatment and management of this animal, in a great variety of cafes, and, at the fame time, of obferving the bad confequences that follow from it; and perhaps there is no fubject of equal importance, in which people are more apt to be led by prejudice in favour of certain eftablifhed 
eftablifhed modes and cuftoms. But a prejudice in favour of popular cuftoms, however plaufible they may appear, when adopted without any inquiry into their propriety and ufefulnefs, farther than the fanction of the vulgar, can feldom ftand the teft of philofophical inquiry.

It is to be regretted with what obftinacy many ridiculous abfurdities are perfevered in, relating to horfes, in oppofition to experience, and to common fenfe, which nothing can ever banifh from ftables, but the interpofition of thofe whofe real intereft it will be, and who thould affume the right they have to think for themfelves, without being dictated to by thofe they fhould command.

The many advantages we derive from horfes, their real and folid fervices, render them valuable; and every thing which tends to improvement in the management of them, or in preventing thofe difeafes they 
they are fubject to, (by error in management, ) are objects worthy of attention.

Horfes, in their natural fate, or running at grafs in the fields, do not require much attention from man. If they have fufficient pafture and water, they eat, drink, and run about at pleafure. Their wants are few, and eafily fupplied; and they enjoy a perfect ftate of health. But, in a domefticated ftate, their conftitutions undergo a confiderable change. They require particular care and attention in the management of them. To be fheltered from the weather, and to be fed with rich food, to enable them to perform with vigour the various labours impofed on them, and which too frequently are exacted with rigour and feverity, beyond what they are well able to bear. Hence the unnatural reftraint, the confinement in too clofe foul aired ftables, together with the violent exercifes they are expoled to, and the injudicious management of them. 
in a variety of refpects, render them liable to a long train of difeafes, which fooner or later prove fatal to them.

The Britifh horfes are jufly efteemed the finet in the world; and, what is very remarkable, it is the finef and beft of thefe horfes that too frequently are moft expofed to be hurt from an injudicious method of treating them. Whillt thofe of an inferior quality, being left more to themfelves, or, in other words, are allowed to live more agreeable to their nature, and free from thofe eftablifhed practices obferved in the more elegant fables, perform the tafk required of them to a good old age in health and foundnefs; a mode of refinement, if it may be fo called, prevails in the ftables where fine horfes are kept, every thing refpecting the management of them is carried almoft to an extreme, infomuch that there is hardly any medium obferved. Thus, a certain degree of warmth is agreeable, and even neceffary, to horfes, yet they generally 
generally are kept too hot, at the fame time frequently loaded with body-cloaths. Food, which ought to be diftributed according to their work or exercife, is frequently dealt with too liberal a hand; whether they work or not, the food is always continued the fame, without confidering whether the wafte in the confitution requires a greater or a leffer fupply of nourifhment. Exercife, that neceffary article for preferving them in health, and fit for the active exercifes required of them, is too frequently neglected. Frefh air, that exhilarating principle of life, which is fo effentially neceffary for the health of all animals, is but too much excluded from their ftables. But that I may not anticipate my fubject, I thall only obferve, that the health and foundnefs of horfes depend greatly on the manner in which they are treated; and it ought always to be obferved, as a general maxim, that the nearer we approach in the management of horfes, to that which is moft agreeable to their nature, they will 


\section{2} INTRODUGTION.

be in the greater perfection; and the farther we deviate from this rule, we lay a reftraint upon them, and injure their confitutions.

In profecuting this fubject, my defign is not to advance or fupport any extravagant hypothefis refpecting medical theories, or to recommend infignificant noftrums, as infallible remedies for this or that difeafe or lamenefs; but to make fome general remarks and obfervations upon the common methods at prefent in ufe in the management of horfes, and to how the bad effects which may arife from any excefs, neglect, or ill conduct, obferved in the management of them in thefe articles. At the fame time, I fhall point out the means by which many difeafes and lamenefs may, in a great meafure, be prevented.

This may be confidered, at firft view, as prefuming too much : But it is furely of greater importance to endeavour to prevent difeafes 
difeafes and lamenefs in horfes, efpecially when it is practicable, by proper care and attention in the managing of them, than by an oppofite conduct, to run the rifk of their health and foundnefs, and afterwards have recourfe to precarious and uncertain cures; for many difeafes and lamenefs in horfes might, without all doubt, be presented, by proper care and attention, which, when once they have taken place, cannot fo eafily be removed. Slight caufes, when neglected, often produce the moft violent complaints, which art, in many cafes, can only palliate; and it ought always to be remembered, that unlefs horfes are in health, and thoroughly found, they are not fit for the laborious exercifes required of them.

This fubject has already, in fome degree, been treated by authors who have written on the difeafes of horfes. The Right. Honourable the Earl of Pembroke, at the end of his Military Equitation, has

likewife, 


\section{I4 INTRODUCTION.}

likewife, with great propriety and judgement, given fome remarks on the treatment of military horfes, which, in many refpects, are applicable to horfes in general. Had his Lordhip extended his plan, this, or any publication on that particular branch, would perhaps have been fuperfluous. As, however, there is ftill a large field for improvement, I apprehend it may be proper to profecute this branch of ufeful knowledge, as it is of importance, and neceffary to be attended to, by every one who wifhes to have his horfe in health, Atrength, and fit for action; and, at the fame time, is defirous of acquiring fome infight into the mott prevailing caufes of the difeafes to which horfes are liable. It will alfo ferve as a neceffary preliminary to a fubfequent publication on the difeafes of that noble animal.

In order to render the fubject more eafily underftood, I thall endeavour to avoid 
all prolix and abftract reafoning, and found my arguments chiefly upon the analogy which fubfilts between the human body and that of a horfe; at the fame time I thall avail myfelf of facts taken from different authors on the fubject, and from my own obfervation and long experience in the management of horfes.

Health is the faculty of performing all the functions of animal life in the mort proper and perfect manner; that is, when refpiration or breathing is performed in a free, eafy, regular manner; when a horfe can bear exercife or labour, without becoming thort-breathed, faint, or appear too much fatigued, in proportion to the labour or exercife he has undergone; when he eats and drinks moderately, with a good appetite, and appears refrefhed by it; when his hair lies fmooth and fhining; when the excretions of dung, urine, \&c. are difcharged in a due proportion and 


\section{6}

confiftency; and when a horfe appears lively, active, and full of fpirit.

In order to preferve horfes in this healthful ftate, it is not neceffary to have recourfe to medicine or blooding, \&c. \&c. by way of preventing difeafes, or preferving them in health. The moft effectual means to attain this end, are a proper attention to the management of them in general, which partly confifts in accommodating them with well aired ftables, with wide ftalls, and allowing them wholefome and nourithing food and drink, in proportion to the labour required of them; together with well-timed exercife, when they are not otherwife employed; to which may be added, good rubbing and dreffing, twice or thrice every day. There are likewife feveral other confiderations relating to the management of horfes, under a variety of circumftances, which are neceffary to be attended to. It will there- 
fore be proper to confider each of thefe feparately under their different heads, to fhow wherein many errors in the management of horfes at prefent confift, and to point out the proper means by which they may be preferved in a healthful active ftate.

C OBSER. 


OB SER VATIONS

\author{
O N T H E
}

\title{
MANAGEMENT OF HORSES.
}

\section{C $\mathrm{H}$ A P. I. \\ O F S T A L E S}

YOUNG horfes generally are accuf-

1 tomed to live and breathe in a pure open air till they come of age, and are fit for labour; it is then found convenient to houfe them. This produces a confiderable change in their bodies, and makes them liable to be greatly affected by the temperature of the air which furrounds them.

That the generality of ftables are kep too clofe and hot, requires no demonftration, as every one who goes into them 
(even when the weather is pretty cool) muft have difcovered it from his own feelings; and, in the fummer feafon, the heat within them is increafed to a very great degree. What renders it ftill worfe, it frequently happens, that from the fituation and ftructure of many ftables, no opening can be made to allow a fufficient quantity of frefh air to render the animals in any degree eafy. The door is the only entrance for air, and that can only happen occafionally when it is open. It is true, the intercourfe that muft unavoidably take place through the day in going out and in, renders fuch ftables colerably fweet aired; yet in the mornings, when the door has been thut up for fome hours through the night ; and efpecially in fummer, the heat is intolerable, and the air fo foul, that a man can hardly breathe in it, whilt, at the fame time, the fharpnefs of the falts arifing from the horfe's urine, \&c. attacks his nofe and eyes, and occafiens a copious difcharge of tears. 
Many of the hovels at prefent ufed as ftables do not even deferve the name; and it is furprifing that, confidering the value and ufefulnefs of horfes, fo little attention is paid to their health in this refpect: For furely there can be nothing more hurtful than keeping a number of them (perhaps 30 or 40 ) thut up in a clofe warm ftable, where they muft conftantly breathe a hot foul air, which, at the fame time, is ftrongly impregnated with the putrid fteams of their own dung, wind, and urine, befide the exhalations that arife from their bodies, which, in this cafe, are kept in a conftant ftrong perfpiration, by the great heat of the air which furrounds them; and, to add to all this, they are perhaps wrapped tight up in body cloaths. How can it be expected that a horfe, who has paffed the night in this fituation, fhould be active and vigorous to perform his day's work? Will he not rather be faint, languid, and dull, his whole fyltem as it were being unhinged, and in a relaxed ftate. Let any

man, 
man, who is an advocate for this treatment of horfes, try the experiment on himfelf; let him leep in a heated clofe room, covered up with cloaths, fweat it out for the night, and try the condition he will be in next day for any employment whatever.

Although the defcription I have given of the fituation of horfes in large clofe ftables through the night, may appear exaggerated to thofe who have not had an opportunity of knowing it from their own obfervation, it is, however, a true one; and the fame obfervation will hold with refpeet to thofe ftables that are of fmaller dimenfions, even although they fhould contain fewer horfes. If, at the fame time, the ftable is made fo clofe as to exclude the admiffion of frefh air, it is well known to be a common practice to thut up every crevice that would admit the leat quantity of air. The very threhold of the door is choaked up with dung; and even the key-hole is filled up with ftraw.

Every 


\section{O F S T A B L E S.}

Every man knows, from his own experience, that, when a number of people are met rogether in a clofe room, the air within it becomes moift and hot, which renders breathing difficult; and, if continued in for a length of time, this uneafy fenfation would be increafed. In churches and crowded affemblies, lighted with candles, the effects of a heated foul air is evident to the fight from the lights burning dim and very faintly; and although the loftinefs of the roofs in thofe places contributes to render it lefs perceptible to thofe who are on the lower or ground floor, (as the heated foul air always afcends); yet, in the higher parts or galleries, the oppreffion it occafions in breathing is great, the perfpiration becomes profufe, and his thirft becomes intolerable. The bad effects of breathing long in a heated foul air is but toơ well known, and will be remembered by every one who has heard of the unfortunate affair of Calcutta black hole.

The 
The lownefs of the generality of ftable roofs renders them unwholefome from this circumftance alone; the horfes heads being too near the ftable roof, are under the neceffity of breathing a heated foul air almoft conftantly. During the time they are confined in the ftable, efpecially through the night, when the doors, \&c. are shut up, it is ftill worfe in the warm months of fummer. A heated foul air is noxious to animal life in general. How then can it be expected that horfes fhould thrive in it ? At the fame time, can there be any thing more inconfiftent than keeping horfes warm to an excefs in the houfe by the ufe of body cloaths, in a conftant ftate of ftrong perfiration, and fripping them naked the moment they are to go abroad in all weathers? The conftitution of a horfe, ftrong as it is, cannot withitand this treatment: It muft, and indeed, does give way, and too often falls a facrifice. The fudden and frequent tranfitions which horfes undergo, almof every day, from being 
being furrounded with, and breathing a cold air to that of a hot foul air, and vice verfa, from a hot to a cold, were there no other caufes, are fufficient of themfelves to produce a number of the moft violent difeafes. It is to be obferved, that great heat and profufe perfpiration diffipates the watery parts of the blood, and renders it too thick for circulation; and from that caufe alone many difeafes proceed. The conftant infpiring of a hot foul air does not expand the lungs fufficiently, fo as to promote the circulation of the blood through them; hence it is accumulated, and proves another fource of difeafes in that organ. It likewife renders them liable to fevers, faintnefs, langour, frequent ficknefs, and lofs of appetite. It expofes them to all thofe external complaints which arife from obftructed perfiration, as rheumatifm, tumors in the glands, fcabs, lumps, fcales on the fkin, ftareing of the hair, \&c. But the danger is ftill-greater when the nerfpirable matter is thrown upon fome of 
the internal vifcera, as the lungs, inteftines, brain, pleura, \&cc. From the firft of thefe proceed coughs, peripneumony, or inflammations of the lungs, confumptions, \&re. From an affection of the inteftines proceed obftructions in the bowels, and diarrhoea or fouring, as it is called, in horfes. When it fettles on the brain, it produces vertigo, or ftaggers, apoplexy, epilepfy, \&cc. And, when on the pleura, it is attended with the molt acute pains or ftitches; fymptoms which nearly refemble thofe of the gripes or cholic. Thefe complaints, if not fpeedily relieved, generally prove fatal to horfes.

Together with the heated foul air which generally prevails in fuch ftables as are kept too hot and clofe, there is always a dampnefs or moifture. This is otcafioned by their being made too clofe, and kept fo; infomuch that no frefh air can be admitted into them, but what pafles in at the ftable door, and that only, as I have already obferved, when it is occafionally

open. 
open. Hence the moifure from the horfes breath (and which may be increafed from a low or damp fituation) gathers, or is collected, in large drops, on the roof, walls, and glafs windows, and runs down in fmall ftreams. At the fame time, the ftable is filled with a hot, damp; and moift air, which is not only extremely pernicious to the horfes health, but deftructive to their furniture of every kind. Foul air, whether from putrid fteams' or exhalations of any kind, is noxious to all animals, and productive of various difeafes which prove fatal.

It would be needlefs te enter here into an inquiry concerning the properties of air, as every one, from his own experience, muft have obferved, at fome time or other, the great difference arifing from his breatning in a foul or in a frefh air ; it will be fufficient to obferve, that air is the chief inftrument of health, and principle of life, without which no animal can fubfift. 
It is likewife neceffary to obferve, that there is a peculiar matter thrown from the lungs of every animal, together with the air, which renders it unfit for refpiration or breathing. Befides, particular fituations and feafons often alter the qualities of the air, and render it more or lefs unfavourable to animal. life. Nature, according'ly, makes ufe of all poffible ways to preferve the air in a wholefome ftate; for it is thinned and purified by heat, and kept in continual motion by the winds.

Although the air is, by fuch means, often preferved in a wholefome ftate, yet, as has been before obferved, particular fituations and feafons often alter its qualities, fo as to render it more or lefs hurtful. Its drynefs produces one fet of difeafes, its moifture another; its heat or its cold others; and fo on. It is well known, that no animal can exift long in the fame indimidual quantity of air.

Thus, 
Thus, it is computed that a gallon of air is fpoiled of its elafticity by the fteams of a man's breath in one minute; confequently a hogthead of air would not fupply a human creature one hour ; nor, indeed, can he live in it one third of that time. Hence, therefore, we may learn, that, without a continual fupply of frefh air, the lungs cannot perform their office. This will appear ftill more neceffary, when it is conficlered that the lungs are fuppofed to be the chief inftrument of fanguification, and mixing the blood and chyle by their expanfion and dilatation, \&c.

Dr Hales, to whom the world is much indebted for his curious and ufeful experiments on air, tells us that he could not live half a minute without uneafinefs in feventy four cubical inches of air, and not one minute in the fame quantity, without danger of fuffocation.

The 
The effluvia from animal bodies are likewife very hurtful to the air. Thrce thoufand men living within the compars of one acre of ground, would make an atmofphere of their own fteams feventy feet high, which would foon become peftilential, if it were not difperfed by the winds. The air of prifons, for this reafon, produces mortál fevers, \&c.

Moift air relaxes all animal fibres. Such difeafes, therefore, as proceed from laxity of fibres, muft be the common difeafes, both of moift feafons and moift fituations. Dry air, by producing oppofite effects, produces oppofite difeafes.

Cold air, by bracing the fibres, and giving then a ftimulus, produces that ftrength and activity of which we are fo fenlible in frofty weather. Hot air, likewife, relaxes the fibres, fo as to occafion that faintnefs and debility fo often expericnced in hot an eather. 
Thofe ftables which contain a great number of horfes are attended with other difadvantages, befide thofe I have already mentioned, efpecially to tired or fatigued horfes, from the great intercourfe which muft unavoidably happen in people going out and in, efpecially in public ftables. Hence thofe horfes that are thy to lie down, or are eafily difurbed, will not reft themfelves in that horizontal pofture, which is of great confequence for keeping their legs fine and clean, as it forwards the circulation of the blood, \&rc. in the veffels, and prevents fwelling and gourdinefs of the legs and heels, which are generally the forerunners of ulcers, fcabs, greefe, \&c. Reft, to horfes that are tired and fatigued, becomes abfolutely neceffary, in order to recruit and refrefh nature. We know how agreeable and neceffary it is to ourfelves. Horfes are fufceptible of the fame fenfations. Therefore every opportunity of refting and ftretching their legs fhould be given them. 
Large crouded ftables contribute greatly to communicate contagious or infectious difeafes. A great number of horfes breathing in one place contaminates the air; and, if it has not a free current, it foon becomes unwholefome, and, like the air of jails, it contracts a malignant quality, which produces fevers in thofe horfes who ftánd in them, and, on changing them to other ftables, they likewife communicate the infection to others. Hence it has been remarked, in thofe epidemical difeafcs among horfes which have appeared in Britain, that it raged with moft violence in thofe ftables where a great number of horfes were confined together in one large ftable, whilf its effects, in fmall well aired ftables, was more mild and lefs deftructive.

To enumerate all the difadvantages which arife to horfes, from their being kept too warm, and breathing a hor foul moift air in clofe ftables, would take up too much of the reader's time, or perhaps weary his patience, 


\section{OF S T A B L E S.}

patience, as the impropricty of this treatment to horfes mult be obvious to every one who allows himfelf to reflect coolly upon the Cubject, and to apply thefe reflections to what he has experienced from his own feelings in the like fituations. I thall therefore only add further, that it renders horfes exceedingly delicate; it enervates their whole fytem, and of courle renders them unfit for the laborious exercifes required of them.

On the other hand too, cold fables are likewife hurtful to horfes, more efpecially after labour or exercife, or when they are kept fanding fixed to one place, or where the cold air is dirceled upon them in a current or ftream from any door or window. A current of cold air is more noxious to animals that fand in it but for a fliort time, than heat. The natural qualities of the former is one of the principal caufes of the diftempers it produces; for its coldnefs checks perfpiration, by conE tracting 
tracting the fkin, and clofing or thutting up the pores.

It is a common faying among fablepeople, that horfes feed beft when kept in darknefs. But this is by no means the cafe. They feed equally well in light, are fond of it, and how evident fymptoms of pleafure when they are brought from a dark ftable into the lighr, by their frifking, \&xc. Such ftables are generally unwholefome; for, as they have no windows, frefh air is excluded, as well as light.

Very dark ftables are likewife hurtful to the eyes. Horfes are naturally timorous, more efpecially when they fee but imperfectly around them. Hence they are the more conftantly upon their guard. By this means the pupils of the eyes are too much dilated, or opened, in fearch of the leaft ray of light, in order to difcover objects near them. This conftant dilatation of the pupils greatly weakens their contractive 
tractive power. That, when the horfe is brought out to the open day, the rays of light fall fo fuddenly, and fo ftrong, upon his eyes, as to caufe a kind of quivering or convulfive motion in them, and in the eye-lids. The immediate efforts of the poor animal to keep out thofe rays of light which give him fo much pain, and that, at other times, is fo very agreeable to him. But this is not the only bad effect that arife to horfes, from their ftanding in dark Atables. It affects their feeing objects diftinctly when abroad, and caufes them to ftartle, and be alarmed at every thing they meet with, which makes them exceedingly troublefome to the riders. The poor animals are blamed, when, in fact, it is in a great meafure owing to the difmal fituation in which they are too conftantly kept. Light, to horfes, is as cheering, agreeable, and natural, as it is to the human fpecies. Therefore they ought not to be denied that common privilege.

Farmers $_{*}$ 
Farmers, from a view of making dung, lay great quantities of ftraw under their horfes, where they fometimes let it remain for weeks rogether. The dung, urine, together with the heat of the ftable, foon reduce it to a ftate of putrefaction, from which iffue fteams of a moft noxious quality, which the horfes conftantly breathe in; and, in wet weather, when they are more confined to the ftable, this hot foul air may occafion fevers of the moft malignant kind; and perhaps this may be the caufe of thofe epidemical fevers which break out in rainy fearons.

In my obfervations upon the fhoeing of horfes, and the difeafes of their feet, I have frequently hinted at the bad effects of keeping their hoofs and legs too hot, by means of too great a quantity of litter, at all rimes, night and day, and perhaps large quantities of heated dung. The great heat of the ftable, together with the accumulated heat arifing from too great a quanity 


\section{O $\overline{\mathrm{F}}$ S T A B L E S.}

of litter about the legs occafion a more than ordinary derivation of blood to the legs, \&c. which caufes a dilatation, or fullnefs of the blood-veffels, and of courfe a fwelling or gourdinefs in the legs. Hence. proceed a ftiffnefs and numbnefs, greafy heels, \&c. If the horfe lies down for relief, the great heat of the litter foon forces him to get up again; and, after repeatedly lying down, and being forced to get up immediately, from the above caufe, he attempts it no farther, but ftands upright, or perhaps a little ftradling, often hifting the weight of his body from one leg to another. This ereet pofition in which he is obliged to ftand, increafes the fwelling of his legs, \&c. Recourfe is then had to all the remedies commonly prefcribed for fwelled heels, under the notion of carrying off humours, as bleeding, rowels, purging, diuretics, \&zc. \& c.

I have been the more particular in the above defcription, as many cafes have occurred $_{2}$ 


\section{$3^{8} \quad \mathrm{OF}^{\mathrm{S}} \mathrm{S}$ T A B LES.}

curred, arifing from the above caufe, when no difeafe did at firt actually exif, and which might have eafily been prevented, by removing the quantity of litter as foon as the horfe's legs began to fwell, keeping them cool, and wathing them frequently with cold water.

The Earl of Pembroke, in his Military Equitation, has a very judicious remark on this head. "After working, (fays he), and "s at night of courfe, as alfo in lameneffes, is and fickneffes, it is good for horfes to "f ftand on litter; it alfo promotes ftaleing, " \&c. At other times, it is a bad cuftom; "s the conftant ufe of it heats and makes " the feet tender, and caufes fwclled legs. "Moreover, it renders the animal deli" cate. Swelled legs may frequently be " reduced to their proper natural fize, by "t taking away the litter only, which, in "fome ftables, where ignorant grooms and "s farriers govern, would be a great faving es of phyfic and bleeding, befides fraw. I Bs have feen, by repeated experiments, legs 
"ss fwell and unfwell, by leaving litter, or " taking it away, like mercury in a wea"ther-glais."

The Arabians *, who are remarkably careful in the management of their horfes, and have them in the greateft perfection, litter them with their own dung, dried in the fun, and afterwards beat down to a powder, and fpread thinly upon the floor, about four or five inches thick; and, after being foiled, it is dried a fecond time in the fun, which clears it entirely of its offenfive odour; and, in order to keep their legs cool, wafh them carefully with cold water morning and evening. This practice has not only the defired effect on the legs, but it keeps their hoofs cool and moift in that dry and warm climate.

The fame author likewife telis us, that the Arabians keep their horfes, as much as poffible, in the open air. "Every day " (fays he) from morning to night, all the "Ara-

* Buffon's Natural Hiffory of the Horre. 


\section{$40 \quad O F S$ T A B L E S.}

"Arabian horfes ftand faddled at the tent

" doors; and, as the Arabians live in tents, "thefe tents ferve them likewife for " ftables."

This method of managing horfes approaches, as near as it is poffible, to the natural or wild ftate, and cannot fail of being attended with falutary effects to the conftitution of this ufeful animal: And although this practice cannot be adopted or recommended in our cold and changeable climate, yet the inference is very obvious, and cannot fail of thewing the propriety and ufefulnefs of keeping our horfes in well aired ventilated ftables.

The above author likewile obferves *, "That very warm climates, it would ap" pear, are deftructive to horfes; and " when they are tranfported from a mild "climate to a very warm one, the fpecies " degenerate." This obfervation, together with the arguments produced in fupport of it, and which appear to be founded in fact, hows

* Page 373 . 


\section{O F S T A B L E S.}

Shows how pernicious and unnatural too hot ftables are to the conftitution of horfes. Stables, with double heads, as they are called, that is, when the horfes ftand with their tails oppofite to one another, are very improper, unlefs there is a confiderable open fpace behind them, as horfes are apt to kick and fight, by which they lame and wound one another; inftances of which occur almoft every day: A precaution of this kind is the more neceffary, as many, if not moft of horfes, when not feeding, ftand as far back as the ftalk of their colar will admit. This practice, I have obferved to prevail moftly in thofe ftables that were kept too hot, probably owing to a foul hot air prevailing near the rack and manger, or from putrid fteams arifing from old mufty litter below the manger, or from that under the horfes fore feet; for, it is to be obferved, that horfes and geldings, when they ftale, throw their urine confiderably forward, and if the wet litter is allowed to remain under them, 


\section{O F S T A B L E S.}

(which indeed is too frequently the cafe), the faline fteams arifing from it are fo Tharp and difagreeable to the organs of finelling, that horfes ftand as far back as they can, in order to avoid the fmell, and to breathe a freer and fremer air.

From what has been faid, it is obvious, that the prevailing cuftom of keeping horfes too warm in their ftables, and

- where, at the fame time, a hot foul air muft of courfe pretail, cannot fail of being attended with bad confequences to their health, \&xc. and thows the neceffity of accommodating them properly with well aired ftables, free from all damp or foul air, and fo contrived as to be kept at all feafons of a proper temperature, avoiding the extremes of heat and cold.

It is well known, that in hot-houfes where exotic and other delicate plants are kept, a thermometer is ufed to afcertain the heat of the air within the houfe, which becomss 


\section{OF S T A B L ES.}

becomes abfolutely neceffary, as any excefs of heat or cold would injure the plants. This practice fhould be adopted in ftables, that, when the heat within them is increafed to a certain degree, the ventilators thould then be opened; and when too cold, they may be fhut, or nearly fo, as may be found neceffary.

Ali ftables fhould be built on a dry fituation, and in a free air. They ought to be at a diftance from all boggy or marhy grounu's, and free from all noife or difturbance. The ceiling or roof thould be high and lofty, as the heated foul air always afcends. The dung thould never be allowed to rot within the ftable, (as is done in fome places,) nor even at the ftable door ; but every thing about horfes fhould be kept fweet and clean. The ftables thould be frequently well aired, by kecping the doors and windows open when the horfes are out through the day. Experience teaches us how agreeable and even necelary 


\section{$44 \quad O F$ S T A B E S.'}

neceffary it is to admit frefh air into our own apartments, it is equally neceffary and ufeful to horfes. No ftable thould contain more than fix or eight horfes at moft, for the reafons already mentioned. The ftalls Thould be large and roomy, fix feet wide, in order that a horfe may ftretch his legs out when he lies down with freedom; and as horfes are fociable creatures, and always thrive beft in company with one another, no ftable thould be made of one ftall only, unlefs it may be fo fituated as the horfe that ftands in it may be wirhin the hearing of other horfes. The ftable-windows fhould be large, in order to admit a good deal of light, and made fo as to let down from the top occafionally. The damp or moilture that fettles on the glafs-windows Thould be frequently wiped away, and kept clean and dry. The litter under the horles fhould always be put up through the day below the manger, efpecially when a horfe goes abroad, in order to let the pavement dry and cool; and when the litter 


\section{OF S T A B E S.}

Iitter is fpread down, it ought never ic too thick, for the reafons already menio .ed. A horfe hould never be allovied io Itand on litter through the day unlers he is unwell or fatigued, when it is prefumed he will lie down to reft himfelf.

Having already hinted, that too much cloathing to horfes, whilft they ftand in the ftable, contributes greatly to render them tender and delicate, befides expofing them to all the difeafes arifing from too great heat about their bodies, and likewife to thofe arifing from an obftructed perfpiration from cold when they go abroad. It will be proper here to obferve, that in fome cafes cloathing becomes highly neceffary. What I condemn is the too conAtant and improper ufe of them, even to excefs, in warm weather and in warm ftables. When a horfe is in health, and ftands idle, very little cloathing is necerfary: A fingle theet or rug will be fufficient, unlefs the ftable he ftands in is very cold. 


\section{A6 OF S T A B L E S.}

cold. But when a horfe has been overheated, from violent labour or exercife, more cloathing will be neceffary, as circumftances may require, till he becomes moderately cool.

On this head, I cannot help taking noice of that pernicious cuftom of girding horfes bodies fo very tight above their cloathing, by means of very broad girths or rollers, with a confiderable number of ftraps and buckles, with the view of taking up the horfes belly (as the phrafe is). If fuch bandages are neceffary, of which 1 have fome doubt, why are they ufed to thofe horfes that are light bellyed? Poft and road horfes, when they are fed for fome time with clean dry food, have as light bellies as the fineft hunters or racers; and yet no fuch thing as broad rollers are applied to them.

Broad girths, when drawn too tighnt round the body, impede the free action of 


\section{O F S T A B L E S.}

the lungs, and, by their compreffing the liver and other vifcera, the circulation of the blood, \&c. in them is confiderably affected. I have feen many horles, when labouring under a feverifh diforder, girded fo tight with thefe broad rollers, that it occafioned a more than ordinary difficulty of breathing, attended with great anxiety and reftleffnefs; and on ungirding the rollers the animal feemed greatly relieved. For the fame reafon, too great a number of girths to a faddle are hurtful, when two good ones will anfwer the fame purpofe. 
in $8=0-3 \times x+x$ 


\section{H A P. II.}

\section{O $\quad \mathrm{F} \quad \mathrm{F} O \mathrm{O} \quad \mathrm{O}$.}

$T$ is not to be expected that I frould

1 here enter into a minute detail on the different methods of feeding horfes for different purpofes, or in particular fituations. It may fuffice to lay before the reader the different qualities of fodder and grain that is ufed for horfes, and to point out the effeets they produce on the body; and the confequences that follow upon an improper ufe of them, by giving them in too great a quantity at,one time; likewife the confequences that follow from the oppofite $\mathrm{G}$ extreine, 
extreme, in feeding horfes too low, in proportion to the labour or exercife they are employed in, and to conclude the chapter with fome general remarks.

Hay is the principal fodder ufed for horfes in Britain. Altho' there are a great number of herbs and graffes mixed with it, yet they are all included under the general denomination of hay. The common dintinction that is made, is that of natural or meadow lay, and the fown or rye-grafs hay. The natural hay is generally ufed in the fouthern parts of Britain. From the method obferved in the making of it, and allowing ic to heat in the rick or Atack, it acquires an uncommon fmell, fometining like that of malt dried on the kiln. This practice likewife gives it a fweetifnnefs to the tafte, and which they call mow-burnt hay. This freet tafte tempts horfes to eat greedily of it; and, as it is of a foti quality, they fwallow large mouthfuls, without chewing it properly. This produces thirit, and caures 


\section{O F F O O D. $\quad 5$ i}

caufes them to drink a great deal of water. This quantity of grafs fodder, together with the water, confiderably increafe the bulk of the ftomach, which, in this Atate compreffes the lungs, the diaphragm; and other vifcera furrounding it, to an uncommon degree. If a horfe is then put to any exercife that requires activity or expedition, he is in danger of becoming broken winded ; for it is always obferved that this diforder may be traced from too tharp exercile performed when the ftomach is full. I have likewife obferved a greater number of broken winded horfes where this kind of hay is ufed, than in thofe parts where rye-grafs is the common fodder.

Mr Gibfon, in his treatife on the feeding of horfes, condemns the ufe of ryegrafs as a proper fodder. He fays, "That " it is feldom given but in the months of "Auguft and September, except to horned " cattle. Before Michaelmas it is tole"rably hard and dry, efpecially in dry

"feafons; 
"feafons; and many feed their working " horfes with it, mixed with dry clover; " but afterwards it imbibes fo much moif" ture, that it becomes unwholefome, and "few horfes that have been ufed to good " hay will care for it." Here 1 muft beg leave to differ from $\mathrm{Mr}$ Gibfon. For, in this country, where rye-grafs mixed with a little clover is much ufed, it is found to be a clean wholefome fodder for horfes; and thofe that are confantly fed upon it are not fo fubject to be broken winded as thofe horfes that are fed with natural mow-burnt hay; and, at the fame time, they perform the exercifes required of them with frength and vigour. Mr Gibfon, in the fame page, fays that "foft hay, of all "others, imbibes moifture the eafieft, and " retains the effects of it the longeft, which " generally turns it rotten and unwhole"fome, and fo affords but a crude faint " nourithment, and thofe horfes that are " forced to feed upon it, for want of bet"ter, are generally weak and faint, and 
" in time grow difeafed, if they continue "long in the ufe of it."

Now, it is well known that natural hay is confiderably fofter than rye-grafs hay, and of courfe more liable to attract moifture, and acquire all the bad qualities he mentions; whereas rye-grafs hay, being harder and firmer in its texture, will not fo readily imbibe moifture; and, from his reafoning, it thould be the wholefomeft fodder for horfes. Another recommendation in its favour is, that, being harder and firmer than natural hay, it obliges a horfe to break it down more minutely before he can fwallow it, which makes it lighter and eafier of digeftion, lefs bulky in the ftomach, and, of courfe, not fo liable to produce the effect I have formerly mentioned.

Upon the whole, I would obferve that, whatever be the quality of hay, much depends upon its being well got in; for the beft grafs that ever was cut for this 
purpofe may be fpoiled by wet weather, or by bad management, in the winning and getting it in; and, where there is a choice, the beft fhould always be given to horfes that are employed in active exercifes.

Clover-hay fhould only be given to cattle and draught horfes, whofe labour is flow and equal. It cannot be recommended as a proper fodder for horfes that ftand much at reft, nor to thofe who are ufed in violent exercife of any kind, as they are apt to over-feed upon it.

Wheat-fraw is generally ufed as litter. It is feldom given as fodder, unlefs to draught-horfes, or when it is chopt or cut fmall, and mixed with oats, \&c. in order to oblige horfes to break their food thoroughly, before they can fwallow it. Yet the higheft fed horfes, when it is fren laid before them, are not only fond of picking the unthrehed heads of wheat that remain 
O F $\quad \mathrm{F} \quad \mathrm{F} O \mathrm{O} \quad \mathrm{D}$.

on the ftraw, but are likewife fond of the Atraw itfelf, by way of a change.

Barley and oat-ftraw are the common fodder of cattle and farm-horfes. They are feldom given to the better kind of horfes, unlefs it be out of oeconomy, or by way of amufement, when they are ftanding idle in the ftable, to prevent them from being reftlefs for want of other food.

Peale and bean fraw are a dangerous fodder to horfes that are not brought up, or gradually accuftomed to it, as it is hard of digetion. It is likewife apt to produce Altulencies and gripes, and obitructions in the bowels. It is commonly given to workhorfes and cattle.

New hay of any kind thould not be given to horles, more efpecially to thofe who are employed in active exercifes, as they feed upon it too greedily, aisd fwallow it without chewing it properly. It overloads

the 


\section{$\begin{array}{lllllll}56 & \mathrm{O} & \mathrm{F} & \mathrm{F} & \mathrm{O} & \mathrm{O} & \mathrm{D} .\end{array}$}

the ftomach, and, at the fame time, produces a crude watery chyle, which difpofes the horfes to fweat much, which weakens them greatly; therefore it hould never be given till the fuperfluous moifture it contains is dried up, which will require fome months after it is got in. It is to be obferved, that the beft hay thould always be given to horfes employed in active exercifes.

Grafs is the moft natural food for horfes; but, whether it proceeds from the coldnefs of the foil or climate in Britain, it does not produce fuch nourifhment as to enable them to perform any active exercifes with the fame ftrength and vigour as in warmer climates, without the addition of grain, as oats, \&cc. When they have a fufficiency of the latter, and, at the fame time, are provided with proper fhades, to protect them from the inclemency of the weather, we find, from experience, that they thrive, and perform any active labour, as 


\section{O F F O O D. 37}

well as thofe horfes that are kept in frabies on dry food only; together with this advantage, that they are not fo fubject to difeafes and lamenefs, but what may proceed from accidents amongt themfelves.

Grafs is not only food, but it is likewife phylic to horfes-I mean the early or fpring grafs. Where the vifcera are found, it cures moft of the difeafes they are fubject to with more certainty and expedition than can be done by medicine alone. After a long courfe of dry feeding and hard labour, it reftores the conftitution to the higheft health and ftrength. It cleanfes the bowels, and carries off thore chalky concretions that are apt to be produced in the ftomach of fuch horfes as have been long ufed to dry hard feeding. It likewife carries off the different fpecies of worms with which they are infefted. It renovates as it were the whole fyftem of fluids in the body. It promotes all the fecretions, and removes glandular obftructions; and in $\mathrm{H}$ many 


\section{8}

\section{O F F F O $\quad$ O D}

many cafes it carries off ftiffneffes in the joints and other lameneffes; and upon the whole it reftores the body to the higheft ftate of perfection of which it is capable.

But the advantages $I$ have now meritioned that arife to horfes from their being out on the fpring grafs, are in a great meafure loft to them: If they are allowed to continue through the fummer when the grafs becomes too rank, they become fat and corpulent; for I would always have it underftood, that a fat corpulent horfe is by no means fit for active exercifes of any kind, neither can he go through them without danger to his health and foundnefs : For, this reafon, it is cuftomary when horfes are too fat, and full of fleih and blood, to reduce them to a proper ftate, by evacuations, as bleeding, purging, \&c. which, when too frequently repeated, impair their conftitutions, and bring on a premature old age. 


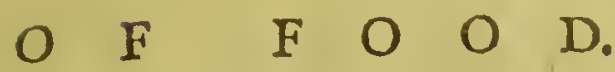

If thofe horfes that are intended for hunting, \&c. were taken up from grafs as foon as it begins to hoot, and kept in conftant daily exercife, although fed with a very moderate allowance of oats at the time, as the hunting feafon approaches, both their feeding and exercife may be gradually increafed. They will become by this management in a proper condition for the fevereft exercifes, without purging or evacuating medicines of any kind. But this will be more fully illuftrated under the article of Purging.

It has been obferved above, that grafs diffolves thofe chalky and other concretions that are apt to grow in the ftomach and other vifcera of horfes. Van Swieten, in his Commentaries upon the Aphorifms of Dr Boerhaave, vol. 9. p. 177. when treating of chalky matter found in the liver, \&c. fays, "Sometimes there are concretions " of the like fort found in this organ, but " of a more friable texture, and of a whiter 
60 O F F O O D.

" appearance, like gypfum or plaifter of "Paris. Such incruftations were often "obferved by Gliffon in the pori biliarii, " and its larger branches difperfed through " the livers of oxen that had been fed in "ftalls with hay and ftraw during the "winter feafon, and without exercife. "But then thefe concretions are very fri" able; and they afterwards diffolve again, " and pafs out of the body, when the cat" tle come to feed upon the frefh grafs of " the meadows; for in oxen that are flain " in the fpring and fummer, they are very " rarely to be found."

In diffecting horfes, I have frequently met with chalky concretions in their livers and in the lungs, efpecially in thofe that have been fed long on clry food, and likewife round balls in their ftomachs, fometimes of an oval thape. The latter feem for the moft part to be compoled of the duft they lick from their own bodies mixed with the hair. Whether the frefn grafs diffolves 
difolves them, is not fo certain; but that it caufes thefe concretions to pafs through the intentines, I have had a full demonftration: In May i 786 , a horfe that had becn long fed on dry food was turned out to grafs; in about eight or ten days afterwards, he was feized with violent griping pains, which lafted about 24 hours, when he died. As the horfe was very fat, the man who had the charge of him wanted to make fomething of his greafe: In fearching for it, he obferved a large fpace of the inteftines of a very black colour; and on feeling it, found fomething hard and weighty within them. He immediately cut it open with his knife, and took out a large oval hard ball, which meafured four inches in length, and three inches and a half in breadth; and which I have now in my poffeffion. That this concretion was originally formed in the ftomach, there can be no doubt, as they frequently, upon diffection, have been found there; 


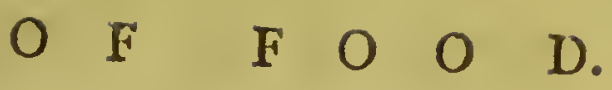

and nothing but its great bulk had hindered it from paffing through the inteftines.

The author I have juft quoted, in the fame volume, page 184 . mentions another very falutary effect of grafs, in curing a man of a moft obftinate jaundice. He fays, "Some years paft I had the care of " a poor man, who was obliged to main" tain himfelf and a family by his day la"bour, and therefore unable to fupport " the expences of a courfe of medicine; "but having good fpirits, and a great de"fire to be relieved of his malady, by pro" mifing him a cure, I eafily perfuaded " him to live altogether upon grafs. He " boiled a large quantity of grafs in pure "water; and, after fweetening the decoc" tion with honey, made ufe of it for his " common drink; and the tenderett grafs " fprouting in the fpring feafon, or rifing " up again after the firft mowing, he boil" ed in frefh broths, and made it entirely " his food. He confeffer, indeed, that "for 


\section{$\begin{array}{lllllll}O & F & F & O & O & 0 . & 6\end{array}$}

"for fome time in the beginning of this " courfe, his diet did but little pleafe him;

" he could afterwards eat it without any "kind of difgult, and therefore ufed it for " two whole years, except for fome parts " of the months in the winter time. He " affured me, that he could eafily diftin"guilh the beft pafturages by the flavour " of the grafs, and that he was obliged "fecretly to cut out his' diet from the " meadows; fince the farmers, finding " him to have fo large an appetite, often "gave him forcible repulfes. By this " courfe only, he was perfectly cured of " a moft obftinate jaundice, in which even " his faliva began to tafte bitter; and I "faw him fome years afterwards in a good " ftate of health."

From what has been now obferved, with refpect to the properties of the early or fpring grafs, it will be obvious how neceffary it is to the health of horfes to let them have it as early in the fpring as circumftan- 
ces will admit; and thofe horfes that cannot be turned out to pafture, fhould have it in the houfe as foon as it will cut. How many of the beft horfes in Britain fall a facrifice to the moft loathfome difeafes, by keeping them for years together upon hard dry food, without ever tafting green herbage of any'kind; yet many peopie, ignorant of the advantages that arife to horfes from the ufe of the early fpring grafs, think it a recommendation, and boaft of their horfes not having had any for fuch and fuch a length of time, or that fuch a horfe (as the phrafe is) has fo many years hard meat in his belly: For my own part, fo far is it from being a recommendation, that, on the contrary, I look on fuch horfes as verging on the moft fatal difeafes; and experience has confirmed the obfervation.

This practice of feeding horfes for years together on hard dry food, does not prevail fo much in this part of the kingdom; but 


\section{$\begin{array}{lllllll} & \mathrm{F} & \mathrm{F} & \mathrm{O} & \mathrm{O} & \mathrm{D} . & 65\end{array}$}

Eut in the more fouthern parts, it is very common: And this I look upon as one caufe why that loathfome difeafe the farcy prevails more in the latter than in the former. We know that failors and others, who are confined for a length of time to live conftantly on dry food, and that which is falted, are very fubject to the fcurvy: Ve likewife know what great advantages they reap from freth greens and ripe fruits, in recovering them from this loathfome difeafe. It is the fame with horfes who are fed long on dry hard food; they are likewife fubject to the fcurvy, which in them is called the farcy.

Perhaps it may be faid, that horfes, who are kept for active exercifes, reap no advantage from their being fed with oats, \&c. whilf they are on grafs; becaufe, fay they, the purging that is brought on by the grafs will carry off the nourifhment that fhould be produced from the oats, \&zc. In anfwer to which, I would obferve, that 
66

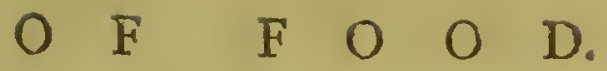

although the early grafs purges a horfe gently at firft, yet it does not continue long, neither is it attended.with that weaknefs, faintnefs, and lofs of flefh, which is obferved in thofe horfes who are purged by ftrong medicines, when the evacuation is brought on fuddenly, and perhaps to an excefs; for neither the human nor animal body can fupport fudden evacuations of this kind, without a weaknefs and faintnefs enfuing, although they can bear a little laxity from diet without any inconvenience.

A change of diet is not only agreeable, but it is wholefome for horfes, as it contributes to keep them open in the body. Malt mixed occafronally with their food proves a medicine.

Wheat, notwithftanding it affords the moft nourifhment, is feldom given to. horfes, probably owing to its price being higher than that of other grain. It is apt 


\section{O}

to purge horfes a little on the firft ufing of it ; they eat it greedily, and are fond of it; but as it becomes very llippery from the moifture in the mouth, it is fwallowed whole, and paffed through the body in that ftate; but when it is given bruifed, or mixed with chopped ftraw, the horfe is cbliged to break it minutely with his teeth before he can fwallow it. It then proves very nourifhing, and enables them to go through their labour with ftrength and vigour: It likewife makes horfes coat well, that is, it makes their hair lie fmooth and fhining.

Lord Kaimes, in his treatife on Agriculture, has been at great pairis to afcertain the weight of the different kinds of grain; from which may be inferred the quantity of nourithment each kind produces. By . his calculation, the boll of middling wheat weighs I 4 ftone Dutch weight; the hurks weighs two ftone; for which reafon, when wheat 
68

\section{$\begin{array}{llllll}O & \mathrm{~F} & \mathrm{~F} & \mathrm{O} & \mathrm{O} & \mathrm{D}\end{array}$}

wheat is given to horfes, a lefs quantity will be neceffary than of oats.

Barley likewife purges horfes on the firft ufing of it; but when it is given mixed with cut ftraw, for the purpofe already mentioned, it proves a wholefome nourifhing diet: It is the principal food of the Arabian, the Barbary, and other caftern horfes, who undergo great fatigue, and perform journies with incredible fwiftnefs. Yet 1 have been informed, by a very ingenious gentleman, who refided feveral years in England, that they are much prejudiced againf feeding their horfes with barley, as they alledge that it gives them the itch. But I can affure fuch, from my own experience, that it has a very oppofite effect; and that if horfes, who are troubled with this diforder, are fed on barley, cither raw or boiled, it will contribute greatly towards the cure. The boll of middling barley weighs is itone Dutch weight, the hufks one tone four pound. When it is boiled, 


$$
\text { O F } \quad \text { F O O D. }
$$

it proves light, and eafy of digeftion; for which reafon, it is frequently given to horfes when they are fick, \& c.

Oats, notwithftanding they are reckoned more heating and binding than any of the former grain, yet they are generally given to horfes in Britain. To poft and other carriage horfes they are frequently given, mixed with beans, which obliges them to break both oats and beans minutely before they can be fwallowed. The adding of the beans makes this feeding very nourifhing. On that account, beans hould never be given mixed with oats to thofe horfes that ftand much at reft, or have not fuffcient excrcife. The boll of middling oats weighs fourteen ftone Dutch weight. The hufks weigh fix ttones. Therefore, as oats have more hufks than any other grain, a greater quantity is neceffary. For this reafon, it is probable that the ftandard mcafure of oats is larger than that of other grain. The conftant feeding with oats, although it is efteemed what is called clean feeding, 
feeding, yet it is apt to make horfes too coltive, \&c.; to prevent which, bran, mafhed up with boiling water, is given once a week, or as circumftances may require.

Beans are feldom or never given to horfes by themfelves, unlefs to work-horfes. When they are boiled, they afford the ftrongeft nourifhment of all the other grain. The boll of middling beans weighs fifteen ftone eight pound; the hufks weigh eight pound; which is the fmalleft proportion of hufks in all the grain now mentioned. Of courfe they contain more nourifhment; but; as they contain a great proportion of fixed air, when given in too great a quantity, they are found to produce flatulencies, gripes, \&c.

Having thus endeavoured to lay before the reader the different properties of fodder and grain, \&x. ufed in the feeding of horfes, it now remains to confider how they 


\section{O F F O O D.}

they are or ought to be applied, in fuch a manner as may be of greateft benefit to their health, \&c.

It has already been obferved, that the food of horfes, in their natural ftate, is exceedingly fimple, confifting chiefly of herbage, as grafs of different kinds, and water for drink. Thefe afford nourifhment fufficient to keep them in flen and frength, whilf they have nothing to do but range the fields at large; but, in a domeftic ftate, where they are put to hard labour, and violent exercife, food of a more generous nature becomes neceffary, to ftrengthen and enable. them to perform the various exercifes required of them.

The food that is commonly ufed for horfes in Great Britain confifts of hay, oats, beans, barley, and bran. 'The latter of thefe is commonly given to horfes when fick, boiled, or made into a manh, with warm water, in order to keep them open 
in 'the belly, when they feem to be cofrive, which happens frequently to horfes when kept long on dry food, even in the beft ftate of health. But oats and beans are given to thofe horfes who perform hard labour, or active exerciles, as they are found to produce the beft and the ftrongeft nourifhment in this country.

It will perhaps be not only entertaining but inftructive, for many of my readers, to be informed how horfes are fed in different countries, and what incredible fatigue they will undergo, upon a very fmall allowance. The Count de Buffon, Vol. iii. page 375. tells us, "That the Tartar "horfes will travel two or three days " without ftopping; receiving, for four or " five days on end, only a handful of her"bage every eight hours; and, at the "fame time, kept from drinking for twen"ty-four hours." And, in the fame volume, page 360 . he fays, "That the Ara"bian horfes are rather mcagre than fat. 


\section{O $\mathrm{F} \quad \mathrm{H} \quad \mathrm{O} \quad \mathrm{O} \quad \mathrm{D}$.}

"During the day they are not permitted

" to eat, but are watered twice or thrice.

"At fun-fet, a bag, containing about half " a bufhel of barley, is paffed over their " heads, and faftened to their necks. This " bag is not removed till next morning; " when the barley is entirely confumed. "When the grafs is good, they are turned " out to pafture; and, during the reft of " the year, they are allowed neither grafs " nor hay, and rarely ftraw, barley being " their only food. And great care is ta"ken to give them only as much as is "barely neceffary; for too much nourifh"ment makes their legs fwell, and foon " renders them ufelefs." In page 37rof the fame volume, the Count de Buffon quotes Pietro della Valle, who prefers the common horfes of Perfia to the finef Neapolitan horfes. He fays they are generally of a middle ftature; and fome of them are very fmall, but ftrong and actise; while others exceed the fize of the Englifh faddle horfes. They have light heads, and fine' K necks. 
necks. Their ears are handfome, and well fituated. They have flender legs, fine cruppers, and hard hoofs. They are docile, firited, bold, and capable of enduring great fatigue. They are extremely fwift, and never ftumble. They are robuft, and fo eafily nourifhed, that their only food is barley, mixed with cut fraw; and they are grazed during fix weeks of the fpring only.

In page 372 . Buffon tells us that " the

" horfes which are bred in the Indies are "very indifferent. Thofe ufed by the "great men of the country are brought " from Perfia and Arabia. They are fed " with hay during the day; and, at night, " in place of barley and oats, they get " peafe boiled with fugar and butter. This " nourifhing diet fupports them, and gives " them fome degree of ftrength; without "it, they would foon perifh, the climate " not being adapted to their conftitution." 


\section{$\begin{array}{lllllll}O & F & F & O & O & D & \end{array}$}

Mr Berringer, in his excellent treatife on horfemannhip, Vol. i. page 134 . quotes a paffage from Cambridge's introduction to his account of the war in India, where he fays, "That the Indians feed their hor"fes in the rice-fields; and, when flerh is " plenty, they boil the offal to rags, and, " mixing it with butter, and fome forts of "grain, make balls, which they thruft " down the horfes throats. In fcarcity of " provifion, they give them opium, which " has the fame effect both on horfes and " men, for it at once damps their appe" tites, and enables them to cndure fa"tigue."

The Count de Buffon likewife tells us, in Vol. iii. page 388. "That, in Iceland, "where the cold is exceffive, and where " often no other food can be had than "dried fithes, the horfes, though fmall, " are extremely vigorous." , 
Pontoppidan *, in his natural hiftory of Norway, fays, That, in the year 1302 , a man, whofe name was Huleickfon, was the firf who gave his horfes oats in that country, whence he had the nickname of Horfen corn.

Quod in Norvegia primus equos avena paverit.

The horfes here are not fubject to fo many difeafes as in moft other countries, and in particular the ftaggers.

In Britain, it was formerly the cuftom to give horfes baked bread, known by the name of borje-bread, inftead of oats, and other grain.

"The Arabian horfes intended for hunt"6 ing in Arabia or Barbary, feldom eat " herbage or grain. Their common food, "which confifts of dates and camel's milk, "6 is given them every morning, and at " night.

Berringer, $14 \%$ Vol. $\mathrm{i}_{\text {s. }}$ 


\section{O F F O O D. $\quad 7 \gamma$}

" night. Thefe aliments, inftead of fat"tening them, render them meagre, ner"vous, and very fleet. They fpontane" oufly fuck the fhe-camels, whom they "follow till the time they are ready for "mounting, which is not before "the age " of fix or feven years."

Berringer, in his Horfemanfhip, tells us, that "Nemefian recommends ftraw and "barley as very nourifhing diet; and ir " certainly conduces very much to keep " horfes in health, fpirits, and wind, and " in a ftate of body fit for any kind of la"bour, as ic fupports and ftrengthens, " without rendering the animal heavy and " corpulent. The ancients, likewife, on "certain occafions, gave their horfes wine "to drink, to animate and refrefh them.

"The Kalmuck hories are fo hardy and "ftrong in their conftitution, as to be ablo " to run three or four hundred Englif, " miles in thrce days. They fubfitt, fum- 


\section{$\begin{array}{lllllll}78 & O & F & F & O & O & D\end{array}$}

" mer and winter, folely upon grafs in the "great defarts."

To illuftrate what may be farther advaneed, it will be neceffary to premife fome remarks relating to the animal oeconomy, in converting the food into nourifhment, and its mixing with the blood.

The food that is taken in at the mouth muft undergo a preparation in the ftomach, before it can be affimilated, or mixed properly with the humours of the body, fo as to be converted into nourifhment. Thus, whilt the food is chewing or grinding between the teeth, it is mixed with the faliva, which is feparated from the glands of the mouth and jaws, and, when fuffciently broken down, it is fwallowed, and taken into the ftomach, and there mixed with other juices, where it undergoes certain changes, and produces a milky liquor, çalled chyle. 


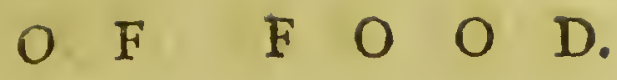

This chyle is conveyed out at the fame orifice of the ftomach, alongft with the groffer part of the food, into the fmall guts, where it is abforbed, or taken up by the lacteal veffels, whole mouths open in almoft every point of the inteftines, and by them is conveyed into its proper receptacle, and from thence into the mafs of blood. The groffer parts of the food, by the periftaltic or wormlike motion of the inteftines, are carried backwards, and' voided, in the form of excrement or dung, but not before it is drained of all the chyle it contains in the larger inteftines.

The chyle being thus mixed with the blood is firft carried, by the force of the heart, into the lungs, where it is faid to undergo certain changes, in order to fit it for circulation and nutrition, \&c. being acted upon by the veffels of the lungs, and at laft thofe of the whole body, it becomes intimately blended with, and acquires the nature of blood. 
So

\section{O F $\quad$ F $O$ O D.}

The chyle that is formed from the food taken into the ftomach partakes of the nature of the food that is eat, which, notwithftanding the digeftive faculty, is capable of forming chyle of different aliments: Yet fome kinds of food will produce a ftronger and a more nourifhing chyle than others, as oats, beans, \&cc. which, like wines taken in moderation to the human body, excite an activity in all the members, and diffufe a certain chearfulnefs and vigour through the whole fyftem. Thus, horfes taken from a low moift diet, and fed with oats, \&c. foon turn wanton and frolickfome: Hence likewife thofe horfes that are employed in very hard labour are fed with fuch nourifhing dier, to cnable them to perform it with vigour. This kind of high feeding keeps them as -it were in a conftant 'ftate of inebriation, and from this we can account why a horfe that (as the phrafe is) has good meat in his belly, will perform any violent labour or exercife for a longer time; and much bet- 


\section{$\begin{array}{lllllll}O & \text { F } & \text { F } & \text { O } & \text { O } & \text { D. } & 8\end{array}$}

rer, and with greater eafe to himfelf, than he would do if he was fed upon more fimple and lefs nourining diet. Hence likewife it will be obvious, from the fame parity of reafoning, that from a defect in the quantity or quality of the food, the body cannot be fufficiently nourihed, and of courfe the animal will become weak and feeble.

The blood being thus conftantly fupplied with frefh chyle, and conveyed to every part of the body by the force of the heart, nourifhes the different parts, and fupplies the walte that has preceded in the body.

The effects of nourining food upon a lean healthy horfe, or on thofe that are not accuftomed to a rich dier, are very foon vifible; it changes the whole fyltem by the alteration it produces in the fluids. The fuids bcing enriched, act likewife upon the mufcular fibres of their containing vefficls, and ftimulate them as it were to difI. 


\section{$\begin{array}{llllllll} & 32 & O & F & F & O & O & D .\end{array}$}

pel the watery or ferous parts of the blood by fweat on the furface of the body, even. when the horfe ftands at reft in the ftable; and, at the fame time, it promotes the neceffary fecretions in the glandular fyftem.

Thus it is obferved, that when horfes are taken up from grafs late in the feafon, and put on a dry nourihing diet, they fweat much, ftanding idle in the ftable; they are then faid to be foul in the body, when, at the fame time, this fweating or foulnefs in the body proceeds entirely from the too great quantity of ferous or watery particles contained in the mafs of fluids, which on the change of diet, are thrown off in this manner by the new acquired ftrength of the mufcular fibres of the veffels, compreffing their contents more clofely, and forcing the ferous or watery parts through the fine capillaries or pores of the ffin in the form of $f_{w e a t}$. This might be farther illuftrated, from the effects of purging and diuretic medicines given in thefe cafess, 


\section{$\begin{array}{llllllll}\circ & \mathrm{F} & \mathrm{F} & \mathrm{O} & \mathrm{O} & \mathrm{D} & & 8\end{array}$}

cafes, and the fuccefs attending them, in removing this fymptom of fweating in the ftable, \&c. and which will be further explained, when I come to treat on the operation of thefe medicines:

Rich feeding, with idlenefs, produces a fuperfluity of nourifhment. The veffels become turgid and full of blood. The body grows corpulent and fat, and of courfe unfit for the active motions required of a horfe; neither is he able to continue labour or exercife for any length of time, without being fatigued; by his own unwieldinefs, and not without imminent danger of his life. Labour or exercife increafes the circulation of the blood, \&c. ; and, if continued long, the red blood is forced into veffels, in which it does not ufually circulate in an unactive fate. The fat is diffolved by the great heat and rapid motion of the fluids, and produces as it were an oily plethora. If a fever enfues, which frequently happens in the above cafe, the fluids 
fluids are difpofed to putrefaction, which, if not prevented, proves fatal.

High feeding, when there is not a proportional wafte in the conftiturion, from labour or exercife, produces a long train of difeafes, which the leaft trifling circumftance may bring forth: For there is no ftate or habit of body more liable to difeafe than that of the too fat and full habit of body, of which we daily fee a number of inftances.

Dr Bracken, in his fecond volume on the article of Feeding Horfes, fays *, "It " is very odd to hear fome men talk with " relation to the allowance of oats, \&c. " which a horfe fhould have per diem; "for a great many imagine they are not " neceffary for horfes that have much reft, " or are not travelled long ftages: Yet I " muft tell thefe gentlemen, that they run "s the hazard of bringing on diftempers, if "they

* Page 99. 


\section{O $F \quad$ F $O$ O}

" they fhould have occafion to ufe their

" horfes upon an expedition, when they " are only fed with hay, and a fcanty

"feeding of oats."

I cannot help diffenting from the Doctor's opinion, and ranking myfelf amongtt the number of thofe who do not imagine that a great allowance of oats * are neceffary for thofe horfes that have much reft, for the reafons I have formerly mentioned. Befides, what the Doctor advances is not only contrary to reafon and experience, but the eftablifhed practice of intelligent fportfmen, who have feen its bad effects in bringing on thofe very diftempers the Doctor alledges they run the hazard of.

I would farther obferve, that no man who is acquainted with horfes would think of ufing them on any occafion that required expedition, withour previoufly preparing

* The Docior generally allows three feeds per day, mixed with beans. 
ring them for it, by good feeding and regrular exercife; for although a horfe was allowed as much oats and beans as he could poffibly eat, yet that alone would not put him in the condition neceffary to perform any labour or exercife where expedition is required.

The Doctor, in the fame page, relates a cafe, in order to corroborate what he advances in the paffage I have quoted, where he fays, "One of my patients having occafion to go to the Bath waters for the recovery of his health, happened to borrow a chafiot and pair of geldings from a gentlemari in Lancafter, in order to carry him to the ftage-coach at Chefter. The geldings were large and ftrong, as well as in good health, and $f a t$, but had had too fcanty allowances of oats, \&c. for their fize; three or four quarts a-piece per day, or, as I think, lefs, as the coachman told me, being the ufual ftint; which made me caution that they fhould travel very thort ftages; becaufe I 


\section{O F $\quad F \quad O \quad O \quad$ D. $\quad 87$}

was afraid he might lofe both of them be: fore he got back to Lancafter, not only by reafon the weather was hot and furfeiting, but they had not eaten a fufficiency of corn and beans before hand; fo that, after they were heated, they would be longer in cooling. In fine, it fo fell out, that one of the geldings kicked up his heels at Prefton, on his return home." Here I would again beg leave to differ from the Doctor, as it would appear, from the circumftances he relates, that it was the fatnefs of the horfe, together with his not being in the ufe of performing fuch violent labour, that was the caufe of his death, to which the heat of the weather, and the habit of body he was in, would no doubt contribute. Neither could the horfe's death be attributed to his not having eat a certain quantity of oats and beans before he began his journey. For, although a horfe be never fo well fed, unlefs he be daily accuftomed to labour, or exercife, his flen will not acquire that rigidity and firmnefs that is neceffary to 


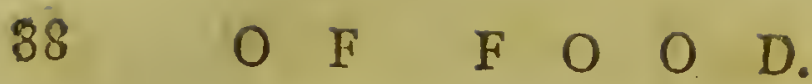

enable him to perform any exercife that requires expedition, and continued for a length of time, without endangering his health or his foundnefs. Thus, if a man who is not accuftomed to athletic exercifes, Thould be under the neceffity of exerting himfelf in walking, leaping, or running, \&c. for a length of time, he will of courfe be overheated, and, when he cools, he will feel himfelf ftiff and pained all over his body. If he continues thefe exercifes daily, they will not produce that effect. 'The habitual practice of them renders the mufcles more pliant ; the profufe perfpiration difpels the ferous or watery parts of the blood, its circulation being lefs clogged, his refpiration or breathing becomes free and eafy, of courfe his exercife lefs fatiguing; and this every man munt, in fome period of his life, have experienced. It is the fame with horfes; for, although the animal body is confructed on a larger fcale, yet its oeconomy is regulated by the fame laws with that of the human body. 


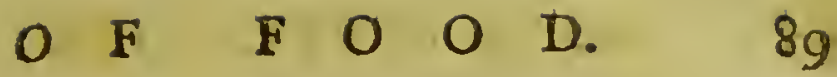

If a lean poor horfe is allowed to ftand idle, and fed plentifully with rich food, he will grow fat, and full of juices. If this horfe is regularly exercifed or worked hard for a few weeks, he will lofe a confiderable quantity of his Aleth and weight; notwithftanding of which, he will be ftronger, and fitter for labour, thân he was before; becaufe the mufcular fibres in general are thereby, as it were, more confolidated. But, let the fame horfe again ftand idle, and be plentifully fed, yét fome confiderable time will elapfe before he become fo fat and full, or, in other words, before the mufcular fibres acquire their. former lax ftate. Hence it is that horfes, when newly taken from the late grafs, are in this lax habit of body, and fweat much when put to labour or exercife. But, on changing their food to that which is dry and more nourining, a richer chyle, and hence better blood, is produced; which, by invigorating the whole fyftem, ftrengthens the fibres, and enables them to ast more powM crfully 
erfully on the fluids, and produces the effects already mentioned. We have a farther proof of this in poft and other horfes, when they are firlt fet to work, whilt their fibres are in this lax ftate, as their exercife or labour becomes violent, they breathe with difficulty; and fweat moft profufely; but, by perfevering in this exercife, and feeding them with rich dry food, as oats, beans, \&c. their mufcular fibres acquire a greater degree of rigidity, their flerh becornes firmer, they breathe with freedom, and at length are able to perform the moft violent labour or exercife with expedition and eafc. In this cafe, according to the common phrafe, they are then faid to be in wind. I might enlarge farther on this head; but it would perhaps be a digreffion too minute for the great. er part of ordinary readers; I thall therefore now proceed to the feeding of horfes.

What an eminent phyfician * has faid, with

- Dr Mackittrick, page 209. 


\section{$\begin{array}{llllllll}O & F & F & O & O & D & & \text { gI }\end{array}$}

with refpect to the diet, \&c. in the human body, may be applied with propriety to horfes. "Many of the occafional cau"fes (fays he) of difeafes, do certainly a"rife from our inattention to the rules of "diet, which are fuggefted to every man "by plain common fenfe, and daily expe"rience. From this inattention it is that "fo many infants, which at their birth "had all the marks of a found conftitu"tion, have either died before they arri" ved at maturity, or have with great dif" ficulty attained it, with irretrievably bro"ken health: Hence alfo it is that many " of the ftouteft men, either thorten their "lives by violent difeafes, or languin thro" "the latter part of life under all the bane"ful effects of debauch."

As horfes are not endowed with reafon, but guided entirely by inftinct to fuch aliments as correfpond with their conftitutions, the appetite for food excites in them a frong defire to gratify this fenfe. They 


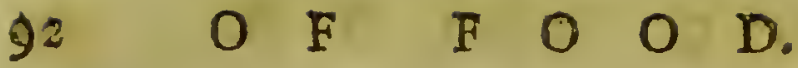

are therefore apt to indulge in it to excers when it is laid before them, efpecially grain of any kind, and more fo when confined in the ftable, where they have no other amufement to divert them from it. For, in the fields at grafs, after they are fatisfied with eating, they run about and play with one another a confiderable part of their time, and do not begin to eat till prompted to it by hunger. For this reafon, there are but few or no inftances of horfes over. eating themfelves when running at grafs.

Young horfes, in particular, are moft liable to be injured by too much feeding with grain. The blood of young animals is naturally difpofed to be hot ; thigh feeding increafes this difpofition, and renders shem more fubject to inflammatory difeafes. Hence high dry feeding with oats, $\&$ c. is faid to burn up the body of horfes. This high feeding, likewife, produces a plethoric or too full habit of body, which renders them more liable to fevers, \&c. and 


\section{O F F O O D. $\quad 93$}

and to fwelled legs and greefy heels, and, upon catching the leaft cold, to a variety of other diforders.

Befides the ordinary feeding with oats, \&c. at ftated times, through the day, it is too common to keep the racks at all times filled with hay. Hence many horfes ftuff themfelves too full. They drink a great quantity of water, which eating a deal of hay prompts them to; and, when they come to be exercifed, or even when performing any'ordinary labour, they are hardly able to breathe. Numbers of horfes are daily ruined from this practice; yet many people are not aware of its effects. If they reflected but for a moment, what would be the confequence to themfelves were they obliged, after a full meal, to perform fome violent exercifes, as running, leaping, \&c. they could hardly fail of being convinced of the impropriety of this injudicious treatment to their horfes. 


\section{4}

O F F.O O D.

It is likewife to be obferved, that there are horfes of delicate ftomachs, who loath their food, from its being too conftantly before them, and not baving fufficient time or exercife to digeft what they have ate. It ought likewife to be remembered, that it is not the quantity of food alone which a horfe eats that produces the wholefomeft nourifhment, but it is what he digefts well, that invigorates and ftrengthens the conftitution; for, when the ftomach is overloaded with food, the body is dull, heavy, oppreffed, fluggirh, and ftupid. It likewife impairs the digeftive faculty, and fills the veffels with crude chyle, from which difeafes arife. Belides the immediate effects which the great bulk of the ftomach. has upon the lungs, \&c. by obftructing their free motion, and ftraining the diaphragm, and producing afthmatic complaints, as broken wind, purfivenefs, \&cc.

Throwing great quantities of clean grain before horfes at one time is very improper; they 


\section{O}

they eat it too greedily, and fwallow whole mouthfuls of it almoft dry. The moifture in the ftomach, or water drunk immediately after eating, caufes the grain to fwell, by which the ftomach is greatly diftended, and thereby lofes its contracting power to act upon the food. By its uncommon preffure upon the inteftines, the paffage for the food backwards is obftructed. The confined air, arifing from the indigefted food not having a ready paffage backwards, and horfes not poffeffing the power of eructation or belching, the air becomes rarified to a great degree, the horfe is feized with the moft acute pains; as rhey increafe, he becomes convulfed, and, in many cafes the ftomach burfts, and death follows of courfe. Out of a number of cafes where the above was difcovered, on diffecting the bodies, I thall only mention the two following.

A young draught horfe was fed in the morning with too great a quanity of bar- 


\section{F $O$ O O D.}

ley mixed with peafe, and had been allowts ed to drink water immediately thereafter. He was yoked to a two wheeled chaife, in order to travel a few miles, and was obferved, about the middle of the day, to be very uneafy, frequently attempting to lie down. As foon as he was unyoked, he lay down, and tumbled about, frequently lying on his back, ftarting up fuddenly, and turning his head towards his belly. He continued thus in great agony till towards next morning, when he died. Upon opening his body, the ftomach was found burft, the barley and peafe moftly entire, only greatly fwelled, and the whole contents of the ftomach fpread through the abdomen.

The other cafe was a horfe who had been fed with too great a quantity of oats and barley, and had been allowed to drink water freely afterwards. $\mathrm{He}$ was feized with griping pains, fo that he frequently lay down and tumbled, feemingly tortured with the moft acute pains. He died next day. 


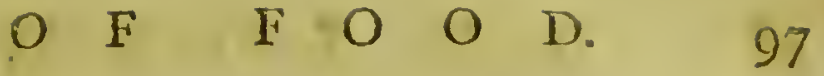

day. Upon opening his body, the ftomach was found diftended to a moft enormous fize, but was not burft. Its coats were fo very thin, from the great diftention it had undergone, that its cohefion was almoft deftroyed, and had more the appearance of a coat of mucous or flime than the ftomach. The oats and barley were for the moft part entire as they were fwallowed, only greatly fwelled, from the moifture they had imbibed.

From the cafes now related, it will appear how neceffary it is not to allow horfes to eat too great a quantity of clean grain at a time, but to give it in fmall quantities, and repeated the more frequently. At the fame time, it will fhow the propriety of mixing with it a little chopped Atraw or hay, in order to make them chew it more thoroughly before they fwallow it. This procefs likewife prepares the food for being properly digefted, and not a fingle grain of it is loft. The method of 
feeding horfes with bruifed grain and chopped ftraw, as recommended by the Right Hon. the Earl of Pembroke, in his excellent treatife upon horfes, is exceedingly proper. "Every grain (fays he) goes to

" nourifhment; none is to be found in " the dung; and three feeds of it go far"ther than four as commonly given, "which have not been in the mill. But " wheaten ftraw, and a little hay too fome"times mixed with it, is excellent food. "To a quarter of corn put the fame quan"tity of ftraw. It obliges them to chew "their meat, and is many other ways of "ufe."

On the other hand, feeding horfes in the oppofite extreme, and keeping them on too fimall allowance of food, when they are worked hard, allo difpofes them to many difeafes; the horfe becomes weak and fpiritlefs, his body is emaciated, the circulation is faint and languid, dropfical fwellings appear in different parts of the body, the 


\section{O F $\quad F \quad O \quad O \quad D$.}

the blood itfelf lofes its colour and glutinous quality, and the animal finks under a complication of difeafes, which are confequent upon an impoverilhed ftate of the blood and juices. Hence, therefore, it will appear what care and attention are neceffary in the feeding of horfes, and how much depends on the conducting it in a proper and regular manner.

Although it is extremely difficult to lay down any fixed rules for the feeding of horfes, yet it may be obferved in general, that all extremes in the feeding of them oughe to be avoided. Thofe that are conftantly employed in hard labour, or active exercifes, require more feeding with grain than thofe that fiand much at reft in the Atable, or only perform gentle exercifes, which occafion no great wafte in the conftitution. Upon the whole, the feeding of horfes ought at all times to be proportioned to the labour or exercifes they are employed in. At the fame time, it thould be given. 
given them in fmaller quantities, and more frequently repeated than is commonly done.

It is equally difficult to afcertain the quantity of grain that fhould be given to a horfe in the twenty-four hours, as the meafures in the different counties differ very much. Poft-horfes and hunters who are employed in fuch violent exercifes ought to live chiefly on grain during very hard exercifes. The former frequently eat from four to fix or more feeds per day of the full corn ftandard meafure, which is the targeft of all other grain. But this high feeding thould not be continued for too great a length of time, without a little relaxation both from fevere labour and high feeding. The latter hould be changed occafionally to that which is foft and moift, as boiled barley, malt, or a little frefh grafs in the featon. This thould be continued for a thort time only. They will then be fit for their ufual cxercifes, without exhaufing 


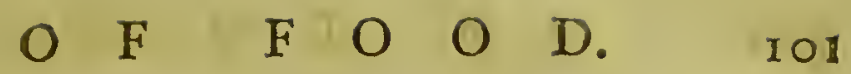

haufting their conftitutions too much at once.

Wheat and barley thould be given to horfes frequently, by way of a change of diet; and all grain that is given them, if poffible, fhould be bruifed in a mill, or otherwife, for the reafons already mentioned; this would not only be a faving of grain, but attended with confiderable advantage in other refpects. Too new grain of any kind fhould never be given to horfes that are employed in active excrcifes; they produce the fame effect as new hay; they fill the veflels with crude watery chyle, which difpofes horfes to fweat much, and hence weakens them confiderably; they likewife frequently occafion a fevere loofenefs, which renders them unfit for the tank that may be required of them; or, if the grain, at the fame time, chance to be bad of its kind, the diarrhoea continues with fuch feverity, that it proves fatal ; of which we have too ma- 
ny initances, although it is not commonly attended to.

Horfes that are fed long on hard dry food, are apt to become too coftive. This fhould be particularly attended to, and guarded againft, as its confequences are dangerous, not only in caufing obfructions in the bowels, but occafioning a ftoppage of urine, from too great a quantity of hardened dung lying in the rectum, and preffing upon the neck of the bladder. This, like molt difeafes, is eafier prevented than cured afterwards, by giving mathes of bran, boiled barley or malt, once a week, or oftener, if found neceffary.

A horfe in this neighbourhood had been neglected in this refpect. He was feized with griping pains, and was treated in a very abfurd manner, by giving him ardent fpirits, aromatic powders, and pepper *.

* A practice but too much in ufe in fuch cafes, and which cannot be too feverely cenfured. 


\section{O F $\quad F \quad O \quad O \quad D$.}

It was at laf difcovered that he had not had any paffage, either by dung or urine. After he was racked *, he ftaled plentifully, but the griping pains ftill continued. Emollient injections were then propofed, but too late to give him any relief. Upon opening his body, a very large quantity of hardened dung was found in the inteftines; the latter of which were of a black livid colour.

Hay that is given ta fuch horfes as are employed in active exercifes thould always be of the beft quality, well flavoured, and well got in. Small quantities at a time, thaked free from duft, thould be put into their racks through the day; and, when they cannot go abroad, as in bad weather, to exercife, they fhould be tied up to the rack

* An operation eafily performed on horfes. After the hand and arm are greafed or oiled, the hand is introduced into the rectum, and the hardened dung taken out by degrees. 


\section{O F}

rack for fome hours, or a bundle of clean wheat ftraw fhould be laid before them, which will amufe them. There is nodanger of their eating too much of it. On the contrary, it will be of great fervice to them. Horfes hould always have their Itated times of fafting, as well as that of feeding. The keennefs of their appetite for hay thould always difcover itfelf by the fame eagernefs which they fhow for their oats.

Many people are of opinion that hay cannot be too old for fuch horfes as are employed in active exercifes. I Aall only obferve, that hay, although kept in the beft manner, like all other herbs and vegetables, will retain its juices and flavour for a certain time only; after which, it lofes both, becomes dry and infipid, and of courfe is rendered unfit for nourihing an animal body. Befides, as it requires a great fupply of faliva from the mouth and jaws to moiften it for fwallowing, which creates 


\section{O F F O O D. $105^{\circ}$}

thirft, horfes are not fond of feeding upon it; neither do they care to eat it without drinking water frequently, which, in the above cafes, would be very improper for them.

The beft argument that can be ufed in favour of old hay, for horfes that are employed in active exercifes, is, that they cannot, for the reafons already mentioned, eat too much of it, and having, at the fame time, a good allowance of grain. They are found to be in a proper ftate for fuch exercifes, becaufe their ftomachs are not oppreffed with too much fodder, nor their bowels loaded with undigefted food. This is what I have all along been contending for, and thows the propriety of giving horfes a very fmall allowance of fodder at one time, even of the very beft quality.

It has formerly been obferved, of the Arabian and other foreign horfes, who are very fleet, and are able to undergo incredible fa- 
tigue, that they are allowed but a very fcrimp allowance of barley-ftraw as fodder, that they are fed moftly with barley; and that their bodies are rather meagre than fat; which is the beft ftate or habit of body for active exercifes of any kind.

By feeding horfes according to the method here recommended, the ftomach will be free from that oppreffion which always attends too great a fulnefs, and, at the fame time, retain its full ftrength, to exert its digeftive powers, fo as to produce the moft wholefome and nourifhing chyle; and hence the body will be healthful, active, vigorous, and fit for the moft violent exerçifes.

C $\mathrm{H}$ A P. 


\section{C $\mathrm{H}$ A P. IIİ。}

\section{O F W A T E R。}

A SEPARATE chapter on water for A the drink of horfes, may, at firft view, appear unneceffary; but, when it is confidered that fome of the difeafes they are liable to may originate, from the conftant ufe of unwholefome waters, it is apprehended fome remarks on the different qualities of frefh water may be of ufe. It is likewife of importance, in the management of horfes, to caution againft indulging them in drinking cold water 
of any kind, in certain fituations and circumftances, as they are guided entirely by appetite, the gratification of which, on certain occafions, may prove fatal to them; although horfes at liberty in the fields are in no danger, in this refpect, at any time, nor in any feafon.

Water is the main diluter of the food and fluids in general. It likewife becomes the vehicle of all nourifhment to animal bodies. On that account, we cannot be too anxious about its qualities, nor delicate in our choice of it, either for our own, or the ufe of our horfes, as it partakes of the qualities of thofe bodies it paffes through, whether they are metallic, faline, or earthy, \&c. thefe foreign matters mixing with the fluids of an animal body, according to their different gravity, and the capacity of the canals through which they circulate, will be, by the laws of motion, depofited on one part or other of the body. 


\section{OF W A T E R.}

As a confiderable proportion of water enters into the compofition of animal fluids, it likewife bears a confiderable proportion in thofe that are fecreted. A large quantity of water being thus diffufed thro' the whole mafs of Aluids in the body, adds to its fluidity. It will be obvious that conftant and frequent fupplies of water are not only neceffary to dilute the food in the ftomach, but the mafs of fluids in general, as they, even in the moft healthy ftate, have a conftant tendency to putrifaction, and require conftant fupplies, both of food and drink, to keep them found and fweet.

Phyficians who have fearched into the caufes of difeafes in the human body, alledge that fome of the molt obftinate chronic difeafes proceed, in a great meafure, from the ufe of unwholefome waters; and, by comparing the different Atrata of earth through which water paffes about populous citics, they affirm that, where the 
water is bad, thofe difeafes prevail moft. It is likewife thought that gravelifh complaints may be owing to the fame caufe. In like manner, water which contains mineral bodies, and nitrous falts, are thought to enlarge the glands of the throat and jaws; and hence it is faid that the inhabitants about the Alps, \&xc. where the waters abound much with thefe qualities, are much difpofed to. this diforder, infomuch that fcarce any who live in fuch fituations are exempted from this inconvenience.

It would appear that thofe waters which are moft unwholefome are not digeftible, or that they do not affimilate or mix intimately with the fluids; and hence they prove the fource of calculous concretions, and hard fwellings, in different parts of the body.

Thus, we find that the effects of unwholefome waters upon the human body 
are great; and, if the difeafes of animals, particularly thofe of horfes, were thoroughly inveftigated, it is more than probable that they would be found equally hurtful to horfes; for it is certain that they are fubject to difeafes which, in many refpects, refemble thofe of the human body. We likewife find, upon diffecting their bodies, that they are fubject to calculous concretions, and hard tumours, in different. organs, and which may originate from unwholefome waters.

Although there are no cafes upon record, in books of farriery, afcertaining the exiftence of a ftone being found in the bladder of a horfe, equal in fize to thofe that are found in the human body, yet, from a variety of fymptoms that may be obferved about horfes, and the frequent attacks they are liable to, of a fuppreffion of urine, together with the great difficulty fome horfes have at times in making water, there is reafon to believe that many of them labour under this diforder in a greater or leffer 
degree. That they have ftones in their kidneys is very well known. The fame is obferved in the kidneys of theep and oxen. It is likewife well known that fome horfes pałs a confiderable quantity of gravel with their urine, and that they are fubject to gravelifh complaints. Hence it may be inferred, that, as the food of horfes is exceedingly fimple and uniform, that the calculous concretions that are formed in the urinary paffages may proceed from the water they drink.

Dr Bracken, in his fecond volume of farriery improved, when treating of the gravel, (page 229.) feems to be of this opinion. He fays, "But the greateft "caufe of it (in my thoughts) is owing to "their drinking fuch waters as, by running " through various ftrata of earth, are im" pregnated with ftony particles. In thort, "whatever can bring on an accumulation "s of earthy, or rather tartareous matter, " in the urinary paffages, whether by ob"Aructing or leffening the capacity of the "canals, 


\section{OF W A T E R.}

" canals, or by immediately or remotely "producing the fubftance itfelf, will caufe "gravel, and in time the ftone."

It has frequently been obferved, that horfes do not thrive on changing from one part of the country to another, although their treatment, in every refpect, be the fame, the difference of water excepted. This, perhaps, may, in a great meafure, be owing to the quality of the water they drink, and which may be poffeffed of different qualities from that to which they had been accuftomed. This is particularly obferved in thofe places where the ftableyards are fupplied from pit-wells, fome of which are very deep, and the water very hard, which occafions that chillnefs, trembling, and thaking, which frequently is obferved in horfes, when they drink it immediately after it is newly pumped, and which caufes their coats to ftare and ftand, as it were, on end, for a confiderable time, 
and fometimes they are griped, and feem greatly out of order.

Spring-water is liable to partake of all the metalline or mineral particles through which it paffes. Hence it becomes noxious or falutary, according to the nature of thore fubftances with which it has been in contact.

River-water has likewife its different qualities from the various foils through which it travels; but, in general, it is much fofter than water that runs under ground, and therefore much fitter for ufe.

Well or pit-water is fubject to all the inconveniencies of fpring-water, with this additional circumfance, that it is generally hard, and, by ftagnating long in the well, it may there take up from the bed it lies upon fuch particles as may render it more, unwholefome; therefore the goodnefs of all well or pit-water is to be doubted, and 


\section{OF W A T E R.}

particularly that which is taken from very deep wells.

Pord-water, under which head may be included all Atagnant-waters, which generally proceed from rain. Where it lies on a clean or a clay bottom, and is freth, it anfwers very well for cattle of all kinds, but, in warm weather, it is apt to corrupt and ferment, which renders it unwholefome, and makes fuch waters the moft uncleanly and difagreeable of any.

Upon the whole, thore waters that are lighteft, and readily break foap, are the beft, as they eafily digeft and affimilate with the fluids of an animal body, and therefore are the fittelt to be ufed for drink.

To correct the hardnefs of pit-water, and render it more falutary for drink, it thould be pumped into a large trough, and expofed to the open air for fome time before it 
is ufed; or, if a cart-load or two of clay or chalk were thrown into the well, it would greatly improve the water. It has likewife been found, that breaking down a piece of clay, about the bignefs of an apple, in a paleful of hard water, before it is given to horfes for drink, morning and evening, that it produced a confiderable change on the coats of horfes to the better; for it will be found that, where horfes are obliged to drink hard water, they are, for the moft part, rough haired, and, at the fame time, they, will have a great deal of dufty matter at the roots of it, even although they fhould be well curried, and brufhed frequently in the day; which plainly thows that there is an obftruction in the pores of the $\mathrm{kin}$, which prevents the natural perfpiration, and, of courfe, that gloffy thining appearance of the hair, which is obferved in all horfes who perfpire freely, through the pores on the furface of the body. Hence it would appear that this cutaneous obftruction proceeds from 


\section{OF W A T E R.}

from the conftant drinking of hard or bad water.

Water that runs through lime-ftone, although expofed to the open air in large ponds, will retain its hardnefs, and produce all the effects above mentioned on horfes that drink it conftantly. This was obferved at a nobleman's feat in this neighbourhood. On mentioning the above circumftance accidentally to a great breeder of cattle from the north of England, he advifed the nobleman to throw fome cartloads of clay into the pond, which produced a confiderable change on the water to the better.

When water in pit-wells is rendered impure, from ftagnating too long, without being drawn off by pumping, or when it has acquired any bad fmell, by impure water getting into it, or full of animalcula or fmall earth-worms, by throwing into the well 


\section{8}

\section{O F W A T E R.}

well a few thovels full of burnt lime, it will become pure and fweet.

Horfes have a delicate tafte and fmell, and are very nice in the choice, both of what they eat and what they drink; of courfe, they thun, when it is in their power, every thing that is difagreeable to either. But, when they are long reftricted from drinking water, they will, in that cafe, offend their tafte, to gratify thirft. This is evident from their readily drinking water ftrongly impregnated with nitre, or with quick-lime, in certain cafes. But this reftriction ought never to be laid on horfes, more efpecially when they are labouring under an inflammatory fever; as, in fuch cafes, they cannot drink too much, in order to dilute their blood, and promote the natural fecretions; but it too frequently happens, through mifmanagement, that they are forced, from neceffity, to drink water which they loath, and that very fpasingly; when, at the fame time, if given them 
them in a proper manner, and of a proper temperature, it might prove, in many cafes, the beft medicine they could get.

Horfes thould never be fuffered to drink too much cold water at one time. If they fhould exceed in this, it fhows that they have been neglected in this refpect; for, if they had always water at command, they would drink often, but never too much at once. For this reafon, water fhould be offered them frequently, but not in too great a quantity. Neither thould they be allowed to drink much water when they are going to perform any active exercifes.

It is very refrefhing to horfes to allow them to wafh their mouths and throat by a glut or two of water, after performing any fevere exercifes; but they ought, on no account, to be indulged in drinking a quantity of cold water when they are overheated. This fhould be particularly guarded againt, as the confequences are dan-

gerous, 
gerous, and frequently prove fatal to them; for, when a quantity of cold water is taken into the ftomach in this heated ftate, when its veffels are full, and diftended with blood, a ftagnation of the blood in thefe veffels takes place, a mortification follows, and death enfues; therefore, when a horfe has been overheated, from exercife, \&c. fmall quantities of water fhould be given him at a time in a pail, but not till he appears to be thoroughly cool; and, in very cold weather, the chill may be taken off, by mixing the water with that which is a little heated. In thefe cafes, it is likewife of fervice to put fome oat-meal in the water, or bran.

It is a common practice to ride horfes pretty hard after they drink water, in order (as the phrafe is) to warm it in the horfe's belly. Walking, or trotting gently, may be of ufe, but any quicker motion, in this cafe, is extremely hurtful. In travel-

ling 


\section{O F W A TER.}

ing toward the end of a ftage, if a horfe is not too warm, it is very proper, if an opportunity offers, to give him a little water, but by no means to fuffer him to drink too much. 



\section{C $\mathrm{H}$ A P. III.}

\section{O F E X E C I E.}

RY Exercife I mean only in regard to

D. fuch horfes as are allowed to ftand too much at reft in the ftable, and at the fame time are full fed, and breathe conftantly a hot foul ftagnated air in clofe ftables; the whole of what is here advanced being calculated to promote the health and foundnefs of horfes, by recommending fuch precepts as may contribute to preferve them in a proper habit of body, and render them fit for active exercifes, in order that they may perform them with eafe and freedom 


\section{OF EXERCISE。}

to themfelves, and with pleafure to their owners. At the famertime, it will how how much it is the intereft of thore who keep horfes, and wifh to have them in health, \&c. to attend particularly to this important article.

It will perhaps appear ftrange at firft view, to affert that a much greater number of horfes who are high fed, and ftand much at reft in clofe warm ftables, die of difeafes which are brought on them from the want of regular exercife, efpecially in great towns, than from any other clafs of difeafes to which they are liable.

Horfes are formed for labour. Inactivity renders them unfit for it; and, at the fame time, it is hurtful to their health, in a variety of refpects.

Inactivity, with full feeding, renders the body dull and nuggifh. The ftomach is loaded with food, which it cannot properly digeft. 


\section{CF EXERISE.}

digett. The food is detained too long in the bowels. Hence indigeftion, coftivenefs, and flatulencies. The inteftines, in this loaded ftate, prefs upon the furrounding vifcera, and obftruct the circulation of the different fluids in them. The liver, mefentery, and fpleen, are expofed to be injured from this caufe ; their natural functions are impeded; the animal oeconomy is difturbed; and, when this is" the cafe, the conftitution muft be injured, and difeafes enfue. The natural fecretions are not in due quantity; they, together with the perfpiration, are retained in the body, "and are abforbed or taken up again into the mars of humours, And hence arifes another fource of difeafe. The circulation of the blood, through the whole fyltem, is flow and languid. Hence the humours or juices are not properly prepared ; glandular obftructions are formed in different organs of the body; the theath and legs fwell ; running fores take place in the latter, commonly called greafe; and the whole 


\section{$\$ 26$ OF EXERCISE.}

whole mafs of fluids are greatly difpofed to putrefaction; difeafes follow, and death frequently concludes the fcene.

On the other hand, conftant and habitual exercife renders the body ftrong and active, and, at the fame time, fit for the moft violent exercifes. All animals, when left to themfelves, are directed by natural inftinct to ufe exercife. Young animals, in particular, fhow a ftrong propenfity to it ; and the very nature and confitution of a horfe requires a confiderable proportion of exercife at all times of life.

Exercife acts as an affiftant to the heart, in promoting a free circulation of the blood and juices through every part of the body. It creates an appetite, and promotes digeftion, and thereby greatly affifts in converting the food to nourifhment. It promotes all the fecretions and excretions, which enlivens the body, and gives room for frefh fupplies of nourifhment; it invigorates the whole 


\section{OF EXERCISE.}

whole fyltem; it gives a flow of fpirits, and adds firmnefs and ftrength to the múfcles and finews. In hort, without a certain proportion of exercife, no animal body can enjoy health.

The motion of the body, or what is called mufcular motion, caufes the blood and juices to circulate freely through every part. As this motion continues or increafes, the breathing becomes quicker and thorter, and the perfiration is forced out at the pores of the fkin. The fweat then becomes vifible on the furface of the body, in the form of iteams, like fmoke. The wetners on the fkin fometimes refembles froth, and is fometimes thin and watery, according to the habit of body the horfe is in at the time. The fweat of a fat horfe is always clammy, and of a frothy appearance; that of a thin meagre habit, when in good condition for excrcife, is rhin and watery. 
The conftant and habitual ufe of exercife or labour increafes the firmnefs of the mufcular fibres, which, being thereby more clofely compacted, the ferous or watery parts of the fluids are more expreffed from their interftices, by which they acquire a degree of rigidity, that caufes, as it were, a drynefs of the whole mufcular parts. Hence the difference is very vifible to the eye, between the firmnefs of the flefh of polt, running, and hunting horfes, and thofe that are fat, and little ufed to labour or exercife.

The effects of exercife to horfes are not only beneficial to their health, but, at the fame time, it keeps them in that condition which is neceffary to preferve them in proper order for performing the various labours which may be required of them. Befides, in many cafes of beginning diforders, its good effects foon become vifible, when it is ufed as a medicine, in thofe - horfes who have fwelled legs, \&xc. from ftanding 
ftanding idle in the fable. For, altho' fuch horfes may have been declared full of humours, and that nothing could relieve them from thefe fuppofed humours, bur purging, diuretic or alterative medicines; yet it has been frequently found, that regular exercife, frequent rubbing of the legs, with a roomy ftall to Atretch their legs when, they lie down, have removed thefe complaints, without any medicine whatever.

It has already been obferved, that, in great towns, moft horfes that are kept there are much injured for want of regular exercife. They ftand in the ftable, pampered to the full with the richeft food, for days, nay even for weeks together, without going any farther than the water, and frequently even that is carried to them. Hence their ftomachs are filled and overloaded with grofs food. This produces a crude indigefted chyle, which vitiates the blood, and difpofes it to difeafe. Rides, or covered thades, for exercifing horfes 
in all weathers, are extremely ufeful; and no ftable-yard, in large towns, fhould be without them; although, at the fame time, the open air is preferable to too clofe thades, or riding houfes.

I remember to have fomewhere read of a fact that feemed to have all the marks of authenticity, and which is applicable to the prefent fubject, the fubftance of which is as follows. The governour of a fortrefs on the continent having been unexpectedly Shut up in his garrifon, by the enemy, at a time when he had admitted a confiderable body of cavalry of his own party on their march. In fuch a fituation, the cavalry were looked upon as loft; but, to the amazement of thofe who faw them when the frege was raifed, they were not only in health, but in excellent order, and fit for the moft active exercifes. The method the governour ordered them to be treated was thus: As he had no room to exercife them but in the ftable, which was bomb proof, 
proof, he ordered three men at a time to each horfe; one to get on his back, the other two were ftationed on each fide behind him, with long whips in their hands, they were ordered to make the horfe ftir about from fide to fide, till fuch time as he was covered with fweat; the men, when tired, were fucceeded by others. Others again were ordered to rub the horfe down till he was quite dry. This manoeuvre was repeated every day; which afforded exercife both to the men and horfes, and preferved both from thofe difeafes which arife from inactivity.

From what has been faid, it will appear how falutary, and even neceffary, regular exercife is, in preferving horfes in health. From the fame reafoning, it likewife may be inferred, that they thould be accuftomed to labour and active exercifes by degrees; for all fudden changes, whether from idlenefs to active exercifes, or from thefe exercifes to idlenefs, produce confiderable changes in the fyttem, and render

both 
both the folids and fuids liable to difeafe. This we experience from our own feelings. When a man, who has not been accuftomed to undergo much fatigue performs any violent exercife or labour of any kind, by which he has been overheated and fatigued, while he is warn he feels no complaints; but, when he cools, he will feel himfelf ftiff, and all over pained in the mufcular parts; but, if he perfeveres in the daily ufe of the fame exercife or labour, it becomes at laft familiar to him, fo that he can perform thefe exercifes with eafe to himfelf, and at the fame time he will be free from thofe pains in the mufcular parts which were at firft occalioned by exertions to which they had not been accuftomed. It is the fame with horfes, on their being firft fet to hard labour, or violent exercifes, although they cannot exprefs their feelings; yet the Atiff contracted fteps, upon moving them about, after a hard day's work, fairly difcover that this is the cafe with them. Accuftom them regularly to the habitual prac- 
tice of thefe exercifes or labour, it then becomes eafy to them, without any ftiffnefs or difficulty of breathing following from it. Hence, when a horfe has arrived at this ftate or habit of body, he is then faid, in the ftable phrafe, to be in wind.

But one great fource of difeafe in horfes arifes from the improper treatment of them after they have been overheated by exercife or hard labour. This, one would naturally think, fhould occur to every man from his own feelings; but this is not the cafe; there are many ftable people of fuch a particular way of thinking, that, although a horfe hould be all over wet, and fmoking with fweat, ftill they will infift, according to their own way of expreffing themfelves, that he is not heated at the heart, and expole him to the cold air uncovered, tied at the ftable-door, and even allow him to drink his belly full of cold water in this heated condition. It would fill a volume to enuinerate the many cafes that have oc-

curred 
curred where this treatment has proved fa. tal to horfes.

When a horfe grows warm from violent exercife, the velocity of the blood, \& is then greatly increafed, by which the fmaller veffels are dilated, and admit of the groffer fluids, which do not ufually circulate in them. This is evident when a horfe has been hard run, from the rednefs of the white of the eye, the veffels of which admitting the red blood into them. There are likewife a number of fmall blood veffels, which may be obferved on the furface of the fkin, that are not vifible when a horfe is cool, and at reft. All thefe circumftances plainly thow the rapidity of the circulation during the time of violent exercife. When the horfe is properly taken care of, and allowed to cool gradually, the celerity of the blood, \&c. abates, the veffels contract, and repel thefe groffer fluids back into the larger veffels, and, by degrees, the Ruids return to their former courfe and place. 
place. But, if the body is fuffered to ftand Rill, expofed to cold air, or if the horfe is fuffered to drink cold water, the veffels, contracting fuddenly by the cold, (whether it is applied to the internal organs, as the ftomach or lungs, or the external furface of the body), retain the groffer fluids that have entered them. Hence, in the former cafes, violent inflammations, gangrene, and, of courfe, fudden death. In the latter, all the difeafes that are confequent upon obAtructed perfpiration. Cafes of this kind frequently happen to the human body, when thofe who are overheated are fo imprudent as to expofe themfelves to cold air, or to drink cold liquors. Death is too frequently the confequence, or they are feized with the moft violent and acute difeafes.

Van Swieten, in his Commentary, (Vol. I. page 34I.) records the cafe of Alexander the Great, who, "when covered with "fweat and duft, went into the Cydnus to "wafh himfelf, in a very hot country, and

"the 


\section{OF EXERCISE.}

"the hotteft time of the day; as foon as " he entered the water, his limbs grew Ptiff " on a fudden, and he turned pale all over; " and the vital heat forfook almort every "part of his body. His fervants received " him like a dying man, and carried him, "fcarce fenfible, to his tent. So fuddenly "was his ftrength deftroyed, young and " hardened as he was by warlike toils, a a violent difeafe immediately feized him, "who was perfectly well before, from " which he very difficultly efcaped, by the "Ikill and fidelity of Philip his phyfician."

Such are the confequences arifing from the imprudent expofure of the bodies either of a man or a horfe to too great a degree of fudden cold, whether it be applied to the ftomach in drinking cold water, or to the external parts of the body, when overheated; of which a great variety of cafes might be mentioned, which have occurred to both, and which is confirmed by obfervation. For every fummer produces frefh inftances 


\section{OF EXERCIS E.}

iiftances of difeafes and death to individuals, from going into the water to bathe when the body is overheated, and every day produces the fame inftances in horfes, as they, when travelling or hunting, are obliged to go through waters that lie in their way. For which reafon, every one who has a regard for his horfe chould, if poffible, endéavour to thun it, and go $\mathrm{a}=$ bout to where the water is lefs deep, or to a bridge, although it may be at a confiderable diftance; as plunging a horfe, when overheated, into cold water, not only endangers his life from the molt violent acute difeafes; or, if he fhould furvive the Thock, it occafions the molt obftinate chronic complaints in the cheft, legs, and feet which may render him ufelefs.

Although a certain degree of exercife be abfolutely neceffary for the health of fuch horfes as ftand much at reft in the ftable; with too full feeding; yet it may be obferved, that, like many orher things relating 
to horfes, it may be carried to excefs, and may prove more hurtful than beneficial; therefore the time and manner of regulating it deferves attention. Thus, it would be imprudent to caufe a horfe exert himfelf too fuddenly after he is newly. fed and watered, becaufe his ftomach is then too full. They fhould be moved flow and gently at firf fetting out. They will naturally mend their pace of themfelves. Their exercife fhould be continued in proportion to their ftrength, manner of feeding, and the labour, \&xc. required of them; and this Thould be repeated every day when it is practicable, and the horfes not otherwife employed; increafing their exercife as circumftances may require. From want of the above precautions in exercifing horfes, how many cafes of broken wind and other afthmatic complaints might be referred to fuch caufes?

It is likewife improper to take out horfes to eascrife in wet or rain, or when they 
are not able to bear it, either from former fatigue, from hard labour, or when they are fick or lame.

But the greateft caution is neceffary to be obferved with horfes that are very fat. They require a long courfe of very moderate and regular exercife, before they can with fafety be put to that which is the leaft violent. Their fat, by the exceffive heat their bodies acquire by violent exercife, is melted, as it were, into oil, and carried into the blood, when it caufes what is called an oily pletbora, which produces the moft violent and fudden inflammations in the lungs, \&c. 'The vifcidity of the oily matter obftrukting the veffels, and preventing the other fluids from paffing through them, frequently occafions fudden death; many inftances of which 1 have known, particularly in thofe horfes that have been fed with a great deal of boiled meat, in order to fatten them fo: fale. Thus a pair of Arong heavy carriage horfes were once offered me for fale. I 
declined purchafing them, on account of their extreme fatnefs, which was thought very fingular. A gentleman in the neighbourhood purchafed them. They were conftantly and regularly exercifed with the greateft care and attention for a confiderable time, in order to reduce their bodies, and bring them into a proper condition for work. After this had been continued for fome weeks, they had occafion to travel pretty fmartly a very thort ftage of feven miles out and home, which finifhed one of them after a thort illnefs. This and a variety of frmilar cafes, which will readily occur to every one who is acquainted with horfes, may ferve to fhow the danger of putting thofe that are too fat and full of juices, too fuddenly on violent exercifes of any kind; for there is no ftate or habit of body a horfe can be in more dangerous, or more liable to difeafe, or that runs greatsi hazard, when attacked with difeafe, than thofe that a:c too fat. 
Thus I have endeavoured to thow the advantages that arife to horfes from the conftant habit of moderate exercife. It perhaps may be of ufe to purfue this fubject a little farther, and confider the effects it produces when carried to excefs, and the confequences that follow from it, on being too fuddenly expofed to cold air, or plunged in cold water.

It has been obferved in animals that have been hard hunted, before they are killed, that, upon taking off the fkin, the whoie panniculius adipofis, and even the mufcular flem, have been found almoft black, from the blood being extravafated under the $\mathrm{kin}$, or by the extreme heat of the body, together with the velocity of the circulating fluid, and that the blood has been forced into thofe veffels, in which it does not commonly circulate. The fame appearance I have obferved in horfes, particularly one that fuddenly fell down dead in a race on coming up to the ftarting poft the laft heat. 
When they were taking off his fkin, the blood appeared as if it had been extravafated between the flerh and the fkin, and xun down in a confiderable quantity, as the horfe was then hardly cold. It is likewife obferved in cattle that are drove too hard, immediately before they are naughtered, that the blood is too much mixed with the flerh, \&c. All thefe circumftances demonftrate, that in violent exercifes the blood is forced by the rapidity of the circulation and extreme heat of the body, into veffels in which it does not circulate in the ordinary courfe of circulation. Whilt the body is in this heated fate, if cold water is thrown upon it, or the horfe plunged into cold water, or too great and fudden a degree of cold in any thape applied to the body, the fluids, as I have formerly hinted, are retained there, by the veffels contracting fuddenly; and as thefe extravafated fluids cannot fo fpeedily be abforbed or taken up by the abforbent veffels, and corveyed into the circulating mars, they may then be faid to be 
in a ftate of ftagnation. Hence inflammation, gangrene, and mortification follow.

This may be farther illuftrated by confidering the manner in which horfes are affected in that diforder, which is commonly termed a founder, the fymptoms that take place in the different ftages of the diforder, and the circumftances that appear on diffecting thofe who have died of it. As this diforder always proceeds from cold too fuddenly applied to the body, whether it be from a current of cold air, or from plunging the body into cold water, when overheated, the effects are the fame. The rymptoms at firft, are, when the horfe begins to cool, he appears very ftiff and feeble in his fore quarters, and, when forced to move forwards, he collects his body, as it were, into a heap, and brings his hind feet as far forward under his body as he poffibly can, in order to remove the preffure of the weight of his body from the fore legs and feet; at the fame time he fets his fore feet 
to the ground with feemingly great pain; his fore parts are extremely hot, the legs confiderably fwelled, and feemingly painful to the animal when touched, a violent fever fucceeds, which, if not properly treated, terminates in death; or, if the horfe furvives the fhock, in incurable lamenefs. On diffecting the legs and houlders of thofe horfes who have died in a few days illnefs of this diforder, the blood is generally found extravafated, as mentioned above, the parts having a black appearance, efpecially between the fkin and the flefh. The fame blacknefs is likewife obferved in the cellular membranes between the interftices of the mufcles and tendons, the texture of the veffels are deftroyed and mortified. The following cafe was communicated to me by a very judicious farrier in London. A gentleman being 18 miles diftant from London, was anxious to be in town before it was dark. He rode his horfe very hard through a decp fnow, during a fevere froft. When the horfe was fuppcred 
fuppered up after being well rubbed over, he lay down, and was found in the fame fituation next morning, but unable to rife, or ftand when up. On the third day, both his fore hoofs.fell off. This was a founder of the very worft kind. The excenfive coldnefs of the fnow, to which his hoofs and legs had been fo long expofed, when they were overheated, produced the effects above related in the cafe of founder. The violence of the inflammation that had taken place within the hoof had deftroyed the texture of the veffels, \&c. Hence all manner of connection between the hoof and internal parts of the foot being deftroyed, they became loofe, and fell off. The fame effeets happen in the human body, when a violent inflammation takes place about the ends of the fingers or toes, the nails come off.

Plunging horfes in cold water, when they are overheated, has the effect to weaken them, as it would appear from the following obfervation communicated to me $T$ 


\section{$\$ 46$ OF EXERCISE.}

by a gentleman who is a great fportfman, and at the fame time is well fkilled and acquainted with horfes: ' That, in hunting,

" when they are overheated and obliged to ' go through deep waters, efpecially if they - are obliged to fwim, they foon after be' come faint, jaded, and tired.'

It may be urged by fome people, that they have known horfes plunged into cold water, when they were overheated, and likewife expofed to the inclemency of the coldeft weather, without any fuch bad confequences following from it. This will readily be granted. I would again ank, how comes it that one man is feized with a difeafe, whilt another, in the fame circumftance, place, and fituation, efcapes it? The anfwer to both is obvious. It depends on certain circumftances of habit of body either may be in at the time. Thus, it frequently happens, that two horfes yoked to a poft chaife, the one a veteran hardened by labour, \&xc. the other a frefh horfe, when 
when overheated on the road, and obliged to go through deep waters; the veteran thall be affected with the difeafe termed a founder, whilt the other is not; although it more frequently happens that young, or fren horfes, are much more liable to be injured from fuch treatment.

As the difeafes which arife from obftructed perfpiration are fometimes rapid in their progrefs, a few general remarks on fome of the moft prevailing, or moft dangerous, may be ufeful in this place, as it may be prefumed that horfes generally are more expofed to catch fuch diforders, after they have been overheated, more efpecially when they are improperly treated, or neglected.

It has been formerly obferved, that, when the body is overheated by active exercifes or violent labour, the circulation of the blood, \&c. is carried on through the veffels with uncommon rapidity; of courfe the refpiration, or breathing, becomes more la-

borious, 


\section{OF EXERGISE.}

borious, and more frequently repeated; at the fame time the perfiration, from the cuticular pores of the fkin, is confiderably increafed on the furface of the body, in the form of humid fteams like fmoke, and fometimes fo profure as to run down the fkin, as if water had been poured on the body.

As this perfpirable matter is very liable to be fuddenly checked by cold, (in whatever manner it is applied, whether by a current of cold air, or water thrown upon the body, or horfes plunged into it), and rerained in the body, it then occafions a number and variety of difeafes, which either affect the fyltem in general, as in fevers, or when more local, and affecting the mufcles, it produces rheumatifm in the houlders, neck, and legs; hence ftiffnefs and lamenefs. When it affects any of the internal organs, as the bowels, it occafions colic pains, diarrhoea, or loofenefs; when it fettles on the lungs, it produces coughs, catarrhs, peripneumony, 
ripneumony, or inflammation of the part, followed by confumption, \&c. When on the membrane called the Pleura, which lines the cavity of the thorax, it occafions the moft violent pains or ftitches, with difficulty of breathing, \&c. When on the glands of the throat, fwelling and inflammation, threatening a fuffocation, and fometimes fuppuration of thefe glands When on the trachea, or wind-pipe, or the pituitary membrane which lines the cavities of the head, diforders peculiar to thefe parts. The latter of which deferves particular attention.

As the pituitary membrane, which lines the infide of the nofe and the cavities of the head, is now pretty generally known to be the feat of that difeafe in horfes called the glanders, and which was firlt difcovered by M. la Foffe, who is very juftly entitled to the merit of it. He has at the fame time pointed out the method of cure, when practicable, before the bones of the 
head become carious; of which Mr Bartlet, in his Gentleman's Farriery, p. II 9. treats pretty fully. He has likewife given a plate for explaining the operation of the Trepan, as propofed in the method of cure by M. la Foffe: But, as Mr Bartlet has adopted an inaccuracy advanced by the former, which, if not corrected, would millead the young practitioner, I fhall beg leave to mention it in this place, and point out the error. In p. I23. he fays, "It is a " curious remark of our author, that the "fublingual glands, or the kernels fituated " under the jaw-bone, which are always, " fwelled in this diftemper, do not dif" charge their lymph into the mouth, as in "man, but into the noftrils; and that he " conftantly found their obftruction agreed " with the difcharge, if one gland only was " affected, then the horfe difcharged from " one nottril only; but, if both were, then "the difcharge was from both."

It is furprifing that $\mathrm{Mr}$ Bartlet fhould not have corrected M. la Folfe in this anatomical 
tomical error of placing the fublingual glands under the jaw-bone on the outfide, and miftaking the fubmaxillary glands for the fublingual; for, if he had infpected the head of a horfe, he would have found the fublingual glands in their proper place, where their very name implies they fhould be, that is, immediately under the tongue, as in the human body he likewife might have traced their duct or opening to the two fmall papillae that are fituated on the infide of the fore-teeth, under the point of the tongue, which demonftrates that they difcharge their lymph into the mouth, as in man; and, in all the diffections I have made on glandered horfes, I never found thefe glands affected; but the fubmaxillary glands that are fituated between the jawbones on the outfide, are always more or lefs fwelled, inflamed, or indurated, according to the length of time they have been affected, or the virulence of the difeafe, they likewife difcharge their lymph into the month as in the human body; and 
their being conftantly fwelled in glandered horfes, according as one or both fides of the pituitary membrane is affected, may arife from the fame caufe, which produces the fwelling of the inguinal glands in the groin of the human body in a gonorrhoea, that is, from the abforption of the virulent matter affecting them, and occafioning that fwelling, induration, \&c. Hence it is evident that the fwelling of the fubmaxillary glands in glandered horfes, and of the inguinal glands in the groin of the human body in a gonorrhoea are only fymptoms of thefe diforders.

The Count De Buffon, in his natural hiftory of the horfe, vol. 3. p. 382 , alledges that this difeafe called the Glanders proceeds from the horfe dipping, or finking his nofe and mouth deep into cold water when he drinks. In comparing the manner of a horfe's drinking with that of the dog, he obferves, that " the horfe, on the " contrary, whofe mouth is too fmall, and "whofe tongue is too thick, and too fhort, "for 
"for forming a fcoop, and who, befides, "drinks with more avidity than he eats, "brifkly finks his mouth and nofe deep "into the water, which he fwallows plen"tifully by the fimple motion of degluti"tion. But this obliges him to drink with" out drawing his breath; while the dog "refpires at his nofe during the time he is " drinking. After running, when the re"fpiration is fhort and laborious, horfes "Thould be allowed to drink at leifure, and " to breathe as often as they incline. Nei" ther fhould they be permitted to drink "water that is too cold; for, independent " of the colics frequently occafioned by " very cold water, it often cools their nofe " to fuch a degree, as brings on rheums, "and perhaps lays the foundation of the " difeafe called glanders, the moft obftinate " of all maladies to which this noble ani" mal is fubject. Befides, thofe travellers "who give a detail of the difeafes of hor"fes in warm countries, alledge not that "the glanders is equally frequent in Ara- 
"bia, Perfia, and Barbary, as in cold cli" mates. Hence I am led to conjecture, "that this malady is owing to the fuperior " coldnefs of the water ; becaufe thefe ani"mals are obliged to keep their nofes in " the water a confiderable time, which " might be prevented by never allowing " them to drink very cold water. Affes, "which dread cold more than horfes, and " refemble them fo greatly in their inter" nal firucture, are not equally fubject to " the glanders, which is owing, perhaps, to " their drinking in a different manner from " the horfe; for, inftead of finking the " nofe into the water, they barely touch, it "s with their lips."

Although I cannot help differing in opinion from the Count in this refpect, as I have known horfes affected with this diforder who never had the cuttom of dipping or finking their nofes deep into water when they were drinking; yet I agree with him on the general principles, that the caufe of this 
this diforder may proceed from cold affecting the pituitary membrane which lines the cavities of the nofe, \&c. for it generally may be traced to its very beginning, from fome cold affecting the head, and which has either been ill treated, or totally neglected: Hence, therefore, it will be evident, that this diforder, like many others to which horfes are liable, may be much eafier prevented than cured, when once it has taken place: Hence the neceffity of paying proper attention to recent colds, in keeping the head and throat warm, and not fuffering the horfe to go abroad before he is thoroughly recovered, more efpecially in very cold weather.

When the pituitary membrane is affected with a recent cold, the fmall glands which are difperfed throughout the fame become dried, inflamed, \&cc. and, in place of feparating a fine thin lymph like to pure water, which ferves to lubricate and moifen the paffage of the nofe and cavities of 


\section{I56 OF EXERCISE.}

the head, as in a healthy ftate, they then difcharge a thick vifcid mucus, known by the name of fnot, which falls from the noftrils, according as one or both noftrils are affected. Though the difeafe at firft is merely local; yet, when it increafes by neglect, or otherwife, it fpreads over the whole membrane which lines the cavities of the nofe, \&c. The membrane becomes thickened, lax, and flabby; its fmall glands become more or lefs ulcerated. Hence the quantity of mucus difcharged from this large fpace of membrane becomes very profufe. The maxillary finufes on each fide of the nofe, (called the antrums) which are of a very particular ftructure, being deep and hollow, refembling a purfe with the opening on the upper part a little inclined to the paffage of the nofe, one or both of thefe cavities, according as one or both fides are affected, are foon filled with the mucus, where it is retained, and, from the heat of the parts, and its long retention, it acquires 
acquires a more virulent corroding quality, which adds to the general diforder. As the difeafe increafes, the fpongy bones in the head, of which there are feveral, become carious. The difcharge then becomes extremely foetid, and of different colours, \&c. the whole fyftem being affected by the abforption of this corroding matter, the horfe becomes hectic. It then becomes neceffary to put a period to his exiftence.

On diffecting the heads of fuch horfes as have been affected with this diforder, I have always found the pituitary membrane to be the feat of the difeafe, and the cavities formerly defcribed filled with vifcid mucus. In the firft ftage of the diforder it is of a mild bland quality, and of a white colour, without any particular fmell. In the fecond ftage it becomes more ichorous, foetid, and difcoloured. In the laft ftage it is of a molt offenfive fmell, and of a black yellowifh colour, mixed with blood, the whole membranc being then turned in- 
to one ulcer, the fpongy, and even the more folid bones rotten and deftroyed, all the cavities of the nofe, \&xc. may then be faid to be converted into one general mars of corruption. I have been the more particular in defcribing the general fympioms of this difeafe, together with the appearances on diffection, as the hints here thrown out may be of ufe in leading to farther difcoveries, either for preventing or curing this loathfome diforder.

From what has been faid, it will be evident, that there can be no great hopes of curing this difeafe in the two laft ftages. I fhall only obferve at prefent, that when a cure is practicable, it can only take place in certain favourable circumftances, and in the firft ftage of the diforder, before the mucus acquires any ichorous or bad quality, or the bones become carious. It will ftill be more favourable when the difcharge of mucus is from one noftril only. For the operation of the trepan, as recommended 
by M. la Foffe, I muft refer theader to Mr Bartlet's defcription of thatperation, which is pretty accurate; only would obferve, that, as he directs th thin bony partition immediately betyen the fcull, where the lower trepan is made, and the bone which forms th bottom of the maxillary finus, where thmucus is lodged, to be perforated with a filetto, or tharp pointed iron; as this lat operation is apt to make long fiffures, racks, or feams in that bone, by whichneans it becomes the more liable to be affeted with the ichorous matter that is to fafs through the parts, and by becoming arious may protract the cure. It will the efore be more advifeable to perforate this thin bony partition with a trepan of a fmaller fize, and then with another ftill lefs to perforate the bottom of the finus.' Hence it will be neceffary to make three perforations with the trepan, before the mucus confined in the finus can be difcharged, befides, the opening in the frontal finus, which is made on purpofe to fyringe the cavities with proper injections.

Thus 
Thus have endeavoured to lay before the readefome of the general effects of a current of rold air, or cold water applied to the furfa. of the body of horfes when they are oveleated. The effects of too much cold wier being taken into the ftomach at once hve been already mentioned in the chapter o water. It remains now to make a very fhort obfervation on too cold air being infired into the lungs, when they are much agiated from exercife, and the body confiderabl? heated.

However dry and eaftic the air may be that is drawn into the hings of an animal body in refpiration or brathing; yet, when it is difcharged from them, it is evidently loaded with humid fteams; at the fame time it lofes confiderably of its elaftic quality. The moifure that comes from the lungs evidently thows, that a very great portion of thin lymph, or perfpirable matter, is difcharged from them at every refpiration; and, as this action is increafed and 
quickened by exercife, the difcharge of this fluid will be the greater. But, as very cold air is apt to conftringe or thut up the cuticular pores on the furface of the body, in like manner when it is applied to the furface of the lungs, efpecially when they are overheated, it produces the fame effect there; hence, that perfpirable matter which should be thrown out from them, is retained in the lungs, and produces colds, catarrhs, inflammation, and confumption.

Thus I have attempted to fhow the reader the difadvantages that arife to horfes from errors in the management of them, refpecting their ftables, food, water, air, and exercife; and I hope I have in fome meafure pointed out how they may be remedied.

The obfervations that follow, on fome of the furgical and medical branches of farriery, are continued on the fame plan, and with the fame view, of pointing out where 
errors likewife prevail in the practice of farriery. At the fame time, I have endeavoured to fhow in what manner they may be rectified. They are not offered to the public as complete difcourfes on the different heads there treated of; but as loofe hints in general, which, if duly attended to by the young practitioner, may be of confiderable ufe to him in the beginning of his practice. The hints on the treatment of horfes when they are taken fick, or otherwife difordered, will, I hope, have their effect in removing thofe practices that too much prevail in thefe cafes, and which only tend to increafe, rather than alleviate the diforders they labour under. 


\section{C $\quad H \quad$ A P. $\quad$ V.}

ONTHE

MANAGEMENT OF HORSES

W II E N S I C K.

HE difeafes to which horfes are liable,

1 have a great analogy to thofe of the human body; at the fame time, they are almoft as numcrous, a few only excepted, which are peculiar to the latter, and which are thought to proceed from the paffions, o: other difturbances of the mind.

Here 


\section{I64 ON THE MANAGEMENT}

Here a queftion naturally occurs: How comes it that horfes are fo liable to fuch a numerous train of difeafes more than other animals of the brute creation? The anfwer is obvious, they are more domefticated, on account of their fervices to man, than other animals, the dog only cxcepted; and even the latter is left more at liberty than the former. The hiftory of the horre, in a natural ftate, afford no inftances of difeafe amongtt the fpecies; neither is it found that they are liable to difeafes when running wild in different parts of Britain. It is likewife obferved, that young horfes are not liable to difeafes while they run at liberty, diftant from towns or villages. They feem to enjoy a perfect ftate of health till fuch time as they are taken into ftables, when they are more immediately under the direction of man; it is then that this great change feems to take place on their conftitutions. Hence, therefore, it may be inferred, that this pronenefs to difeafes in them, mut arife from the treatment they 
are fubjected to in general; from the multy, clofe, hot, foul-aired, damp ftables, \&c. they are confined in ; from errors in their diet, drink, \&c.; from the want of regular airings and exercife; from the fudden tranfitions they are compelled to undergo, from heat to cold, and from cold to heat, and from a variety of other errors in treating them when over-heated by violent or acive exercifes, from fuffering them to drink cold water in that fituation, or plunging them in cold water, neglect of proper friction or dreffing, \&cc. \&zc.

On confidering the varicty of difeafes to which horfes are liable in a domefticated ftate, it is furprifing what affinity there are in the fymptoms attending each of them, with thofe which take place in the human body in the like fituation, infomuch, that, if the fympioms attending any one of the difeafes to which horfes are liable, were faishfully related to a phyfician, although he never faw a fick horfe, yet he could from thence 


\section{I66 ON THE MANAGEMENT}

thence name the difeafe under which the horfe laboured at the time. From thefe, and a variety of other arguments which might be offered, it will be obvious, that the cure of the difeafes in horfes muft depend upon the fame principles as thofe of the human body, and that the prevention of difeafes in the former, mut likewife depend on obviating the caufes which difpore them to and render them liable to thefe difeafes.

The plan I have adopted, will not permit my particularizing the treatment, or medicines, neceffary to horfes under different difeafes; that will be the fubject of a fubfequent work. I only propore, at prefent, to make a few general obfervations on the common treatment of them when they are taken fick, or anywife difordered, and thow the pernicious confequences that follow, from errors in the management of them in that fituation. I Mall, thereforc, confine myfelf to a few cares only. 
In cafes of Fever.

If a clofe, hot, foul-aired ftable, is pernicious to horfes whilf they are in health, it is much more fo to thofe that are fick, efpecially of a fever, and panting for breath. The extraordinary care that is then taken to keep the ftable uncommonly warm, by which means all frefh air is excluded; the very threfhold under the door, as I have elfewhere obferved, even the key-hole, and not a crevice that would admit the leat frefh air, but what is thut up: In fuch circumftances, the air within the ftable is fpeedily exhaufted, and becomes extremely corrupted, infomuch, that it is not only hurtful to the fick, but to the other horfes that are in the fame ftable with him. This caufe alone is fufficient to excite the moft violent fever, and inflammation in the lungs, even of the moft healthy and found animal.

Befides 
Befides the great heat of the furrounding air, in which the horfe ftands and breathes, his body is kept uncommonly hot by meáns of a greater load of cloaths than ufual, together with a greater quantity of litter under him, and, to add to all this, the vapour and hot fteams which arife from the other horfes bodies, excrements, wind, and urine, that . are thut up in the fame ftable, render the air very unfit for refpiration, the fick horfe is ftifled with heat and the clofenefs of the ftable, he pants for that frefh air which is excluded from him; the great heat in which the horfe's body is kept, increafes his diforder, and, if fweating is produced, this, in many cafes, aggravates it ftill more, by carrying off the thinner parts of the blood, the remaining mafs becomes more vifcid and inflamed, which renders it lefs fit for circulation. In this fituation, the beft medicines, however judiciounly prefcribed, can be of no avail to the lick, as their effects are counteracted by the above treatment. 
I have formerly hinted at the pernicious confequences of ufing too tight rollers above the horfes cloaths, which confines the lungs, \&c. by their compreffing the parts too much, even in health, it is much more hurtful to horfes when fick, and particularly in the fituation above mentioned. If a man in a fever were girded round the breaft with a roller or bandage, it would occafion the utmolt anguifh, and difficulty of breathing, and endanger a fuffocation; even the weight of the bed-cloaths is found oppreffive in thefe cafes; how much therefore muft this anguifh and oppreffion be in hories that are fick, and panting for breath under a fever, when thefe rollers are girded fo tight, that a horfe, even in health, can hardly breathe with them. I have frequently found, that the ungirding of the fe rollers gave immediate relief to fick horfes, efpecially in the above fituation, and, on admitting frefh air into the ttable, the violence of the fymptoms were confiderably abated. 
For the reafons now mentioned, a fick horfe thould, if poffible, be removed to a well-aired ftable by himfelf. But, as horfes are very fociable creatures, and fond of being in company with others, where they are found to thrive beft, another horfe may be put in the fame fiable with him, but at as great a diftance as the place will admit of, in order to let the fick breathe a purer air. His cloathing fhould be very moderate, and by no means girded on too tight about the breaft, but only in the flighteft manner, to prevent them from falling off. The rack and manger ought to be wafhed clean from dirt, \&c. with foap and water, beforc the fick horfe is put into the ftall; all the old litter, wet or mufty ftraw, fhould be removed; the frefh litter that is put under him thould be fpread thin, as too much of it increafes the heat about his legs, \&zc. The rack and manger are afterwards to be kept clean, and free from the fnot, and other difcharges that may come from the nofe and mouth, as they are very apt to lick 
it up with their food, or by way of amufement. When the horfe's breath is very foetid, or of a bad fmell, the violence of the fever ftill continuing, the rack and manger ought to be frequently walhed or fprinkled with vinegar.

\section{Diet for Sick Horjes.}

With refpect to the diet for fick horfes, it may be obferved; that, in fome difeafes, even of the inflammatory kind, the appetite for food is not much diminifhed, in others, when very fick, they refufe every kind of food. In the former cafe, it ought to be given in a fmall quantity at a time, and frequently repeated; it Thould be of the fofteft kind, as manhes of fcalded bran, boiled barley, malt, or dry bran, if the horfe refules foft food. In the latter cafe, when the horfe refules food of every kind, it is too common to force it upon 
him, by pouring wine foaps, \&zc. down his throat, under the apprehenfion that the horfe will fuffer from the want of nourinment: But this is not the cafe; if the ftomach loaths food, it is a certain fign that it is difordered, and therefore cannot digeft it. The throwing or forcing more food into the ftomach, ferves only to aggravate the diforder, by increafing that oppreffion which already prevails there too much. It is to be obferved, that the ftomach of a horfe has not the faculty of vomiting, or even belching up wind by the mouth, which, in thefe cafes, might give him inftant relief. If a horfe will drink water freely, that is the beft medicine in fuch a fituation, as it dilutes the contents of the fromach, which affords an eafier paffage for them into the inteftines. Therefore, no food whatever fhould be forced on fick horfes; neither fhould they be tempted with oats, or other nourining food, as it is by no means proper for them in fuch a fituation, although they thould feem to relifh 
fuch food, which they frequently feem to do by way of a change.

In place of oppreffing the ftomach of a fick horfe, by forcing food on him in the manner above mentioned, with the view of nourifhing him, art furnifhes us with another refource to fupport him, if found to be abfolutely neceffary, and that is by clyfters. How nourifhment may be conveyed to an animal body by clyfters, I refer the reader to the chapter on that head. I hall here only obferve, that, after the inteftines are emptied of excrement, by clyfters of warm water, or of very thin water-gruel, in which a handful of common falt, or a few ounces of glauber falts, have been diffolved, nourifhing clyfters, compofed of two or three quarts of thick watergruel, may then be given with fuccefs, and repeated as often as may be found neceffary. There is no danger of a horfe's fuffering from the want of nourifhment by the mouth, in a fever; but there is great danger 
danger to be apprehended from its being forced on him, as above mentioned, when the ftomach cannot digeft it. After the great inteftines have been thoroughly emptied of the hardened excrements by clyfters, the contents of the ftomach find an eafy paffage into the fmaller ones; it is then freed from oppreffion, and the horfe naturally craves frefh aliment; when he.recovers his appetite, there is danger in indulging him with too much at once; this Thould by all means be guarded againf, in order to prevent a relapfe.

With refpect to giving medicines to fick horfes, the greateft caution is neceffary; for, in inflammatory cafes, to which they are very liable, every thing that is heating or irritating is extremely hurtful, and may occafion the moft untowardly fymptoms, and even death may be the confequence. The common cordial drenches that are too frequently given on moft occafions, are the moft pernicious and hurtful in inflamma- 


\section{OF HORSES WHEN SICK.}

tory cafes; as they are compofed of hot fpices, aromatic powders, with the oil of anife, \&c. they aggravate the oppreffion at the ftomach, and increafe the fever.

In order to leffen the great heat of the body, and to allay the internal commotion which prevails, fuch medicines may be given which are termed coolers or fedatives; from their known qualites of reftoring regularity to the vafcular fy ftem, and, at the fame time, have the power of removing fpafmodic confriction in the veffels, from the calm which fucceeds their adminiftration; for which purpofe, nitre, or falt petre, is amongtt the belt, and agrees very well with horfes; one ounce of which, diffolved in a quart of warm water, may be given three, four, or five times a-day, by a horn. I would here obferve, that, in order to render the nitre more effectual, that it be in powder, and mixed with the water immediately before it is adminiftered, as it lofes confiderably its cooling efficacy on 


\section{ON THE MANAGEMENT}

being long diffolved; the draught may be fweetened with honey or molafles, in order to render it the more palatable. Another neceffary caution I would recommend is, that the horfe thould be as little fatigued as poffible in giving it. One man fhould hold up the horfe's head with both his hands, whilft another pours the drink by degrees into the horfe's mouth, and, when the horfe feems tired or fatigued, to allow him time to reft himfelf at intervals. A variety of other cooling draughts might be mentioned; but, as there is no abfolute neceffity for ftudying the tafte of horfes in this refpect, and, as nitre is found in general to fit eafy on their ftomachs, it will be found to be the beft medicine that can be given in fuch cafes; thofe who may be willing to change the prefcription, may give the infufion of lintfeed, mixed with acids, as the juice of lemons or oranges, or a fpoonful or two of vinegar, where nothing elfe can be got, adminiftered as above, and a little fweetened. 
In cafes of Gripes or Gbolic Pains.

Horfes are very fubject to griping or cholic pains; they may proceed from $\mathrm{Ala}-$ tulencies, or wind pent up in the ftomach and bowels, from inflammation of the coats of the ftomach and inteltines, or from worms, fpafms, \&c.

When a horfe is feized with griping pains in the bowels, it is common to give fuch things as are of a heating quality; by the mouth, as pepper, ginger, the different kinds of aromatic powders in gin, or fome other ardent fpirit, together with oil of turpentine, oil of juniper, \&c. Such prefcriptions are highly improper, for the reafons formerly mentioned, in cafe the, diforder thould proceed from inflammation, as the fymptoms of gripes in general have a near refemblance to ordinary attendants, 
who cannot be fuppored capable of making the diftinction between each fpecies of them; ncither is it neceffary to particularize them at prefent, as the hints here offered are only calculated to thow the bad confequences that may follow, from the giving of hot irritating compofitions to fick horfes, or in cafes of cholic pains; for, even on the fuppofition that the pains proceed from flatulencies pent up in the ftomach and bowels, the above mentioned heating compofitions are improper, as it would appear they rarify the confined air, which cannot find paffage either upwards or downwards, it then occupies more fpace, and, of courfe, by diftending the parts, increafes the pain.

In fuch cafes, the horfe is generally cortive, and the bowels are loaded with hardened excrements, which being collected in the rectum, or great gutt, it preffes down upon the neck of the bladder, and caures a ftopage of urine; and, as the horfe naturally 


\section{OF HORSES WHEN SICK.}

rally tries every means to relieve himfelf, he makes frequent motions to ftale, but without effect; hence, many people overlook the real caufe of the diforder, and attend only to the effect it produces; they therefore prefcribe the ftrongeft diuretic medicines, with a view to make the horfe ftale; from this treatment, and total neglect of the original caufe of the diforder, it increafes, the bowels become inflamed, a gangrene and morifification take place, and death follows.

To corroborate what I have here advanced, I could add a number of cafes, which have occurred in practice, and which have afterwards been confirmed, by infpecting the bodies of horfes immediately after death; but the following will be fufficient: A horfe in this neighbourhood, who had laboured under fevere griping pains for two days, (a diforder commonly, though very erroneoufly, termed the botts or batts in horfes, although that diforder is not produced 
duced by that fpecies of worm perhaps once in twenty or thirty cafes, when they are faid to be the caufe) all the heating fpices, aromatic powders, gin, oil of turpentine, \&c. above mentioned, had been poured into his ftomach, at different times, the diforder fill increafing. The proprietor defired I hould attend him: But, on feeing the horfe, I concluded, from the fymptoms about him, that he would foon die; which happened a few hours afterwards. On opening the body, a confiderable portion of the bowels rufhed out with great noife, they were inflated with air to a very uncommon degree, as if they had been blown up with a bellows; the ftomach was in the fame fituation; but the lower or back part of the inteltines, towards the anus or fundament, was filled with dry hardened excrements, as if they had been dried in an oven; a great part of the inteftines which -inclofed this dry hardened dung, were black and mortified. From thefe circumftances, it would appear, that the hot medicines, 


\section{OF HORSES WHEN SICK. I8I}

medicines, \&c. which had been poured into the ftomach, had probably rarified the air in the ftomach and bowels, and, as it could get no paffage upwards, for the reafons formerly mentioned, by the mouth, nor backwards, by the anus, on account of the hardened excrements lodged in the lower inteftines, that the means which were ufed as a cure, contributed greatly to increafe the diforder. But, if emollient or purgative clyfters, or even thofe of warm water only, had been given the horfe in the firt ttage of the diforder, they would have thinned the hardened excrements, and rendered them fit to be expelled out of the body, the wind or air, that was pent up in the ftomach and bowels, would then have found a palfage backwards by the anus, and the horfe's life might have been faved.

In all cafes of violent griping pains in the bowels, bleeding is the firft thing neceffary, and that pretty freely, as that re- 


\section{ON THE MANAGEMENT}

laxes the whole fyttem, and paves the way for other means, which are to empty the rectum, by taking out with the hand the hardened excrements that are lodged there; fometimes they appear foftin, and the horfe dungs, frequently from pain, in very fmall quantity at a time; but generally they are very much hardened; in this cafe, the operation formerly mentioned (which is called back-racking) gives the horfe great relief, by removing the preffure from the neck of the bladder, the horfe will then be able to ftale; but the pain, from the air that is pent up in the bowels, may ftill remain; emollient clyfters are then of great benefit, as they not only empty the intertines of the excrements, which affords a paffage for the wind backwaids, but they ait as an internal fomentation, by which means, they contribute to remove the fpafmodic conftriction from the bowels, and prevent inflammation; they may be frequently repeated, till the confined air finds a paffage backwards by the anus, which, when once 


\section{OF HORSES WHEN SICK. 183}

this takes place, it frequently paffes off in great explolions, to the great relief of the horfe. I have obferved, in fuch cafes, that the air they paffed, from being long pent up in the bowels, was more inflammable than ordinary, fo as to catch fire from a candle, if it happened to be near, and fpread a blue flame for a confiderable fpace around, and fometimes to finge the hair and eye-brows of the by-ftanders who were within its reach.

All the different fpecies of cholic pains in the bowels, whatever caufe they may proceed from, ought to be treated in the fame manner, on their firt attack, as it is a neceffary ftep in freeing the inteftines from what may tend to aggravate, or add to the diforder. This becomes the more neceffary, as it is the only means that can be ufed with fafety in horfes; to clear the paffages, and pave the way for medicines, which may be afterwards found neceffary; at the fame time, carefully avoiding the giving 
giving of medicines, by the mouth, that are either hearing or irritating; if opiates are found neceffary, laudanum may be given, to the extent of a table's fpoonful at once, in a pint of thin water-gruel, by the mouth; the fame quantity, if needful, may be repeated about three or four hours afterwards, or it may be given after the inteftines are cleared of excrement, in a clyfter, increafing the quanticy to two fpoonfuls, or more; a fecond bleeding may be neceffary when the fymptoms are violent.

When horfes fall fick, it matters not with fome what may be their complaint; it is too common to give them fuch things as many people efteem cordial or comfortable things to themfelves, (according to the phrafe); thefe are ardent fpirits, a little diluted, or wines, ales, \&c. either by themfelves, or heated and mixed with different kinds of fpices, wines, or ales, may be given in a very fmall quantity to horfes that are in health, when tired or fatigued on 
a journey, or from very hard labour; but they are by no means proper to be given in any quantity to horfes that are fick, more efpecially ardent fpirits, as neither the ftomach nor the head of horfes, even in health, can bear much of them at any time, they foon turn giddy, and lofe the ufe of their hind quarters, during the fit of intoxication; and, when given to horfes that are fick, they may prove as it were fewel to the difeafe. It would take up too much - of the reader's time, to enumerate the cafes which have fallen under my own obfervation, where the above treatment has been ufed, and the fatal confequences that followed, from giving thefe comfortable good things, as they are called. It may be obferved, that every thing is good of its kind; but, at the fame time, it is obvious, that thefe good things may be mifapplied, or not proper to be given in cafes of difeafe. Thus, roaft beef every one in health, and with a keen ftomach, will allow, is a very good A $a$ thing, 


\section{ON THE MANAGEMENT}

thing, but it is not fo to a fick perfon; he will naufeate and loath the very fight and fmell of it; or, allowing that in fome cafes he may have a little relifh for, and eat fome of it, yet it is not proper food for him, as the fomach cannot digeft ; a fick horfe will likewife often thow an inclination for oats, beans, \&c. yet they are not proper food for him, for the fame reafon, they opprefs the ftomach, and add to the diforder.

It is amazing what different kinds of compofitions are forced down horfes throats on thefe occafions. If thall mention one inftance: A gentlemen in London, who was greatly prejuciced in favour of vinegar, as a cure for many difeafes; he was fond of it himfelf, and ufed it frequently with his food. His favourite horfe was taken bad in very warm weather, and, as he thought vinegar was a very good cooling thing, he ordered one Englifin pint of it to be given his horfe at once; it was no foon- 
er fwallowed, than the horfe lay down, Aretched himfelf, and died.

The treatment, in this laft cafe, differs entirely from any of the former above mentioned, in a very oppofite extreme; but, as the nature of the 'horfe's complaint, in this laft cafe, was not known, as the owner would not fuffer him to be opened, and as I never knew or heard of any other inftance where fuch a quantity of vinegar was given at once to a horfe, I cannot take upon me to fay what effects it may produce; but, if I may be allowed to conjecture, I would prefume, from fimilar cafes, that the coats of the ftomach had been inflamed, a diforder which frequently takes place in horfes, efpecially when there are worms in it; and, in fuch cafes, any thing that is too cooling, acid, or fharp in its nature, when poured into the ftomach, may produce the fame effects, and haften the horfe's dearh. I was once defired by a farrier in this neirhbourhood, who was indifnofed, 
difpofed, to vilit a horfe that had been a patient of his for fome days, and report the firuation he was in. His fervant was giving the horfe a drink when I entered the ftable, which, I was afterwards informed, was compofed of an infufion of lintfeed, in which was diffolved one ounce of fal nitre, with honey to fweeten it, and, in the laft hornful was poured, from a frnall vial, about half an ounce, or more, of fpirits of hartfhorn. The horfe feemed very uneafy after the drink; he was foon feized with a violent trembling and thaking, a profufe fweat broke out all over his body, and run down his fides, as if water had been poured on him; at the fame time, his legs and ears were quite cold; he lay down, feemingly in great agony; he was foon after convulfed all over, and died in about half an hour from the time the drink was fwallowed. I obtained leave to take out his ftounach where he was, on condition I fhould few up the fkin afterwards, in order to prevent any bad fmell in the fable, till he could 
be carried off. On infpecting the ftomach, the coats of it were greatly inflamed, a mortification had taken place on one fide, where it appeared of a darker colour, in which there was a fmall hole, through which a lead probe paffed into the cavity of the ftomach from the outfide; the coats of the ftomach were confiderably thickened, and of a darkifh red colour, refembling that of the liver; at the fame time, it was confiderably diftended, and full of food; on turning it infide out, an incredible number of fmall worms, called botts, were found fticking all round the fides and lower part of the ftomach, infomuch, that it appeared entirely covered with them, and fticking as clofe to one another as bees in a honey-comb*, and fo firmly were the heads of thefe vermin fixed in the coats of the ftomach, that, in endeavouring to pull fome of them

* A fection of this fomach, with the worms flill adhering in the fame fituation, I lave by me, preferved in firits, in which is the perforation or hole where the mortification had taken plącc. 


\section{I9o ON THE MANAGEMENT}

off when alive, they broke in two, and their heads remained fticking in the coats of the ftomach.

The great irritation caufed by fuch a number of thefe worms fticking in the coats of the ftomach, had no doubt occafioned at firft the inflammation there, and, from its - continuance, was tending to a mortification, before the drench was given, which would foon have occafioned the horfe's death; but there is every reafon to think that the drench haftened it *

When

* One remark, which is worth notice in the above cafe; the horfe was very fat, and had been oniy three weeks out of the dealer's hands, where he had been fed with a great deal of what is called foul feeding, which is grain of different kinds boiled together with the chaff, and which, it is thought, produces worms of different kinds in the ftomach of horfes; another circumftance is, that the horfe died in the winter feafon, when bott worms are very uncommon, although they are fic. quently found in horfes in the beginning of fummer, and may be obferved fticking in the anus; they like- 
When horfes are fick, warm water is generally prefcribed them for drink; this, from a variety of circumftances, is either totally neglected, or over-done to fave trouble, efpecially when it happens that the ftable is fituated at a diftance from where it is heated; on that account, a pailful of over-heated water is prefented to the fick horfe, which he loaths. It is likewife too common, to mix fal nitre in the water, the difagreeable tafte of which prevents many horfes from drinking it ; befides, many horfes are particularly fhy in drinking warm water at any time; hence they fuffer confiderably from the want of water to dilute their fluids in general, and to promote the neceffary fecretions of urine, \&c. likewife to dilute the food that may be in the ftomach. This deferves particular at-

tention,

wife may be obferved in confiderable quantities amongit the horfe's dung at this time. The bott worm feems to be a fly in a chryfalis ftate, for I have frequently found the outer cafe or thell open at one end when the fly had left it. 
tention, and ought to be guarded againt; every means thould be tried to tempthorfes, if poffible, to drink freely in fuch cafes; and fometimes it may be forced on them, by pouring it down their throats with a horn, for the following reafons. I have already obferved, that the difeafes to which horfes are moftly liable are of the inflammatory kind, and, as the thinner parts of their fluids are carried off by the frequent and ftrong perfpiration they are expofed to, from the nature of their exercifes or labour, when they are feized with acute difeafes, their blood and other fluids are then more difpofed to be thick, vifcid, and inflammatory; therefore, as water is the principal diluter of the fluids in general, in fuch cafes, a confiderable quantity of it drunk at this time, becomes highly neceffary, and, perhaps, in fome cafes, it might prove the beft medicine that could be given them. When they are inclined to drink, but refufe water that is warmed, I never found any bad confequences follow from indulging fick 
fick horfes with cold water, after a little oatmeal was mixed with it, and giving it in very fmall quantities at a time. I was once called to a horfe that had got what is called a piffing drink, for a thicknefs in his legs. The drink or drench, I was informed, confifted of eight ounces of yellow rofin in powder, a table fpoonful of oil of turpentine, and about half that quantity of oil of juniper, in a quare of forge water. The horfe was very fick; he refufed both food and water, his pulfe was hard and quick, his mouth dry and parched, his legs and ears cold, his belly greatly difended, \&c. He was immediately blooded; after which he was back racked, that is, the dung or excrement was taken out of the rectum by the hand; in performing of this operation, the operator was fenfible of uncommon heat in the body; an emollient clyfter was then given, half a pailful of water, the chill taken off, was poured into his ftomach, after which he feemed confiderably relieved; he then ftaled a little, which was

B. b 


\section{ig ON THE MANAGEMENT}

of a reddifh colour and very thick; water was then offered him, of which he drank with more freedom; he afterwards began to ftale very profufely, 'and which continued, witli thort intervals, for the fpace of twenty-four hours, which reduced his flefh and Arength confiderably, and it was fome rime afterwards before he recovered either. I have fometimes met with cafes attended with the above fymptoms, when horfes had got improper phyfic, or bad drugs thrown into the ftomach, which I have treated in the fame manner, and with fuccefs.

In the above cafe, it is probable, from circumftances, that the drench remained in the ftomach undigefted, by which it was oppreffed, and its action in tome meafure furpended by the injudicious prefcription of fo much rofin, as it was near double the quantity that fhould have been given by itfelf, even to the coarfeft or molt robuft horfe; and, as the drench could not be thrown up again by the mouth, for the reafon 
seafon formerly mentioned, the pouring water into the ftomach contributed to dilute and wah it out at the lower orifice into the inteftines, where it was abforbed, and, in the courfe of circulation, carried by the renal veffels to the bladder; the bleeding contributed to remove the fpafmodic conftriction which had taken place, and the clyfter was of ufe in emptying the intentines, and particularly the rectum, of hardened dung, which, for the moft part, generally takes place in violent ficknefs, attended with' great internal heat of the body, and, by removing the preffure from the neck of the bladder, left it at freedem to cxpell its contents, which, from the colour and vicidity, appeared to have been fupprefied for fome time.

The fame method of procedure, as I have juft now obferved, when horfes have got improper phyfic that does not operate, or bad drugs that may oppres the ftomach, and create ficknefs, will be found to give relief, 


\section{ig6 ON THE MANAGEMENT}

relief, only the clyfters may be repeated twice or thrice, in order to empty the inteftinal canal, and forward the difcharge of what has been hurtful, by the anus.

\section{In cafes of a Swelled Throat.}

Horfes, in every period of life, are fubject to violent inflammations of the glands about the throat, \&cc. on catching cold; but young horfes, in particular, are more liable to this diforder, which is always more or lefs attended with a fever; at the fame time, they refufe food and drink, as they cannot fwallow either on account of the violent pain it occafions. This circumftance is too frequently overlooked, and, as it is too generally apprehended that the horfe will fuffer from the want of nourifhment, or from the want of medicine, which may be thought neceffary, in this cafe, their heads 
heads are forcibly held up, and they are compelled to fwallow whatever is poured into the throat, though with the utmoft pain; and as the lungs, in fuch cafes, are more or lefs affected by the inflammation extending downwards on them, whatever is poured into the mouth irritates the upper part of the larynx or wind-pipe, and occafions the moft violent coughing, and difficulty of breathing, attended with trembling, cold fweats, and other alarming fymptoms. In fuch cafes, whatever is forced upon them by the mouth, whether food or medicine, does them more real injury than is generally imagined; the fever, by this means, is increafed, the circulation is carried on with uncommon rapidity, attended with great internal commotion, the whole fyftem is deranged and put out of order, and, if thefe fymptoms are not fpeedily allayed, the diforder acquires frength, the powers of life are foon overcome and exhauned, and death foon follows. 


\section{ON THE MANAGEMENT}

Therefore, in ficknefs or diftrefs of any kind, every thing that tends to add to the diforder, whether by oppreffing the ftomach with food or medicine, or caufing any great commorion or difturbance in the fyftem, ought to be carefully avoided; a fick horfe thould, in every refpect, be as little difcompofed as poffible. There is not the leaft neceffity for expofing them to fo much diftrefs and hazard, as it is very evident, from the foregoing obfervations, that nourifhment may, with the greateft eafe, be conveyed into the body of a horfe by the anus, in the form of a clyfter. This method I have always practifed with fuccefs, and fupported horfes for feveral days together, when they could not take any nourifhment whatever by the mouth. 


\section{$\begin{array}{lllll}C & H & A & \text { P. } & \text { VI. }\end{array}$}

\section{OBSERVATIONS ON BLOOD- LETTING.}

LTHOUGH the method of per-
forming the operation of bloodletting is generally thought to be pretty well known, yer there are many untoward accidents that frequently happen from the unfkilful and inexperienced, in performing this operation.

As horfes are naturally timorous and fearful, which is too frequently increafed by bad ufage, and improper chaftifement, they require, in fome cafes, particularly in 
this of bleeding, to be taken unawares, or by furprife, and the orifice made into the vein before their fears are alarmed; for this reafon, the fleam and blood-ftick (as it is called) have been long in ufe, and, in kkilful hands, are not improper inftruments for the purpofe; although, with many practitioners, the fpring-fleam would be much fafer, and, on that account, ought to be preferred. When a lancet is ufed, the inftant the horfe feels the point of it, he raifes or thakes his head and neck, in order to thun the inftrument, before the operator has time to make a proper orifice, which, frequently proves too fmall or too large; for this reafon, thofe who have tried the lancet have been obliged to lay it afide.

Many people tie a ligature or bandage round the neck, in order to raife the vein, and that they may ftrike the fleam into it with the greater certainty; but a llight view of its effects in preventing this, and its other confe- 
ON BLOOD.LETTING. 20I

confequences, will thow the impropricty of this practice.

When a ligature is tied round the neck, previous to bleeding in the jugular veins, it is to be obferved, that it ftops the circulation in both veins at the fame time; hence they become turgid and very full of blood, infomuch, that they feel under the finger like a tight cord, and, as the parts around them are loofe and foft, when the ftroke is given to the fleam, the vein, by its hardnefs or tightnefs, flips to one fide; of courfe it eludes the ftroke; hence a deep wound is made by the fleam to no purpofe, and this is fometimes too frequently repeated. Unfkilful people have likewife a cuftom of waving or thaking the blood-ftick, before they frike the fleam, in view of the horfe, whofe eye is fixed on that inftrument, and, when they intend to give the froke, they make a greater exertion; hence the horfe, being alarmed by its motion, raifes his head and neck, a difappointment C c follows. 
follows. The ftruggle that enfues, by this means, prolongs the operation; the ligature, at the fame time, being fill continued round the neck, a total ftagnation of the blood in the reffels of the head takes place; and hence it frequently happens, that the horfe falls down in an apoplectic fit. In fuch cafes, I have obferved the operator greatly difconcerted, and defift from any farther attempts to draw blood at that time, being prepoffeffed with the idea that the horfe was vicious and unruly, although the very treatment the horfe had juft undergone rendered bleeding at this time the more necelfary, in order to make a fpeedy revultion from the veffels of the head. Therefore, a ligature or bandage ought never to be ufed till fuch time as the opening is made into the vein, and even then it will not be neceffary at all times, if the horfe can ftand on his feet, as a moderate preffure with the finger on the vein will make the blood flow freely; but, if the horfe is lying 
ON BLOOD.LETTING. 203

ing on the ground, a ligature will be neceffary.

But farther, the concuffion or thock the horfe receives from his falling down in the above fituation, which will always happen if the ligature is too long continued, may caufe a blood-veffel within the head to burft, and death may be the confequence.

-Another cuftom equally abfurd, is allowing the blood to fall in a dung-hill amongt ftraw, in dry fand, or in dry duft, by which means, no diftinct idea can be formed of the quantity that is, or ought to be taken away. In fuch cafes, I have feen horfes fall down in a faint from the lofs of too much blood, before the operator thought of ltopping up the orifice*. For this, and a variety of other reafons, which might be mentioned, a meafure ought always to be

uled,

* A cafe of this kind happened in Londion; a mafter farrier wats the operator. 
ufed, in order to afcertain the quantity of blood that is taken away.

In pinning up the orifice, fome people have a cuftom of raifing or drawing out the fkin too far from the vein, hence the blood flow's from the orifice in the vein into the cellular fubftance between it and the flin, which caufes a large lump or fwelling to take place immediately; this frequently ends in what is called a fwelled ed neck; a fuppuration follows, which proves both tedious and troublefome to cure. In cafes, when a horfe may be tied up to the rack, after bleeding in the neck, pinning up the external orifice may be difpenfed with; but, when a horfe is troubled with the gripes, or any other acute difeafe, in which he lies down and tumbles about, it is neceffary that the orifice be pinned up with care, in order to Erevent the lofs of too much blood. 
As the neck or jugular vein, on the near fide, is commonly opened for conveniency by thofe who are right-handed, the young practitioner hiould learn to perform on both fides of the neck. This he will find, in practice, to be not only ufeful, but neceffary, as he may frequently have occafion to draw blood from horfes in very aukward fituations; he will likewife find his account in it in a variety of cafes, which is needlefs here to particularize.

The proper place for making the opening in the neck, or jugular vein, is likewife neceffary to be attended to; for, when the orifice is made too low, or about the middle of the neck, where the vein lies deep under the mufcular teguments, the wound becomes difficult to heal, and frequently ends in a fuppuration, with a jetting out of proud flefh from the orifice, which, unluckily, is as unfkilfully treated. in the common method of cure, \&rc. which is, by introducing a large piece of corrofive 
fublimate into the wound; this not only deftroys the proud fleh in the lips of the wound, but a confiderable portion of the fle $h$ around it ; and, in farriery, it is called coreing out the vein. It frequently happens, that this corrofive application deftroys the vein likewife; I have fometimes feen violent haemorrhages follow from this caufe, infomuch as to endanger the life of the animal.

The moft proper place for making the opening in jugular veins, is, where the teguments are thinneft, which is about a hand breadth from the head, and about one inch below the branching or joining of the vein which comes from the lower jaw, and which may be diftinctly feen, when any preffure is made on the main brarch of the vein.

In performing the operation with a fleam, the operator thould hold the fleam between the fore-finger and thumb of the left hand, with the fecond finger he 
is to make a flight preffure on the vein, and, before it becomes too turgid or full, make the opening; the fame degree of preffure is to be continued on the vein, till fuch time as the quantity, of blood to be taken away is received into a proper meafure.

Another great error, which generaily prevails in opening the veins with a fleam, is the applying too great force, or giving too violent a ftroke to it, by which it is forced through the oppofite fide of the vein; hence, there is danger of wounding the coats of the arteries, as they generally lie under the veins, or, in fome particular places, of wounding the tendons, efpecially when this operation is performed in the legs, thighs, \&c. or in the veins, commonly called the plate veins, under the breaft, the confequences are frequently very troubletome to remove, and, in fome cafes, prove fatal; hence, the remedy fometimes proves worfe than the difeafe or lamenefs it was intended 
intended to remove. Mr Gibfon ${ }^{*}$, in his treatife on the difeafes of horfes, mentions a cafe of a fine horfe, that was blooded in the plate veins, for a lamenefs of the fhoulder, which was followed with a hard oval fwelling about the fize of a goofe egg, which extended upwards on the breaft, and likewife down the leg, attended with excelfive pain, fever, deadnefs in the horfe's looks, and all the other fymptoms of a beginning mortification. I could likewife aud a number of fimilar cafes, which have fallen under my own infpection, but thall not trouble the reader with them at prefent.

In order to avoid the confequences fometimes attending thefe local operations in the breaft, legs, \&zc. and, as horfes are more or lefs troublefome and reftlefs, whereby accidents of this kind may happen, it will perhaps be advifeable, in moft cafes of lamenefs, \&xc. to draw blood from the larger

* Vol. II. page 187. 
larger veins in the neck only, where there is lefs danger of accidents, more efpecially if a fpring fleam is ufed; for, although it might be of fome advantage, in particular cafes, to draw blood as near the affected part as poffible, yet the bad confequences frequently attending it, ought to counterbalance any advantages that may be expected from it, efpecially as the quantity of blood drawn from the fmall veins is but inconfiderable, and, of courfe, no great benefit can be expected from it in horfes when they are difeafed.

The principal view, in drawing blood, is the leffening of its quantity, by which the remaining mafs circulates with more frectom in the veffels; it likewife takes off the inflammatory tendency of the blood, it removes fpafms, \&cc. and prevents other bad confequences that may follow, efpecially in plethoric habits; and it ought always to be remembered, that, when the figns or fymptoms of a difeafe are taken

D d from 
from the motion of the blooid, the difor. ders arifing from it depend upon its circulation being either increafed or diminifhed; hence, therefore, all the changes which take place in the texture, quantity, and quality of the blood, are attended with a diminution or increafe of its velocity.

Although the cafes which may require bleeding are numerous, yet I would recommend one general caution, which is, never to take away blood but when it is abfolutely neceffary; for it is a fluid that may be eafily taken away, but cannot be fo eafily replaced; befides, the practice of bleeding frequently, or at ftated times, is exceedingly improper, as it difpofes the body to become lax, weak, and plethoric.

In bleeding, therefore, a due regard muft always be had to the confitution, age, ftrength, \&c. of horfes, and the ftate or habit of body they are in at the time. 
It is commonly faid, that the taking away a little blood from horfes, even when they are in health, or when they are in the lealt indifpofed, will do no harm; this, in one fenfe, may be allowed to be literally true, but why draw blood from them on every trifling occafion, unlefs there may be fuch fymptoms attending as may require it. I have obferved in many horfes who have been very frequently blooded, and which may be eafily known, from the cicatrices or marks on the neck-veins, that their blood was poor and thin, and had loft that renacity peculiar to rich blood, together with a confiderable portion of its florid and red colour. Butchers who flaughter calves, may find their account in bleeding them frequently, as it renders their flem white, by taking away the red particles of the blood. But in horfes it is quite otherwife, as they are deftined for hard labour and active exercifes, it impairs their conftitutions, fubjects them to difeafes, and haftens a premature old age. 


\section{OBSERVATIONS}

As the blood of horfes, more efpecially thofe who are confantiy employed in hard labour, or in active exercifes, when drawn from a vein, appears of a dakifh or deep red colour even in the higheft tate of health, it is commonly faid to be bad blood, and more fo, when a thick yellow or buff-coloured cruft forms on the furface after is is cold; hence thefe appearances are faid io require a repetition of bleeding; for it ver unluckily happens, that moft of the difeafes to which horfes are fubject, are thought to proceed from fome impurities or humours, as they are called, in the blood, which require to be drained off by bleeding, and other evacuations.

With regard to any information that may be drawn from the appearance of the blood when cold, it will be found, that no certain conclufion can be formed from it, fince blood that is drawn from a horfe who is cvidently difordered, will fometimes have the 
the fame appearance, when cold, as that drawn from a horfe in health. On the other hand, blood drawn from a horfe in health, will fometimes have all the appearance of that drawn from one labouring under the moft dangerous difeafe; and this may depend on fo many concurring caufes, that renders it difficult to fix any precife ftandard how we may judge, either of the healthy or morbid itate of the blood in horfes when cold; as its appearances are even affected by the manner in which the operation of blood-letting is performed, and that of the blood's being received into the veffel.

When blood is drawn from a vein of a horfe that is in health, it appears to be an uniform fluid of a red or darkifh colour; but, after it has been expofed to the cold air, \&c. it coagulates into a ftiff mafs, which gradually feparates the thinner parts into a pellucid ferum, the thicker parts into 
"a red or darkifh mafs, which is called the craffamentum.

Although I am thus fparing of drawing blood from horfes, on trifling occafions, when they may be faid to be in health, yet when cafes occur that do require it, I would recommend the taking away a greater quantity at once than is generally done, that is, from fix to eight pounds, which will be about three or four quarts Englifh meafure, according to the urgency of the fymptoms, \&c. at the time, ftrength and age of the horfe confidered. For, as horfes are very fubject to inflammatory difeafes, and thofe that are of the fpafmodic kind, and as bleeding plentifully relaxes the whole fyltem in thefe cafes, the taking away a fmall quantity of blood, about one quart, or two pounds, is in fact trilling with the difeafe; the horfe is faid to have been blooded, that fatisfies his owner and the farrier; time is loft; the difeafe acquires ftrength, it will then be beyond the power 
of art to mitigate or to conquer it; hence the horfe falls a facrifice to timidity and ignorance. It is to be remembered, that, in inflammatory difeafes, (particularly when the bowels are affected) that they make a very rapid progrefs in horfes, and, if they are not overcome at the beginning, by bleeding plentifully, the horfe commonly dies, in twenty-four or thirty hours, of a gangrene and mortification in the inteftines. I have feen fo many cafes of this kind, and which have been confirmed on diffecting the bodies afterwards, that I cannot be too full on the fubject, in warning practitioners how they fhould act in fuch cafes; and, perhaps, few occurrences in practice gave me more uneafinefs than to be confulted in the laft ftage of there complaints, when nothing could be done for the relief of the horfe.

The quantity of blood here recommended to be taken away at once, may, by many people, be objected to: In anfwer to which, 


\section{OBSER VATIONS}

which, I would obferve, that, in inflammatory cafes, I have always found the greateft benefit from it in practice. At the fame time, I would beg leave to quote a paffage from Doctor Bracken, who has been at fome pains in calculating the quantity of blood in a horfe of a middling fize, and which will ferve to corroborate what I have advanced. In his firft volume, page 50. he fays, "That it is fuppofed there paffes thro" "the heart of a horfe 1800 times four " ounces, or 450 pounds of blood in an " hour. Now, the common received o"pinion is, that the whole mafs of blood " in a man is about twenty-five pounds, " and in an horfe fix times as much; and " therefore, according to this allowance, " a quantity of blood cqual to the whole " mafs paffes through the heart in an hour " in a man, and in an hour and twelve " minutes in a horfe; and, from thence, " it may be obferved how neceffary it is to " take away greater quantities of blood in " many cafes thar is commonly practifed; 


\section{ON BLOOD-LETTING. 217}

"for what fenfible effect can the taking " away a quart of blood from a horfe have "upon him, if we confider that he has " near 225 times as much in his body."

The blood is a fluid of a peculiar nature; it is the great fountain of life, and the fource of all the humours in the body; it circulates through, and nourifhes every part of the animal fyltem, being conveyed from the heart by the arteries to the extremities and furface of the body, and returned to the heart again by the veins. This circulation is fo complete, that the moft trifling wound or fcratch is immediately followed with a difcharge of blood from the fmall capillary veffels of the fkin. In order to explain more fully how the circulation is performed, it will be neceffary to give a fhort defcription of the heart, the arteries and veins, with fome general remarks on the pulfe of horfes.

$$
\text { Fe }
$$

The 
The heart is a mufcle of a conic figure, that is, broad at its bafis, and terminating in a blunt apex or point; it has four cavities, two of which are called auricles or ears, and the other two ventricles. The auricles are fituated at the bafis of the heart, and receive the blood immediately from the veins; the right from the vein called vena cava, and the left from the pulmonary vein; at the bottom of thefe auricles, are certain valves which open into the venrricles, and thut again when the latter are filled with blood, in order to prevent its return to the auricles: Thus, when the right ventricle receives the blood through its auricle, the valves fhut, and the blood is forced, by the contraction of the hearr, from the ventricle into the pulmonary artery, which rifes immediately out of the right ventricle, and is carried into the lungs; it is returned from thence by the pulmonary veins into the left auricle, which empties itfelf into the ventricle on the fame fide, and by it the blood is forced into the great 
great artery or aorta, which rifes out of that ventricle, and which conveys it all over the body; the blood is returned to the heart by the veins (which, in their courfe, take in the chyle or nourifhment) to the right auricle of the heart, which completes the circulation.

The heart is fixed at its bafis, by the veffels, \&c. which belong to it, and to the mediaftinum, \&x.; it is contained in a bag or purfe, called the pericardium, within which there is a fmall quantity of a clear watery lymph, feparated there by the exhaling veffels, that the furface of the heart may not grow dry from its continued motion; the heart is fupplied with nerves and bloodveffels for its own nourifhment.

The arteries are conical tubes or pipes, which convey the blood from the heart to all the parts of the body; they poffefs a very elaftic quality, by which they contract 
and dilate themfelves, according to the im. pulfe of the blood, which is propelled of forced into them by the heart; This contraction and dilation of the arteries is called the pulfe, and which takes place in all the arteries at the fame inftant of time; for, as the left ventricle throws out the blood into the arteries, they are dilated, and, as foon as the elafticity of the arteries can overcome the impulfe of the blood, they are again contracted; hence thefe two caufes, viz. the action of the heart, and the elafticity of the arteries, operating alternately, keep the blood in a continual circulation. .

The arteries being conical canals, are large at their origin, and gradually diminith towards their extremities (refembling the trunk and branches of a tree) where they anafamofe, or join with the extreme branches of the veins; hence, the latter may be faid to be a continuation of the arteries. 
ON BLOUD-LETTING. 22 I

The reins, as I have juft now mentioned, are a continuation of the extreme capillary arteries reflected back towards the heart, uniting their channels or branches as they approach it, till at laft they form the larger veins; hence, they may be faid to refemble the branches and trunk of a tree, inverted from the extremities to the heart. There is no pulfation in the veins, becaufe the blood is thrown into them in a continued ftream from a narrow channel to a wider.

In moft of the veins where the blood rifes in a perpendicular column, as in the legs, \&c. there are valves which open towards the heart, and admit the blood to pafs freely; but it cannot fall back or repafs thefe valves; therefore, if it is not purhed on with fufficient force, it may diftend the veins, and caufe a fwelling of the legs. Hence it is obferved, that this lentor or fluggifh circulation of the blood in the leg-veins, is removed, and the circulation 
lation greatly forwarded, by mufcular mosion, or, in other words, by exercife.

The vcins, for the moft part, accompany the arteries; hence, when a vein mult be opened, it is to be remembered, that an artery is near, and, frequently, immediately under it, as large as the vein itfelf, (and which may be eafily diftinguifhed by its pulfation); and hence the coats of the arteries are liable to be wounded by an untkilful operator in drawing blood. The extreme branches of the arteries and veins have numerous communications with one another, refembling the fibres in the leaves of plants, by which communications, the blood, when obftructed from any caufe in the branchings of thefe veffels, may pafs through by other channels that are not obftructed; this likewire takes place when the larger veffels are divided; the circulation is continued by the detached branches of the remaining veins. 
ON BLOOD.LETTING. 223

Thefe remarks being premifed, it remains to make fome obfervations on the pulfe of the arteries in horfes, a due atttention to which is of the utmolt confequence to practitioners in farriery, and which, in the general practice, feems either to be not underftood, or not attended to ; for, without a proper knowledge of the pulfe, we neither can form a right judgment of difeafes, in which the vafcular fyftem is affected, the velocity of the blood increafed or diminifhed, neither can we judge rightly when it is neceffary to let blood, nor to refrain from it. It will therefore be proper, firft to confider the pulfe in a healthy ftate, before we can form a juft idea of it when a difeafe takes place.

The pulfe of a horfe that is in health, and nowife terrified or alarmed, is from 36 to 40 beats in a minute; it may eafily be felt by preffing the fingers gently on the temporal artery, which is fituated about an inch and a half backwards from the upper 


\section{OBSER VATIONS}

corner of the eye. It is neceffary to obferve, that, if the fingers are preffed too hard, (as the bone or fcull lies below the artery), no pulfation will be felt, as too great preffure ftops the circulation in the artery at the time. It is likewife neceffary to obferve, that the pulfe of a horfe, about thirteen or fourteen hands high, is quicker than one of a larger fize. When a horfe is in great pain, or in a violent fever, the pulfe will be raifed from 80 ; to 100 beats in a minute, and fometimes confiderably above it.

The pulfe, in a healthy ftate, is equal, moderate, and free, which hows, that the heart and vafcular fyftem in general are firm and vigorous, and that the heart empties itfelf freely at each contraction and dilation, that there is no impediment to the paffage of the fluids through the vifcera and veffels, and that the nervous power acts uniformly upon every part of the circulaing fystem. Whereas, in a morbid or dif- 
feafed ftate, it will be unequal and intermitting every now and then, varying in the time between the ftrokes, as well as the force of the ftroke; fometimes it will ftop entirely, and fometimes it will be immoderately quick, at others unnaturally now; fometimes it will be raifed greatly above the healthy degree of Atrength, and at others funk as much below it. This urequal or intermitting pulfe, fhows, that the nervous fyftem is greatly difordered, and portends great danger, efpecially if it becomes fo after long illnefs, when the ftrength is much exhaufted.

When the pulfe beats ftrong and quick; it thows, that the morbid or difeafed fti mulus, excites the heart to expel the blood, with great force, and that the progreffive motion of the blood is more rapid and inpetuous than it ought to be; as this ftrong pulfe ftrains and fpeedily exhauts the vital powers, it portends great danger, if not foon removed.

$$
\text { Ff } \quad \text { The }
$$


The hard; quick, and ftrong pulfe, is generally a fymptom of confiderable irritation, and hows, that the heart is greatly ftimulated; this takes place in inflammations of the vifcera, as in peripneumony, or inflammation of the lungs, ftomach, inteftines.

The hard, quick, low, or fmall pulfe, hows great inward pain, which, by fympathetically affecting the heart, excites it to empty its ventricles before they are fufficiently filled with blood.

A quick pulfe is generally a fign of a fever; when it is exceedingly quick and weak, it is always a very dangerous fymptom, as it fhows, that the powers of the heart are nearly exhaufted, and that, in order to fupport the circulation, it is forced to act more frequently, and to empty its ventricles by a number of weak contractions. 
When the pulfe beats, foft and weak, it may be owing to a general laxity of the. fibres of the arteries, or to a thin watery ftate of the blood, which enables it to glide too eafily through the veffels, that the heart is not under the neceffiry of exerting to much force in propelling it through the arteries, as when they are more firm or unyielding, or when the blood is more denfe or vifcid, which are great impediments to a free circulation in particular crgans.

A weak pulfe is a fign either of a confiderable debility or weaknefs of the heart, or too finall a quantity of blood in the veffels in general, or fome impediment to the influx of the blocd into the heart, or to fome, or all of thefe caufes combined; for this reafon, it is to be met with frequently in low fevers, or towards the end of difeafes that prove fatal.

When 
When the pulfe remains full under the fingers during the contraction and dilation of the arteries, it is a fign of too great fulnefs of the veffels, either from a plethora, or too great a rarification of the fluids, by febrile, heat, or other caufes; it indicates danger from accumulation, diftenfion, and even rupture of fome of the blood veffels in particular organs. But, if the pulfe, though full, is at the fame time foft and diftind, it is a favourable fymptom, as it Ihows, that there is no confiderable conftriction in the veffels.

Upon the whole, the pulfe is always bad when it is very different from its natural ftate; for, as a weak and quick pulfe thows debility in the heart and vafcular fyftem, regard at the fame time being always had to other fymptoms, if the pulfe fink in fevers there is great danger.

On the other hand, when the pulfe is equal, regular, and moderately full, efpecially 


\section{ON BLOOD-LETTING. 229}

cially if it becomes fo from being languid, weak, and irregular, on the breaking out of fome critical difcharge, as that of fweat or loofenefs, or the ftaleing frequently, it is a fign of amendment.

From what has been obferved, it will be obvious, that the information to be attained from a due attention to the ftate of the pulfe in the difeafes of horfes, is of confequence in the practice of farriery. Young practitioners ought therefore to make themfelves well acquainted with all the variations that take place in difeafes, together with the changes that happen when deviating from the healthy ftate to the morbid or difeafed.

It may be neceffary again to obferve, that, in feeling the pulfe of a horfe in health, that he be not frightened, nor anywife alarmed, as that will make an alteration in the quicknefs of the pulfe, which will be apt to millead the unexperienced.

Thus 
Thus much may fuffice at prefent concerning the pulfe in general; it will be neceffary to be more particular when the figns to be taken from it are applied to particular difeafes, and corroborated by other fymptoms, which will be mentioned in a future work. I thall therefore proceed to enumerate the different cafes that may require bleẹding.

The cafes which may require bleeding, are in all violent bruifes or ftrains in the mufcular or tendenous parts; in large wounds, efpecially when there is a laceration or tearing of the parts without much lors of blood from the wound; in the beginning of all cuticular diforders or eruptions on the fkin, as little puftules, dry fcabs, \&xc.; in large fwellings on the body or legs; in all deep punctures, or fmall wounds, when the horfe hows fymptoms of great pain, \&c.; in fwellings of the legs and heels, from inflammations, \&zc. 


\section{ON BLOOD-LETTING. $23^{2}$}

Bleeding is neceffary in moft difeafes where great fickners prevails, and is the fpeedieft method of giving relief in the beginning of inflammatory fevers, to which horfes are very liable; it is alfo neceffary in all violent acute pains, as in the gripes or cholic, ftrangury or fuppreffion of urine; in rheumatic complaints, where the ftiffnefs or lamenefs thifts from one limb to another, or when it affects the neck, and caufing great Atiffnefs, which is commonly called the chords; in inflammations of the eyes, or palate of the mouth, which is called the lampars, when the horfe cannot eat his food on account of the tendernefs of the parts; in all recent colds, attended with rheums or defluctions about the throat, eyes, \&c.; in recent fwellings of the glands about the throat, jaws, \&c.; in the jaundice, inflammations of the lungs, pleura, ftomach, inteftines, and other vifcera; in apoplexy, vertigo, or giddinefs ; and in all diforders where the head feems affected; in the beginning of import hurnations, 
mations, or collections of matter in any part of the body, attended with great pain; in plethoric or full habits of body, where proper exercife has been long neglected; and when a horfe becomes breathlefs on the leaft exercife.

On the other hand, bleeding is to be avoided, unlefs in verý urgent cafes, in all extremes of very hot or very cold weather, and whilft a horfe is overheated from violent exercife ; in all cafes of extreme lownefs of body, or weaknefs, through fatigue, difeafe, \&zc.; after all evacuations by purging or fcouring, diabetes, or profufe ftaleing, lofs of blood, from great wounds, or profufe fweating. Bleeding is likewife to be avoided, when impofthumations, or collections of matter is once formed properly in any part of the body; likewife during the time horfes are moulting in the autumn.

Thus, 


\section{ON BIOOD-LETTING. 233}

Thus, I have endeavoured to thow the principal cafes where bleeding is neceffary, and likewife where it ought to be avoided; no doubt, particular cafes and accidents may, befides thofe above mentioned, happen, when bleeding may be neceflary, but thefe, from what has been faid upon the fubject, will readily occur to the judicious practitioner.
G $g$
C FI A P. 



\section{H A P. VlI.}

\section{O B S E R V A TIO N S O N \\ R O W E L S.}

R OWELS for horfes, anfwer the R fame purpofe as iffues in the human body; the method of introducing them is by making an incifion through the fkin, about three eighths of an inch long, and then feparating the fkin from the flem with the finger, or with a blunt horn, all round the orifice, as far as the finger will eafily reach, then introducing a piece of leather, very thin, thaped round, about the fize of a crown piece, having a large round hole in the middle of it; previous to introducing 


\section{OBSER V A TIONS}

cing the leather, it fhould be covered with lint or tow, and dipped into fome digeftive ointment; a pledget of tow, dipped in the fame ointment, hould likewife be put into the orifice, in order to keep out the cold air : The parts around it foon fwell, which is followed with a plentiful difcharge, from the orifice, of yellowith ferum or lymph; and, in two or three days at mott, the difcharge turns into thick grofs white matter: The rowel is then faid to fuppurate.

Thefe artificial vents act by revulfion or derivation; and hence they become of great ufe in many cafes, as they empty the furrounding veffels by a regular flow difcharge of their contents, and are even of great fervice when there is a redundancy or fulnefs of humours in general, which may require a gradual difcharce, in preference to greater evacuations by purging medicines, \&cc. Rowels thould be placed (efpecially in fome particular cafes) as near the affected part as poffible; and, at all times, 
times, they ought to have a depending orifice, in order to admit of a free difcharge of the matter that may be contained in them.

The parts, where they ought to be inferted, and where they are found to anfwer beft, are the belly, infide of the thighs, the brealt, and outfide of the fhoulders and hips; they are fometimes, but very injudicioufly, put in between the jaw-bones under the root of the tongue, where they never come to a proper fuppuration, on account of the conftant motion of the parts in eating, \&c. neither do they anfwer any good purpofe from being placed in that $f_{1}$ tuation. In fome diforders it is found neceffary to put in feveral of them at once, in order to make a fudden revulfion from the parts affected; but this thould be determined by the horfe's age, ftrength, and circumftances that require them. 


\section{O B S E R VA T I O N S}

But, though rowels are found very beneficial in fome cafes, yet, like a number. of other operations common to horfes, they fometimes, by the improper ufe of them, become hurtful to the conftitution, and, in fome difeafes, they frequently, inftead of fuppurating, turn gangrenous; hence, the cure proves worfe than the difeafe they were intended to remove; thus, in violent fevers, where they are frequently very improperly applied, they never fuppurate properly; whether this proceeds from the quicknefs of the pulfe, together with the violent rapidity with which the fluids in general are then carried through the veffels, or from the violent agitation in which the whole fyftem is thrown, it is difficult to determine; but experience confirms the obfervation, when properly attended to. In fuch cafes, the furrounding parts, where the rowel is placed, feldom or never fwell, (as in the ordinary courfe, when they fuppurate properly), but appear dry, or much in the fame ftate as when they were firft 


\section{O N R O W E L S.}

put in, there is little or no difcharge from the orifice, and the little that does come is thin, ichorous, and bloody. In fuch cares, they ought to be taken out immediately, and the parts well fomented with a Atrong infufion of chamomile, or an emollient poultice applied, if it can be properly fixed, and frequently repeated; at intervals, the parts ought likewife to be bathed with ardent fpirits, as that of wine, turpentine, \&c. covering the parts from the external air, and, providing there is no fever at the time, two or three ounces of Peruvian bark may be given through the day, either made into balls, or given in a liquid; and this continued till the threatening fymptoms are removed.

Rowels are of great ufe in carrying off rheums, or defluctions from the eyes; in great fwellings of the glands, \&c. about the throat and jaws, which threaten a fuffocation; or when the head feems particularly affected, as in the vertigo, or ftaggers, apoplexy, 


\section{OBSER VATIONS}

poplexy, \&c. \&c. ; in recent lamenels; fwellings of the legs and heels, attended with a difcharge of thin ichorous matter, \&xc.; in large and fudden fwellings in any part of the body; or when extravafations of the fluids have taken place, from blows, bruifes, \&c.; or when a horfe has had a fevere fall, \&c.; and in a varicty of other cafes, which will occur to the judicious practitioner. 


\section{H A P. VIII.}

\section{OBSERVATIONSON S E TON S}

Q ETONS are of great ufe in carrying $N$ off matter from deep feated tumors, or abfceffes in different parts of the body; they ought at all times to be ufed in preference to making deep incifions into the mufcular parts, which not only disfigure horfes, but fuch deep incifions are very difficult to heal up in them, on account of the fituation of fome of thefe tumors, and the horizontal pofition of the body, which is unfavourable in many cafes for procuring a depending opening, in order to carry off the matter, as in tumors on the back, withers, and the upper part 


\section{O B S E R V A T I O N S}

of the neck, immediately behind the ears, which are very common. Befides, the horizontal pofition of the body, the natural reftlefsnefs and impatience of horfes, renders it impracticable to fix proper bandages on thefe elevated parts; the fituation of them likewife will not admit of proper dreffings being fixed on them with any degree of certainty of their remaining for any length of time; by which means, the openings made into fuch tumors or abfeeffes are frequently left bare, and expofed to the cold air, \&c.; hence, fuch openings degenerate into very foul ulcers, and produce a great deal of proud flefh, which require to be repeatedly cut away with the knife, as the ftrongert cauftics that can be applied are not fufficient to keep it under.

Setons are introduced by long, thin, Tharp pointed inftruments, or ncedles, fhaped like a dart at the point, and having, at the other extremity, an eye to receive the end of the chord, which is to be left in 
the tumor. The fize of the inftrument may be determined by that of the tumor, and the thicknefs of the chord which is to follow it, and which at all times ought to be fmaller than the perforation made by the point of the needle. Every practitioner in farriery thould always have a number of thefe needles by them, of different fizes, that is, from fix to fourteen or fifteen inches long, a little bended on the flat or under fide. The following is the method of applying them in cales of tumors, \&xc. When the matter is found to fluctuate in the tumor, the needle, armed with a chord at the other end, is to be introduced at the upper part of it, and the fharp point of the inftrument directed to, and brought out at the under or lowermolt part of the tumor, including the whole length of it; or, if needful, through the found mufcular flefh , on the under part, in order to make a depending orifice for the matter to run freely off; the chord thould be dipped in fome digeftive ointment, and then tied together 


\section{OB SER V A T I O N}

at both ends with a thread, in order to pre vent its lipping out; but if, from the length of the perforation, the chord thould not admic of being tied together at the ends, a fmall button of wood, or fome fuch fubftance, may be fixed at each end; only, from this circumftance, the chord will require, when thifted, occafionally to be drawn upwards and downwards; whereas, when the ends of it are tied together, it forms a circle, and may always be thifted downwards to the lower orifice; when the matter in the tumor appears to be wholly difcharged, or dried up, and no thicknefs appearing but where the chord is, it may then be cut out, and the orifices fuffered to neal up.

When the needle for introducing the feton is to pafs near to any large bloodveffels, or nerves, in order to prevent the chance of their being wounded, it may be concealed in a canula or cafe, open at both ends; and, after an opening is made at the 
the upper part of the tumor, fufficient to admit the needle, with its cafe, it may then be directed, with fafety, to pafs the bloodveffels, \&c. it may then be puthed forward through the canula and the oppofite fide of the tumor, and, having only the common reguments to perforate, all danger will be avoided.

The common method of treating thofe large tumors which are feated on the upper part of the neck, immediately behind the ears, generally known by the name of the pole-evil, and thofe which are feated on the withers, or upper parts of the fhouldders, is exceedingly improper; they are either allowed to break of themfelves, or are opened the whole length of the tumor on the upper part; in this fituation, efpecially in the pole-evil, when the head is always kept in an erect pofition, the matter contained in the tumor cannot be difcharged from it, but is retained in the bottom of the wound, and expofed to the external 
ternal air, \&cc. it foon acquires a moft ichorous corroding quality, and produces one of the largeft and the moft fordid fiftulous ulcers that horfes are infelted with; a great quantity of fungus or proud fleth is foon produced; this requires to be repeatedly extirpated with the knife, the lors of which cannot be again fupplied; hence the horfe is greatly disfigured, the cure becomes both tedious and uncertain, and is feldom radical. In fome cafes, I have known the vertebrae of the neck affected by the Tharpnefs of the confined matter, forming lodgements there, and, after great trouble and expence, the horfes were put to death.

All thefe kinds of tumors, \&xc. are eafily and fpeedily difcuffed by the ufe of fetons, as above defcribed, without any lors of fubftance, or disfiguring of the parts, and cured with the greatef certainty when the operation is properly performed. Of a number of cafes, in my practice, where 
this operation has fucceeded with great expedition in curing thefe tumors. I thall only mention the following.

About fix years ago, an Arabian horfe, belonging to a gentleman in this place, had a large tumor feated a little to one fide of the withers, or upper part of the thoulder ; it was forwarded by applying emollient pultices; and, as foon as the matter was perceived to fluctuate in the tumor, a large feton needle, armed with a chord at the other end, (as defcribed above) was introduced at the upper part of the fwelling, and brought out at the under or lowermolt part of it; the matter was difcharged at the lower orifice in a very thort time, the tumor was by that means foon difcuffed, and, in a few weeks, it was intirely healed up, without any fcar or blemifh remaining, farther than a little baldnefs about the lower orifice, occafioned by the fharpnefs of the matter, which likewife foon difappear- 
$e d$, and not the leaft trace of the diforder remained.

The other cafe happened about feven years ago: A coach-horfe (belonging to a nobleman in the neighbourhood) had a large tumor a little behind the ears, on the neck, which I have formerly obferved is called the pole-evil; the tumor extended to both fides of the neck, and was divided in the middle by the mane; the tumor had been opened on one fide, in a very fuperficial manner, by a farrier in the country, before the matter in it was fufficiently digefted; after applying a few emollient poultices, in order to ripen it, a ftrong feton needle, as already defcribed, was introduced at the upper part of it, almoft clofe to the mane, and after paffing it through the bottom of the tumor, which was very deep, the needle was brought out through the found mufcular parts below the tumor, in order to procure a nopping or depending orifice for the matter to run freely off.

The 
The fame operation was likewife performed on the oppofite fide, beginning near the mane, and finithed in the famc manner. In a few weeks the cure was compleated. The horfe run for feveral years in the fame nobleman's carriage, without the finalleft veftige of his former diforder.

From this method of treating thefe tumors, together with the ufe of alterative medicines, \&c. which, in cafes of this nature, ought never to be onitted, they were intirely difcuffed, and the perforations made by the needle foon healed up, without the leaft deformity of the parts. I have there. fore given the hiftory of thefe cafes, to thow with what facility and expedition fuch tumors may be carried off, by the ufe of fetons in preference to the common methods ufed, and even recommended by differcnt authors; fuch as, after opening thefe tumors by deep incifions, and pouring into them the moft corrofive mixtures, made 
fcalding hot, together with a long tedious courfe of hot irritating applications, by which the poor animals are kept in the utmoft torture for a confiderable time, and, in the end, are fo disfigured by the lofs of fubftance, occafioned by the cutting away fo much of the fleth from the parts, that fuch horfes are generally rendered unfit for any thing but the meane? drudgery.

Deep feated abfeffes are cured in the fame manner by the ufe of fetons; after tracing the finufes or cavities of the abfcefs with a long flender blunt lead probe, (which yields eafily without forcing its way thro' the cellular membrane, or taking a direction between the interftices of the mufcles), the needle, armed with a chord, fhould follow the direction of the finews or pipes (as they are commonly called) to the moft depending part; and, in cafe there fhould be two or more finufes, which fometimes happens, each of them fhould be treated in the fame manner, 

O N S E T O N S.
25 I

manner, in order to obtain a depending orifice for a free difcharge of the matter, and which, being once procured, feldom fails of compleating a cure.

\section{H A P.}





\section{H A P. IX.}

\section{O B S E R V A T I O N S O N}

\section{P U R G I G HOR SE S.}

URGING medicines are given to

1 horfes with different intentions, that is, either to prepare their bodies for active exercires, or to cure them of difeafes. In the firft cafe, they are always to be confidered as in a ftate of health ; in the fecond, in that of difeafe. Previous to entering on thefe different heads, and that they may be the better underftood, it will be neceffary to premife a few things relating to the ftomach and inteftines, the chyle, the different fyltems of veffels, with their 


\section{OBSERVATIONS ON}

their contents, which will ferve to illuftrate what may be advanced on the fubject of purging horfes.

The ftomach of a horfe, notwithftanding his fize of body, is but fmall, and its coats are thin; the numerous circumvolutions and foldings of the inteftines, are wifely ordered, to detain the aliment till fuch time as it is thoroughly drained of its nourining particles by thofe veffels called the lacteals, the office of which is, to abforb or drink up, and to convey the chyle or nourifhment into the blood; their mouths open into the inner cavity of the inteftines. The length of the alimentary canal, from the upper end of the gullet to the anus or fundament, is faid, by Doctor Bracken, to be about 35 yards. The inteftines have a motion peculiar to themfelves, which, from its refemblance to that of a worm, is called perifaltic or vermicular; according as this motion is increafed or diminifhed, the evacuation 
cuation by ftool or dunging is in a great meafure regulated.

The ftomach is fupplied with a humour or juice peculiar to itfelf, which, by mixing with the food, as the faliva, bile, and other juices, fupplied by the pancreas, \&c. undergoes a fermentative procels of a peculiar nature, which is called digeftion, and from which the chyle is the refult.

The infide of the inteftines are covered with a llimy mucus, which is feparated from the glands, in order to preferve them from being irritated by the food, in its paffage backwards. The coats of the ftomach and inteftines are fupplied with an infinite number of blood-veffels and nerves, which are every where difperfed; and hence, they are exceedingly liable to inflammation, irritation, fpafms, \&c.

Befides the vafcular fyftem, which includes the arterics and veins, there may be 


\section{$25^{6}$ OBSER VATIONS ON}

faid to be another fyftem of veffels, called abforbents; they are of two kinds, the lacteals, and the lymphatics. The ufe of the former has been already mentioned. The lymphatics are tubes or canals, furnihed with valves, which convey fluids that are taken up by abforption on the external furface, and from the extremities of the body; they likewife abforb particular fluids from the different cavities of the body, and from the cellular parts, \&c. which are by them conveyed into the thoracic duct, where it is mixed with the chyle, and from thence it is carried into the blood.-Let us now confider the manner in which purging medicines operate on the firt paffages only.

The action of purging medicines confins in irritating the fenfible fibres of the ftomach and inteftines, by which means, not only the periftaltic motion of the latter are confiderably quickened, but alfo the fecretions of mucus and lymphatic juices, and vapour, which ouze every where into the cavities 
cavities of the inteftines, are increafed, together with unufual quantities of pancreatic juice and bile from their feveral fources; hence it will be obvious, how great a quantity of the foundeft humours, or even the chyle that is derived from the food, before it is mixed with the blood, may be carried off by purging medicines, and how much the whole mafs of fluids in general may be decreafed and drawn off.

Since, therefore, purging is occafioned by giving fuch medicines as are found, by their irritating quality, to ftimulate the coats of the ftomach and guts, and, at the fame time, quicken the periftaltic motion of the latter, fo as to caufe them to Thake or throw off their contents by ftool. It would appear, that the different kinds of purging: medicines differ only in degrees of ftrength, and that they operate no otherwife upon the different humours of the body than as they ftimulate the firft paffages more or lefs, and hence caufe a greater or leffer e-

$\mathrm{K} \mathrm{k}$

vacuation 
vacuation by ftool. So that, by this operation, we only leffen the quantity of the Auids, and clear or fcour the firft paffages from any offending matters that may be lodged there. From hence it may likewife be inferred, that there is no fuch thing as elective purgation, that is, by giving certain medicines, we drain off this or that particular humour from the body. This may be farther illuftrated in the following cafe or example: When a horfe, who has fwelled legs, or greafy heels, gets purging medicines, they do not act immediately on the fluids contained in the legs, by carrying them off only, they act by revulfion, that is, by drawing away the fluids, \&cc. from the ftomach and inteftines; thofe that are in the legs are, at the fame time, abforbed or drawn away from the extremities by the abforbent veffels, to fupply the want in the former; and hence the fwelling in the legs, \&cc. fubfide. 


\section{PURGING HORSES. 259}

It is a common phrafe, when a horfe is any way out of order, to fay, that fuch a horfe is foul in the body, or that he is full of humours, an expreffion which can only mean that the horfe is in a bad habit of body; as to a horfe's being full of humours, the propriety of the expreffion in this fenfe cannot be admitted, as every horfe, even in the higheft ftate of health, properly fpeaking, is full of humours, as every gland in the body, of which there is a confiderable number, feparates a particular humour, which becomes neceffary for a variety of purpofes in the animal oeconomy; thus, the liver feparates the bile, the tefticles the femen, and every joint in the body has its glands, which feparate a particular humour, and fo of others. Therefore, the expreffion or phrafe of a horfe's being full of humours, in the common acceptation of it, is improper, and betrays a want of knowledge of the animal oeconomy. 


\section{OBSFRVATIONS ON}

Many people are but too fond of giving purging medicines, and frequently prefcribe them whether the cafe may require them or not. Doctor Bracken has a very pertinent remark on this head: "* This fort of " evacuation," fays he, "feems very much " to quadrate with the outward fenfes, " and makes the ignorant part of mankind " (whofe heads are fuller of humours than " their horfes) imagine, that purging me" dicines carry off the offending matter in " moft diforders, never confidering the "general rule, which ought ftill to be "kept in mind, viz. That, in proportion " to any one evacuation's being heightened " or increafed, moft, or all of the other " natural evacuations, are proportionally " diminifhed."

It is a practice with many people, to ride their horfes very hard before they give them purging medicines, in order, as the phrafe

\#ol. I. page 86. 
phrafe is, to ftir up the humours, that, when they are afloat, (according to their ideas) they may be carried off by the purging. It has been already obferved how exercife operates on the circulation of the blood, by increafing its velocity to a great degree, and hence inclining it to an inflammatory difpofition, which, in this cafe, is the very worft thing that could happen, upon the fuppofition that the horfe is in a bad habit of body; for purging medicines, when they are given in this ftate, may occafion inflammation in fome of the principal vifcera cr inteftines; or they may bring on a fever, or other diforders, which, if they do not prove mortal, yet they may, as is fometimes found to be the cafe, occafion thofe diforders that terminate in blindnefs, incurable lamenefs, or in fome chronic diforder, which may render the horfe ufelefs.

Riding horfes about the day after they have got purging medicines, in order to forward their operating, if continued too 


\section{OBSERVATIONS ON}

long, till the horfe is warm, or to produce fweating, ought always to be guarded againft, as fuch rreatment not only expofes them to catch cold, but hinders the operation of the medicine in the ordinary way; for it has been obferved, that purging medicines fometimes go off by fweat, or by urine, \&c. which the ignorant and unkilful are not acquainted with; they therefore conclude, that, as they fee no great difcharge of dung, the dofe has been too weak, and give another too foon, without allowing a proper interval between them, which, at the fame time, is made confiderably ftronger than the former, which weakens the horfe very much, and a confiderable time elapfes before he recovers his ufual ftrength.

I have already taken notice of the great length of the inteftines; this, together with the horizontal or prone pofition of the body of a horfe, is unfavourable to the operation of purging medicines, which, on that account, 


\section{PURGING HORSES. $2 \sigma_{3}$}

account, remain in the bowels a confiderable time before they operate, being from 18 to 28 or 30 hours, according to the ftate of the bowels at the time, and, in fome confttutions, even longer, In thefe cafes, it is not advifeable to give any medicines in order to quicken or haften their operating; walking exercife, but not long continued at a time, together with plenty of warm water, if the horfe will drink, is the beft and the fafent means to forward the operation of them. At the fame time, it will be neceffary to notice whether the horfe Aales more than ufual, as purging medicines, as I have juft obferved, are found fometimes to operate in that way, withour any confiderable evacuation by dung. I would likewife recommend one general caution in giving purging balls, which is, That the operator thould purh the ball over the root of the tongue, and that he be certain of the balls being fwallowed entire, and not broke or thrown out of the mouth; miltakes of this kind have frequently oc- 


\section{OBSERVATIONS ON}

curred when the ball breaks, one-half, perhaps, is only fwallowed, the other drops out of the mouth, or it may happen, that the whole ball drops out unperceived. In thefe cafes, it is concluded, from the purge's not operating in due time, that it has been too weak, and, therefore, the next dofe is made confiderably ftronger, and hence a fuperpurgation enfues, attended with great ficknefs, lors of ftrength, and other bad confequences; therefore, when purging balls are given to horfes, the head fhould be kept up, and care taken that the ball paffes down the gullet, which may eafily be difcovered fliding down from the outfide ; but, if any doubt remains of its being fwallowed, a little water may be given the horfe to drink, and one glut or two will put it out of all doubt.

It is a common practice to give purging balls early in the morning, upon an empty ftomach ; this, in fome conftitutions, occafrons great ficknefs, faintnefs, trembling,

griping 
PURGING HORSES. $26 \%$

griping pains, \&c. a long while before they begin to operate; to prevent which, I have always ordered, and with fuccefs, a mafh of bran to be given about an hour or more before the ball, which prevented thefe effects, and the purge operated in the moft gentle and eafy manner; and, perhaps, this practice would be advifeable in all cafes, and in all conftitutions, when purging medicines are neceffary.

Another error many people fall into is; That, although a purge operates very. well; yet, if the horfe is not very fick during its operation, they conclude that it will have no effect, nor be of any benefit to the horfe; they therefore give the next purge made a good deal ftronger, in order, as they fay, to ftir up the humours; for they conclude, that the ficker a horfe is under this operation, the humours are the more ftirred up; and the eafier carried off by the purge; without confidering the danger that attends this operation, and how much they expofe L 1 the 
the life of the horfe by fuch injudicious treatment.

When purging medicines are intended to be given to horfes, it is neceffary that they thould be kept quiet and at reft for fome time before, that is, from any violent exercife, and the fame rule thould be obferved for fome days after they are done operating, walking exercife only excepted. It is owing to the want of thefe, and fuch like precautions, already mentioned, that fo many accidents happen daily in the purging of horfes.

It may be now expected, that I fhould make fome obfervations upon the practice of purging horfes, by way of preparing them for running, hunting, \&c. It muft be acknowledged there is a difficulty in combating a practice which too generally prevails, although there are a number of facts which will ferve to demonftrate, that the purging of horfes indifcriminately is 
PURGING HORSES. 267

not neceffary in order to prepare them for thefe active exercifes. On the contrary, it muft, and indeed is, in many cafes, exceedingly hurtful to horfes, on account of the too frequent repetition of them, together with the too fhort intervals generally allowed between each purge.

As to the vulgar opinion of humours falling down into this or that particular part of the body, if horfes are not properly purged, \&c. before they are put to thefe active exercifes, it is exceedingly erroneous, and muft depend on a variety of circumftances, that ought to be taken in to the account.

It may be of ufe to the young practitioner, to explain what is meant by the phrafe of humours falling down; but, at the fame time, I muft inform him, that this phrafe is fo generally in ufe, that, when a horfe's eyes are affected, the humours are faid to fall down into them, although they are fi- 
tuated nearly in the moft elevated part of the body. But, to explain their falling down to the extremities, I thall take a cafe that frequently occurs: When a horfe that is in the higheft ftate of health, but too fat and full of juices, \&c. and accuftomed to. ftand much at reft, is fuddenly put to violent or long continued exercifes, his legs, $\&$ c. will be apt to fwell foon thereafter; they will perhaps continue in that ftate for fome time; they may at laft break out in running fores about the heels, and form cracks, fcabs, \&c. \&c.; in this fituation, it is then faid that the humours have fallen down to the legs. Here a queftion naturally occurs, Where was thefe humours before the horfe got this hard ride, or other fevvere exercife, and how come they to fall down on this occafion only? This requires a different explanation.

It has been obferved, in the chapter on exercife, the effects it produces when too fudden and violent, before a horfe is gradually 
dually habituated to it for fome time previous to his undergoing fuch violent or long - continued exercifes. The veffels being too full of fluids, they, from the rapidity of the circulation during the exercife, efpecially the finer capillary veffels, admit the groffer fluids that do not circulate in them for ordinary; they likewife are liable, in thefe cafes, to rupture; hence the fluids they contained are extravafated into the cellular parts, where they ftagnate, and, being then out of the courfe of circulation, they occafion a fwelling. If this happen in the legs, as they are the molt depending parts of the body, (the humours are then faid to be fallen down), the fwelling caufes a diftenfion of the flkin, \&c.; the cuticular pores are then enlarged, and admit through them the thinner parts of the fluids to the outward furface on the fkin, which, on being expofed to the external air, are then changed in their quality, and acquire, according to circumftances, either a foapy, clammy, or greafy appear- 


\section{OBSERVATIONS ON}

ance, or a fharp foetid ichorous quality, that erodes the $1 \mathrm{kin}$, and, by lodging there, forms fmall ulcers.

It is well known, that horfes, by good feeding, regular exercife, \&c. may be brought to perform the molt active exercifes, and that many inftances daily occur of horfes both running and hunting, without undergoing any previous preparation by purging medicines; and it is likewife well known, that, even when purging medicines are given, ftill regular exercife is found to be abfolutely neceffary, in order to habituate the horfe to this kind of active labour.

Polt horfes likewife furnifh a farther proof of what has been advanced; it is well known how they can be brought to travel very long ftages, and with great fpeed, without any preparation farther than good feeding, and inuring them by degrees to this violent labour. Doctor Bracken, who 
who underftood this fubject very well, and who was likewife a great fportfman, has been at great pains in exploding this manner of reafoning, by a variety of found arguments, in his fecond volume of farriery improved, where he has likewife given it as his opinion, "That, in 'moft cafes, " good feeding, regular exercife, \&c. will, " in time," fays he, "make a horfe fic " to ftart for a plate, without fo much " noife of the virtue of this or that drug " or compofition, to carry off greafe, and " mend his wind; for, in my humble o" pinion, the jockies are too fond of gi" ving purges to horfes, whereby they " weaken their conftitution, by caufing "the fibres of the ftomach and guts to be" come lax and flabby." And, in the fame volume, he mentions the following cafe of a mare of his own, "That he had run "fix years with only two purges; nei" ther," fays he, " had the an ounce of " any kind of medicine during that time, "s except every morning, and moftly every " evening, 


\section{OBSERVATIONS ON}

" evening, about the bignefs of a pigeon's " egg of my cordial ball; and, I fancy, "The performed as well as the molt of her " neighbours, for the won eight plates out " of nine, and four out of fix every year."

It ought always to be remembered, that great evacuations weaken an animal body, and, if they are repeated too frequently, and too clofe upon one another, without allowing a proper interval between each, or, if they are carried to excers, which is fometimes the cafe, the weaknefs in the animal fyltem is thereby increafed, the powers of life are quite overcome, and death follows of courfe.

I would not be underftood, from what has been faid, to mean, that purging medicines are never to be ufed on thefe occafions-No, I am fully fenfible of their good effects, when judicioufly adminiftered, and horfes properly managed during their operation; but I do not approve of repeat- 
ing purge after purge, merely becaufe this or that horfe is to run or hunt, without firft confidering whether the animal be fat or lean, or whether he has been kept at hard meat, with proper exercife, or whether he has run a confiderable time, or late in the feafon at grafs; all thefe; and a number of other circumftances neceffary to be attended to, ought to be duly weighed, and maturely confidered, before purging medicines are adminiftered; for example, if a horfe has run long at grafs, and is of a plethoric or full habit of body, evacuations by purging, and diuretic medicines, to a certain degree, are neceffary, together with length of time, good feeding, and regular exercife, to bring his body into that proper habit to enable him to perform, with freedom, fuch active exercifes. But, if a horfe is of a lean, low, or dry habit of body, whether it may proceed from the want of proper food, from fatigue, \&cc. Why reduce him ftill lower by repeated evacuations of any kind? There is fuch an inconfiftency 


\section{OBSERVATIONS ON}

in this practice, that it would not even deferve to be mentioned, or taken notice of, if it were not too much practifed every day; for, with fome people, it is no matter of confideration with them what fate or habit of body a horfe may be in, that is, whether he be of a fat, or full, or lean dry habit of body, fill he is faid to be full of humours, and which muft be purged off before he can run, \&c. Horfes, in the latter fituation, require only good feeding, and regular exercife, to ftrengthen and improve their conftitutions, which cannot fail of taking place, if the vifcera are found, and the horfe otherwife in a healthy ftate. And, even although a horfe may be a little inclined to the fat, or of a plethoric habit, yet, from the ufe of diuretic medicincs, which are commonly given on thefe occafions, together with regular airings and proper exercife, good feeding, dreffing, \&c. he may be brought into that proper habit of body, which will enable him to perform the moft violent labour with the greate? 


\section{PURGING HORSES. 275}

greateft eafe to himfelf, and without any bad confequences arifing from it.

3.

But, farther, from the too frequent ufe of purging medicines to horfes, their conftitutions, though otherwife good, are ruined by it, their ftrength is impaired; it likewife contributes to thorten their days. Befides, it frequently happens, that, when they are brought to action too foon after fuch evacuations, their. Atrength being quite exhaufted by the treatment the have undergone, they fail in performing what was expected'from them.

From thefe, and a variety of other arguments which might be urged, and which will readily occur to the judicious reader, it is obvious, that repeated evacuations, of any kind, are not neceffary to horfes, in order to prepare them either for running or hunting; and, if thole that are intended for the latter were only allowed the fpring-grafs, and taken 


\section{OBSERVATIONS ON}

taken up about the middle or towards the end of June, before the grafs becomes too rank, although it may be rather inconvenient to have them in the houfe at that feafon, yet the owner would find his account in it; the allowance of oats may be but fmall for fome time, and which might be increafed, together with the horfe's exercife, as the hunting feafon approached. Running horfes might be treated in the fame manner, according to the feafon in which they are to run, allowing both a greater length of time in the habitual practice of thefe exercifes, together with proper feeding, drefling, \&c. This treatment, together with the ufe of thofe alterative and diuretic medicines, which are ufually given on thefe occafions, would render horfes much ftronger and fitter for thefe active exercifes, without wearing out their conftitutions by the repeated ufe of purging medicines, too frequently very injudicioully adminiftered. 


\section{PURGING HORSES. 277}

I thall clofe this head with a cafe that happened here fome years ago: Two military gentlemen betted their horfes to run againt one another on Leith fands, for a confiderable fum, and which was to take place three weeks after the bet; the horfes to be rode by their grooms. Captain $\mathrm{R}$-'s was a poney about $13 \frac{x}{2}$ hands; Captain $\mathrm{M} \longrightarrow$ 's was a gelding about 15 hands high; both their grooms were bred at Newmarket, and were keen advocates for bleeding and purging, (notwithftanding both the horfes had been kept on dry food and in the beft order, and the fhort interval of time for fuch treatment) in order to prepare them for running, \&c. Captain M-'s horfe was blooded once, and purged twice ; Captain R_'s was bloodded once, and purged once; they were both fweated in the ftable with a great load, of cloaths; at the fame time, their ftables, though feparate, were kept uncommonly hot and clofe thut up, night and day, in the midft of fummer. From this treament, 


\section{OBSERVATIONS ON}

they foon lot their appetite for food, and, in about eight or ten days, they were hardly able to undergo their exercife on the fands, their ftrength was fo much exhaufted by the treatment they had undergone, the conftant and violent fweating in the Atable, which, of all evacuations, when continued, weakens a horfe the moft. In this fituation, Captain R-gave up his bett as loft, together with his poney, for. which he had a great value; luckily for him, however, his groom, who was rather inclined to be corpulent, had put himfelf under a courfe of phyfic, \&c. in order to reduce his weight; the poney was then put under my care, with another groom to attend him; his cloathing was immediately reduced to a fingle rugg, the ftable-windows were thrown open in order to admit frem air, the poney recovered his appetite for food, together with his ftrength, fpirits, and activity; whilft his antagonift continued under the manner of treatment above mentioned. And, although bets were confiderably 
fiderably againft the poney at ftarting, yet he won with great eafe, and which Captain $\mathrm{R}$ - frankly acknowledged was intirely owing to the difference of treatment they had been under.

I have hitherto confined my obfervations on the adminiftering purging medicines to horfes in health, in order to prepare them for active exercifes, as running, hunting, $\&$ c. ; it remains to confider their ufe in difeafes.

It would take up too much of the reader's time to enumerate the various forms of prefcriptions that are in ufe for purging horfes, or to confute the ridiculous encomiums beftowed on the variety of recipes that are handed about witb a probatum eft, or atteftation of their peculiar virtues in carrying off this or that particular humour, \&cc. as many of thefe compofitions, when examincd, appear to be a confured jumble of ingredients, calculated more for the apothecary's 


\section{OBSERVATIONS ON}

pothecary's profit, than benefit to the patient; and the bad effeets arifing from them in practice, are too apparent in a variety of cafes which occur daily.

The fubltances that are ufed for purging or emptying the alimentary canal, may be diftinguifhed into two kinds, the lenient which open the belly gently, and the draftic which purge more brifkly. The lenient ought always to be preferred when there appears any unufual commotion in the vafcular fyftem, which may eafily be known from the quicknefs of the pulfe, \&c. ; for, although purging medicines increafe the motion of the pulfe during their operating, yet they afterwards abate or leffen the motion of the blood, by drawing off a confiderable quantity of the animal fluids by ftool; they likewife clear the inteftines of fharp ftimulating watters or worms, which occafion an unufinl der ge of irritation in the fyltem; they tix in may be given with different intentions, as circumftances 
PURGING HORSES. 28I

may require, in fmall dofes, to keep the body open, and prevent an accumulation of faeces or dung in the intentines, which happens in difeafes. In cafes of frequent returns of the gripes or cholic, but not during the fit, left the guts fhould then be inflamed, they thould therefore be given in the intervals, in order to prevent the return of the complaint.

But, in cafes where it is thought neceffary to clear the inteftines thoroughly in ftrong robult horfes, the draftic purges may be given, providing there is no great commotion in the circulation of the blood at the time. Purging medicines are of great fervive in cafes where the intertines appear to be loaded with vifcid or thick flime, or when it appears, by long continued coltivenefs, that the periftaltic motion of the inteftines is in te degree fufpend$\mathrm{ed}$; in grofs habits, . . is any tendency to fwe in s in the legs, attended with running wr, \&zc.; in dropfical fwellings in any part of the body; in 


\section{OBSERVATIONS ON}

difeafes of the head, rheums, or defluctions about the eyes; in rheumatic lamenefs, when the pains feem to move from one limb to another; in the jaundice; in obftinate coughs, efpecially when the horfe is of a full habit of body; in moft cutaneous difeafes, or when a number of fimall pimples or lumps arife on the fkin, and fuddenly difappear again, or when the lumps difcharge a tharp fluid of an ichorous quality; in plethoric or full habits, when the horfe is intended for violent or aclive excrcifes, as running, hunting, \&c.; in cates where it is judged neceffary to lefien the general mafs of fluids, or to divert them from flowing to any particular place in too great a quantity, as in inflammations of the lungs; in this lant cafe, liquid purges are mott proper, as they operate more expeditioufy. In very delicate conftitutions, rhubarb thould conftitute the greatef part of their purging medicines; they are likewife molt proper in cafes of want of appeite; no doubt there may be other cafes where 


\section{PURGING HORSES. 283}

where purging medicines may be necefiary; but thefe muft depend on the diferetion and judgment of the prefcriber.

On the other hand, it will be prudent to avoid giving purging medicines during extreme cold weather; likewile in all feverifh complaints, when the pulfe beats ftrong and quick, till fuch time as thefe fymptoms are confiderably abated; in all cafes of extreme weaknefs, whether arifing from fatigue or long continued difeales; in all lean dry habits, unlefs there is reafon to apprehend it proceeds from worms; in cafes of very obftinate coftivenef, till fuch time as that complaint is in fome degree removed by clylters, foft feeding, \&xc; in cales when : horfe labours under any violent acute complaint; in diarrhoea or loofenefs. Aloetic purges, or thole in which aloes enters into the compofition, are to be avoided likewife in fevere cholics or griping pains, although liquid purges, that are quicker in their operation, and lefs irritating, may be 


\section{OBSERVATIONS ON}

given with fafety in the intervals, when it is obferved that horfes are fubject to frequent attacks of this complaint.

Previous to the giving of purging medicines to horfes, efpecially to thofe who have been kept on hard meat, it will be prudent to keep them from all violent exercifes for fome days before the purge is given. If they are fat, and of a full habit, it will be neceffary to draw fome blood, to lower their feeding, and to give them that which is foft and relaxing, as boiled barley, maíhes of bran, malt, \&c. When horfes are to be purged at grafs, no preparation is neceffary, farther than in plethoric or full habits, to treat them as above, obferving, at the fame time, that they be not coftive, as this frequently happens although feeding on grafs; in that cafe, they are to be taken into the ftable, and treated as if they had been on hard feeding. 
PURGING HORSES. 285

In giving purging medicines to horfes, it will always be moft prudent to begin at firt by giving mild lenient purges, in order to find out the ftrength of the conftitution, \&cc. as very ftrong robuft horfes, to appearance, are fometimes eafier purged than thofe of a more delicate make; and it frequently happens, that the fame horfe is eafier purged at one time than at another, according to the ftate of the ftomach and inteftines at the time the purge is given.

Mild purges are therefore much fafer at all times, and of more benefit to the conftitution, than too ftrong ones; for the latter caufe too great an irritation of the ftomach and bowels; hence follow griping pains, great ficknefs, \&c. and fometimes inflammation of the inteftines; they likewife may occafion a fuperpurgation, by which the bowels are fo much weakened, that they never afterwards recover their former tone; and hence follow lofs of appetite, 


\section{OBSERVATIONS, \&c.}

petite, general weaknefs, and, perhaps, an habitual diarrhoea or loofenefs.

When it is intended to give mercury with purging medicines, which is neceffary in cafes of worms, or as an alterative, it is proper to give the mercury in the evening, and the purging-ball the next morning, as formerly directed. In this cafe, great care fhould be taken that the horfe be not expofed to cold, nor fuffered to drink very cold water, although he may be indulged with plenty of water milk-warm, mixed with a little oatmeal. 


\section{H A P. X.}

\section{O B S E R A T I O N O N C L Y S T E R S.}

CLYSTERS adminiftered to horfes, are of greater importance in relieving them from many acute complaints, than is generally imagined; and it were to be wifhed, that, in place of the more expenfive cordial drenches, \&c. which are but too frequently given in moft of thefe cafes, a fimple clyfter of warm water, or thin water-gruel, were fubftituted in their ftead; the latter proves of great benefit, whilft the former too frequently prove hurtful.

Clyfters 
Clyfters ferve not only to evacuate the contents of the inteftines, but alfo to convey very powerful medicines into the fyrtem, when perhaps it is not practicable to do it by the mouth; for, although they are only conveyed into the larger inteftines, and, perhaps, hardly penetrate into the fmaller, ftill they are extremely ufeful, by fomenting as it were the latter, and, at the fame time, by foftening the hardened excrement that is accumulated in the former, and rendering it fo foft as to be expelled out of the body, by which flatulencies or other offending maiters, that may be pent up in them, are likewife expelled; befides, by their warmnefs and relaxing powers, they act as a fomentation to the bowels; and hence may be of confiderable fervice in removing fpafmodic conftrictions in the bowels, carrying off flatulencies, and in preventing inflammation in the inteftines, \&c.; or, by conveying opiates to the parts affected, give fpeedy relief in cholics, \&c. \&c. 
The ufe of emollient clyfters in fevers are confiderable, they act by revulfion, and relieve the head when too much affeeted; befides, by throwing in a quantity of diluting liquor into the inteftines, it not only relaxes and cleanfes them, but may be faid to cool the body in general; at the fame time, a confiderable portion of the liquid is abforbed and conveyed into the mafs of blood, by which means it is diluted; and, in particular complaints in the bowels, clyfters give almoft immediate relief, as the remedies, when judicioully prefcribed, pafs immediately to the parts affected, as they undergo little or no alteration from the powers of the body. Doctor Sydenham * efteemed clyfters fo much in fevers, that he affirms he could quiet the too great heat of the blood in the human body at pleafure, by the ufe of them only; what he recommended were extremely fimple, generally compofed of emollient decoction

$\mathrm{O}$ o

and

- Sect. 1. cap: iv. page 69. 
and fugar, and fometimes only of water, or of water mixed with an equal quantity of milk.

Van Swieten, in his commentaries, vol. $V$. page $37 \mathrm{I}$, on the ufe of clyfters to the human body, obferves, That "clyfters " cherifh the bowels like an emollient va" porous bath, wanh out the foeces, dilute " what is abforbed by the venal orifices, " and refolve the concreted humours, by " the faponaceous virtue which refides in "fugar and honey; and thus, by all thefe " powers confpiring together, they allay " too great motion of the humours." Hence, therefore, as the difeafes of horfes are cured on the fame principles as thofe of the human body, the doctrine laid down by phyficians for the cure of difeafes in the latter, are applicable to horfes in fimilar circumftances; only it ought to be obferved, for obvious reafons, that the inteftines of horfes thould always be emptied of dung by the repetition of clyfters, which have. fome- 
fomething ftimulating in their compofition, previous to the adminiftering any kind of medicine by way of clyfter.

Nor is the ufe of clyfters confined to medicines only; food and nourifhment may be conveyed into the fyftem in this way, when a horfe is unable to fwallow any thing by the mouth. This I have frequently experienced in practice, and fupported horfes for feveral days together by nourifhing clyfters, made of thick water-gruel, during violent inflammations or tumors in the throat, till fuch time as they have been difcuffed or fuppurated.

Thofe who are not acquainted with the anatomical Atructure of the body, will no doubt be furprifed at this doctrine, for the infruction of whom, I would remind them of what has been faid on this head in the chapter on food, where it is obferved, that the lacteal veffels, whofe mouths open into the inner cavity of the intefines, ab- 
forb or drink up the chyle or nourifhment that is produced from the food, and convey it into the mafs of blood. The fame procefs takes place when nourifhment is conveyed into the inteltines by the anus or fundament, only the food requires to be fo far prepared, broke down and diluted with water, fo as to render it fit to be abforbed by the veffels mentioned above.

In adminiftering clyfters, it ought always to be obferved, that the contents of the clyfter be neither too hot nor too cold, and only milk-warm, as either of thefe extremes will furprife the horfe, and caufe him to eject or throw it out before it has had time to have any effect; previous to introducing the clyfter-pipe, the operator, after anointing his hand and arm with oil, butter, or hogs-lard, (obferving, at the fame time, that the nails of his fingers are fhort), may introduce it into the rectum, and draw out the hardened dung gradually. This operation, in farriery, is termed back-racking, 
ing, and becomes the more neceffary, as it frequently happens that great quantities of hardened dung is, in fome cafes, collected in the rectum, and which the horfe cannot void eafily without affiftance of this kind.

The compofition of clyfters thould be extremely fimple, on that account they will be eafily prepared, and as cafily adminiftered, providing the operator is provided with a fuitable inftrument for the purpofe. The generality of clyfter-pipes that are commonly ufed, are by far too fmall and too hort; although it may appear a kind of paradox, yet it is a fact, that a clyfterpipe of a larger fize than the ordinary ones, and of a proper thicknefs, is much eafier introduced into the anus than one that is confiderably fmaller. It is likewife obvious, that, when the pipe is too fhort, it renders clyfters of no ufe, becaufe it cannot convey the clyfter fo far up into the inteftines as is neceffary for them to be retained; a fmall thort pipe of fix or eight inches long, is not capable of conveying the 
the injection to the end of the rectum, which, in a horfe of a middling fize, is about fixteen or eighteen inches long. I have frequently obferved, in giving injections with thefe thort pipes, that the clyfter flowed out at the anus, in proportion to the force with which it was injected from the bag or fyringe; this muft always be the cafe, efpecially if the bladder fhould happen at the time to be full of urine, which frequently occurs, from its being too long retained there by the hardened dung in the rectum preffing upon the neck of the bladder, and which prevents the horfe from ftaleing.

But farther, after the hardened dung is taken out of the reatum by the operation above mentioned, the bladder being diftended and full of urine, it cannot exert its contracting power immediately, fo as to expel its contents; it therefore preffes up the empty rectum, and forms as it were a kind of tumor in it ; if the pipe is too hort, 
it cannot reach beyond this rifing in the rectum, which forms as it were a declivity back towards the anus; and hence the liquor regurgitates or flows back at the anus, as foon as it is difcharged from the pipe.

The fmallnefs of the bag or bladder, which is generally proportioned to that of the pipe, is another very material objection to thefe fmall inftruments, as it feldom contains one quart of liquid; from which circumftance, very little benefit can be derived from the ufe of them in fuch large inteftines as that of a horfe. Doctor Bracken, in his firft volume page 203. has a very judicious remark on the ufe of clyfters; he obferves, That " the colon of a horfe "feems to be three guts, by reafon of the " two necks of about half a yard each, " is drawn up into many cells or purfes, " by means of two ligaments, one of " which runs along the upper, and the o" ther the under fide of it, which, with " the affiftance of a valve or flap at its be" ginning, 
"ginning, hinder the excrements eithei

"from returning back into the fmall guts, " or falling too foon downwards, before " the chyle or milky fubftance prepared "from the food be fent into its proper "veffels. And, indeed, the caecum or " blind gut, which is the firft of the three "larger guts, feems to be fo contrived in " the manner of a valve, to hinder the a" liment and chyle from paffing too foon "into the colon; for, if the aliment and " chyle were not in fome meafure hindered " in their paffage through thefe large guts, " the body could not be fufficiently fupplied " with nourifiment.

"The firft of thefe colons is about a "yard and a half in length, the fecond " about a yard, and the third, or that part " which joins the rectum or arfe-gut, " near fix yards in length; fo that the " colon of a horfe fourteen hands high, " may be faid to be nearly eight yards and "s a half long; and, from it, along the rec- 


\section{ON GL Y S T ER S.}

"tum or ftraight gut to the anus; where " the excrements are difcharged, is not a"bove half a yard; fo that it is plain, "clyfters operate moftly in the colon; tho" "I muft fay they are given in too fmall " quantities; for what fignifies two quarts " of liquor in a gut nine yards long, and "four or five inches diameter, in a natu" ral ftate; but, in the colick, it is fo di"flended with flatulencies, that its dia" meter exceeds feven or eight inches, as "I have frequently obferved in thofe dy" " ing of that diftemper."

Large fyringes are frequently ufed for the purpofe of giving clyfters; but of all the inftruments ever invented, in my opinion, they are the moft improper for horfes; the fhortnefs and fmallinefs of their ivory pipes, are not only a material objection againt the ufe of them, but they are apt to tear and wound the gut; for, if a horfe thould prove reftlefs, either from pain, as in cafes of the gripes, or from vicioufnefs; 
the fyringe and pipe being quite inflexible, in the ftruggle to throw up the injection, the gut may be wounded or hurt, by which a difcharge of blood and other bad confequences may follow. But, although there was not the leaft chance of their hurting the horfe, or wounding the gut, yet the force with which they throw up the liquor, always caufes a furprife, of courfe a refiftance, attended with a vigorous effort to throw it out, which indeed frequently happens before the pipe of the fyringe is withdrawn, and frequently upon the operator.

The molt proper inftrument for the giving of clyfters, is a fimple bag or ox-bladder, which will hold two or three quarts, tied to the end of a wooden pipe about fourteen or fifteen inches long, one inch and a half diameter where the bag is tied, and of a gradual taper to the extremity, where the thicknefs hould fuddenly increafe, and be rounded off at the point, and 
and made as fmooth as poffible; the perforation or hole through the pipe may be made fufficiently large, fo as to admit the end of a common funnel, for pouring in the liquor into the bag. By the flexibility of the bladder at the end of this inftrument, no danger can happen to the horfe; the clyfter is conveyed fo far up into the inteftines that it will be retained; it caufes no furprife (providing the liquor be neither too hot nor too cold, but milk-warm), as no other force is required to throw it up than the holding the bag a little higher than the level of the pipe; by which means, the. liquor flows gently into the gut, without any furprife to the horfe. After ufing the bag, it may be blown full of wind, a cork pur into the pipe, and hung up in fome dry place, to prevent it from rotting; by which means, it will laft a confiderable time.

Clyfters are diftinguilhed by different names, which denominate the quality of the ingredients of which they are compofed, 
as cmollient, laxative, diuretic, anodyne, \&c. As the more general ufe of clyfters, in the practice of farriery, would be attended with the molt falutary effects, efpecially in acute difeafes, where the fpeedieft affiftance is neceffary, I fhall here fubjoin fome forms of recipies for cormpofing them, together with the cafes in which they may be adminiftered with adyantage.

\section{Emollient Clyfter.}

3. I. Two or three quarts * of thin water-gruel:

Sallad oil, and

Coarfe fugar - of each fix ounces.

Diffolve the fugar in the water-gruel, then add the fallad oil-Give it milk-warm.

Laxative

Englifh meafure is always meant. 


\section{Laxative Clyfter.}

5. 2. Tẉo or three quarts of thin watergruel,

Glauber falts eight ounces,

Sallad oil fix ounces.

When glauber falts are not at hand, common falt may be ufed in its ftead.-A great variety of recipes might be added for making clyfters, compored of the infufion of different herbs, feeds, \&c. but, as the above ingredients are always eafily got, they will be found to anfwer all the intentions required under this head, which is to foften the hardened excrements, to lubricate the inteftines, and, by exciting a gentle ftimulus, promote a free difcharge of their contents, which, when once obtained, feldom fail of giving relief in inflammatory cafes, fpafms, \&xc. 


\section{Purging Clyfer.}

R. 3. Infufe two ounces of fenna in two quarts of boiling water, ftrain it off, then add Syrup of buckthorn, Common oil, - of each four ounces.

This clyfter will operate more brifkly than the former, and, on that account, may be preferred when an immediate or fpeedy difcharge is neceffary.

\section{Anodyne Clyfter.}

B. 4. The jelly of ftarch, or infufion of lintfeed, one pint, liquid laudanum, one ounce, or about two table fpoonfuls.

When there is reafon to apprehend inflammation in the bowels, opium may be given in place of. laudanum, from 20 to 
30 grains, in proportion to the urgency of the fymptoms; it ought to be well triturated or rubbed in a mortar, with a little of the liquid, till it has thoroughly diffolved. The fmallness of the quantity of liquid here recommended, gives it the better chance of being the longer retained, as the good effects to be derived from the opium depend intirely on this circumftance. This clyfter is proper to be given in violent gripings, attended with purging, in order to blunt the harpnefs of the corroding humours, and to allay the pain ufually attending in fuch cafes. The ftarch will in fome meafure fupply the deficiency of the natural mucus, or covering of the inteftines, which has been carried off by violent purging; it may be repeated, if the fymptoms continue violent, only diminifhing the quantity of laudanum, or of the opium. 


\section{OBSER V A T I O N}

\section{Nourifhing Clyfter.}

B. 5. Thick water-gruel three quarts.

When clyfters of this kind are found neceffary, they may be given four or five times in the day, according as circumftances may require; they are of confiderable fervice in cafes where the horfe cannot eat fufficiently to fupport him, or fwallow any thing, from inflammation of the throat, jaws, \&c. or in convulfions, attended with a lock'd jaw, \&cc.

\section{Diuretic Clyfter.}

B. 6. Venice turpentine, two ounces, Caftile foap, one ounce; diffolve the foap in two quarts of warm water, then add the turpentine, after it has been well beat up with the yolks of two eggs. 
This diuretic clyfter is of great ufe in the ftrangury, and obftructions in the urinary paffages; and, as it is immediately applied to the parts affected, it feldom fails of giving relief, and has a much better effect; when prefcribed in this manner, than when given by, the mouth, as it then mixes with the whole mafs of fluids, it may lofe a confiderable portion of its diuretic quality before it reaches the kidneys; but, by being adminiftered in the form of a clyfter, it is readily abforbed by the neighbouring veffels, and promotes a free difcharge of urine.

It would be needlefs to add more forms of clyfters, as thofe above mentioneu will anfwer moft cafes, without any material alteration, but what may be eafily fupplied by rhe judicious practitioner.

There are a variety of cafes where clyfters may be adminiftered with great fuccefs; befides thofe already hinted at, as in inflam: matory fevers, fpafmodic conftrictions, and cholicky complaints in the bowels; in reQ. $q$ cent 


\section{OB S R V A T I O N S}

cent coughs, apoplexy, convulfions, paraJytic complaints, fwelling of the belly, whether from air pent up in the bowels, or from hardened excrements; in cafes where horfes are troubled with worms, as the afcarides which lodge in the lower part of the inteftines, or when bott-worms are obferved fticking in the anus, or voided with the dung; in very coltive habits, before laxative or opening medicines are given by the mouth; in wounds which penetrate deep into the mufcular or tendenous parts, or in the belly, \&zc.; in inflammations of the eyes, or when the head feems particularly affected; in inflammatory fwellings on any part of the body, when a horfe cannot fwallow any food, \&zc. whether it proceeds from fpafm in the mufcles of the throat, inflammations, or fwellings. Clyfters compoled of mucilaginous fubftances, as narch, lintfeed, \&cc. are of great benefit in violent diarrhoeas or loofenets, whether it proceeds from a natural difcharge, or from too ftrong purging medisines. 
It ought always to be remembered, that clytters thould be repeated frequently, till fuch time as the diforder for which they are given is either removed or greatly abated. This injunction may be the more readily complied with, as the adminiftering clylters to horfes is not attended either with much trouble or difturbance to them.

Before I conclude this chapter, I would make one obfervation, which is this; if frequently happens in colicks, and other complaints in the bowels, that a horfe will dung frequently, probably from pain, \&x. but in a very fmall quantity at once; at the fame time, what he pafies may appear foftin or loofe. In fuch cafes, the practitioner may be told that clyfters are unneceffary and fuperfuous; this, however, ought not to prevent him from prefcribing them, as, in fuch cafes, the flatulencies which occafion the diforder may be feated in the colon, where the excrements at the fame time are extrcmely hardened; and it frequently hap- 
308 OBSERVATIONS, \&c.

pens, that, after the fecond or third injection, they are difcharged in fuch a quantity, and in fuch a ftate, as to furprife thofe who were juft before deriding the giving clyfters. I have frequently had thefe prejudices to combat with, for farriers frequently have as troublefome nurfes to deal with, as the phyficians fometimes complain of, and who are no lefs ready in their infinuations where they are attended to. 


\section{G $\mathrm{H}$ A P. XI}

O B S E R V A I O N S ON DRINKS OR DRENCHES.

$\mathrm{T}$ has been the practice amongft far-

1 riers to dittinguilh their formulae of medicines, or recipes, as they are called, by the titles of cures for particular difeafes; and this practice has been too much followed, even by authors who have treated on the difeafes of horfes. Hence it happens, that many people, if they can but difinguifh one fymptom which is faid to attend any particular difeafe, immediately apply to their receipt-book for a cure, without troubling themfelves any further 


\section{IO OBSERVATIONS ON}

ther in inveftigating the caufe, the nature, and the various fymptoms attending different difeafes, that have a refemblance to one another; hence, very grofs miftakes too frequently happen. Thus, I have known pleuritic complaints taken for the colick or gripes, on account of fome of the fymptoms in the latter that are likewife attendant on the former complaint, and treated according to that pernicious method too much followed in cafes of colick, by giving hot irritating medicines, ardent fpirits, \&c. \&c. till the miftake has been difcovered when too late to admit of a remedy. The only fymptom that is common in the two cafes now mentioned, and which are in fome refpects fimilar, is that of the horfe's lying down frequently, and rifing up fuddenly; but there are other fymptoms which diftinguifh the one from the other, and may eafily be perceived by an attentive obferver; for inftance, pleuritic complaints are more or lefs attended with a fhort troublefome cough, which colick 
colick pains are not. It ought, therefore, to be a general rule with every man who takes it upon him to prefcribe medicines for the difeafed, to confider every fymptom with the greateft attention, and to compare them with thofe that are in any refpect $f_{1}-$ milar in other difeafes; and, when he has carefully compared them together, he will be able to make a proper diftinction, and, in a great meafure, to determine the true feat of the difeafe, fo as that he may apply the proper remedies. At prefent, I hall not profecute this fubject farther, as it will fall to be treated more properly under the head of the different difeafes.

As the method of giving drinks or drenches to horfes is generally underftood, I thall only obferve, that great care fhould be taken to compound them properly, and not to mix drugs of oppofite qualities, which do not unite or mix intimately together. From not attending to this circumftance, the drenches which are frequently given 


\section{OBSER VATIONS ON}

to horfes, are fo very naufeous and difagreeable, that they will not fwallow them; on this account, they are rejected and fpilt in the adminiftering, or, when fwallowed with reluctancy, they occafion fuch a nafuea or ficknefs, that they too frequently increafe rather than alleviate the complaints they are intended to remove. Thus, when balfams are adminiftered, if they are not properly blended with fome mucilaginous fubftances, they fwim intire on the furface of the liquid in which they are given; and hence they are poured into the mouth in their original form, the pungency of which. irritates the membranes of the mouth and throat, and occafions violent coughing, they are fpilt in the ftruggle, and the horfe may prove thy afterwards to take any thing. that is forced upon him in the form of a drench; all rough fubftances, hot fpices; ardent fpirits, wines, powders, \&c. produce this effect when they are not properly compounded; and I have frequently known pieces of folid gums, as large as a wall-nut, 
forced upon horfes in a, drench, from the prefcriber's not knowing how to difolve, or neglecting to reduce them to a powder. Venice or common turpentine (when good of its kind) is frequently prefcribed to horfes with fuccefs, when properly prepared; yet, when they are given in fubftance, without any other preparation than being reduced into a fluid ftate by the heat of the liquid in which they are given, prove extremely difagreeable by their fticking about the mouth and throat, and occafioning violent coughing. The fame obfervation holds with refpect to other balfams, \&c. Thus, by the injudicious compounding of drugs, the molt powerful medicines may be rendered of 'no effect, whilt the poor animals fall a facrifice to ignorance, and are deprived of that affifance to relieve them under their various difeafes, which it is in the power of art to give.

The proper time of adminiftering drenches is likewife of great importance, and, indeed, R r on 


\section{OBSER V.ATIONS ON}

un this circumftance, in a great meafure, depends the whole fuccefs in practice; for, however well adapted the compofitions may be at a certain particular period of a difeafe, to remove or to mitigate it, yet, in certain cales, the very adminiftering of medicines in the form of a drench proves hurtful, particularly when the throat, jaws, \&c. are fore, fwelled, and inflamed, the forcing a drench on a horfe in this critical period is followed with the moft violent fymptoms; and I have frequently obferved a fimple folution of nitre in water, fweetened. with honey or molaffes, given in the above cafes, occafioning the moft violent coughing, trembling, panting, \&xc. infomuch, that the poor animals were like to drop down, merely from the acutc pain they fuffered from adminiftering any thing by way of a drench at this critical period; the very pofition a horfe's head is put in to reccive a drench in thefe cafes, creates to him the moft exquifite pain, from the diftenfion the mufcles of the throat, \&x. undergo, when 


\section{DRINKS OR DRENCHES. 315}

when the head is held up by force, at a time when thefe mufcles, \&c. can hardly bear to be touched by the fingers even in the gentleft manner.

From what has been now obferved, it will be evident how highly imprudent it is eren to attempt the giving food or medicines by way of a drench in thefe cafes, till fuch time as the fwelling, inflammation, \&cc. are abated; and even then no medicines fhould be given but fuch as are of the emollient kind, and, at the fame time, well blended with mucilaginous fubftances, as the infution of linteed, folution of gumarabic, or the yolks of eggs, as thefe fubfances fheath or blunt the pungency or fnarpnefs of the drugs that are adminiftered.

As all herbs, feeds, \&c. of vegetables, yield their virtues readily to water, they fhould be infufed in that which is boiling, and the thin parts drained off for ufe; bal- 
316 OBSERVATIONS, \&c.

fams thould be incorporated with mucilages; gums thould be powdered or diffolved; and all drenches thould be made as agreeable as poffible, and fweetened with molaffes or honey. 


\section{H A P. XII}
O B S E R V A T I O N S
O N B A L L S.

1

A LL S for hories are fimilar to the pills that are adminiftered to the human body, and are intended to convey thofe fubftances in that folid form into the ftomach, which cannot, (or at leaft is not proper) to be done in the form of drenches.

What has formerly been obferved with refpect to drenches, may likewife be applied to balls in the general practice of farriery; they are diftinguifhed by the appellation of cures for fuch and fuch difeafes, and too frequently given with as little caution; 


\section{OBSER VATIONS}

tion; the fame confequences follow as upon the mifapplication of drenches; and hence, errors in practice too frequently occur in prefcribing them.

Balls thould be made of an oval thape, and about the fize of a fmall egg, but longer, and conveyed over the root of the tongue by the hand. To perform this operation with eafe to the horfe, the operator's fingers fhould be extended and furrounding one end of the ball, the whole hand and thumb muft be contracted inwards, in order to occupy as little fpace as poffible, the ball is then to be punthed over the roor of the tongue; the fmaller the liand is, the ball will be given with more eafe both to the horfe and to the operator. In order to prevent the fingers, \&c. from being hurt by the teeth, an iron infrument covered with cloth (which is known to moft grooms under the denomination of a balling iron) is put into the fore-part of the horfe's mouth, which kceps it at a proper 


\section{O N B A L L S.}

widenefs, having an opening of an oval form, fufficient to admit the operator's hand and arm; at the fame time, the tongue thould be drawn a little out, and held to one fide by the other hand, and kept clofe to the under jaw, which pofition contributes greatly to facilitate the operation; the inftant the ball is delivered, the tongue mult have its freedom, as it is neceffary in the action of deglutition. I would here caution the operator, that he does not pull. the tongue too far out of the mouth, without preffing it down upon the lower jaw, and keeping it in that pofition by grafping the jaw at the fame time; for, if he holds the tongue fingle by itfelf, as horfes are apt to fruggle much in thefe cafes, he may hurt the tongue confiderably, inftances of which have occurred by fuch practices; or the mufcles of it may be fo much frained, as to prevent the horfe from fwallowing any thing but with the greateft difficulty for fome confiderable time afterwards.

The 


\section{OB S E R A T IONS}

The adminiftering of medicines in the form of balls is preferable in moft cafes to that of drenches, as the operation of giving them, when rightly performed, gives the horfe no fatigue; the dofe prefcribed is conveyed with certainty into the ftomach, without any diminution or lofs of its quantity.

Farriers have one great advantage in adminiftering medicines to horfes, viz. That, if they are properly compounded and adapted to the difeafe, once they can convey them into the ftomach, they cannot be thrown up again, the ftomach not poffeffing the power of vomiting. From the fame caufe, on the other hand, the effects of hurtful or injudicious prefcriptions muft be pernicious in their confequences.

In compounding balls, after the ingredients are properly prepared, they mult be made into a fiff pafte, by the addition, if neceffary, of balfams, fyrups, mucilages, molalfes, 
molaffes, or honey, the mafs then divided into one or two balls of a proper fize, according to the dofe prefcribed. It is likewife neceffary, when they are to be kept for any length of time, to have them tied up in a bladder, and rolled in fome dry powder, as flour, liquorice, \&c. in order to prevent them from fticking together.

It is common to make up large quantiiies of balls for horfes in too great a mals at once; this requires attention; for, if great care is not taken that the different ingredients are thoroughly incorporated with the general mafs, they will be unequally divided, too great a proportion of one ingredient being in one ball, and too little in another; therefore, when any prefcription that requires nicety in the dofe is recommended, every ball thould be made up fe. parately, with the exact quantity prefcribed in each, as in purging balls, \&zc.
S s
C H A P. 



\section{C $\quad$ H. A $\quad$ P. XIII}

\section{O B S E R V A T I O N S}

O N D I U R E T I C S.

T NER this head are included thofe medicines whofe moft remarkable propertics appear in their increafing the difcharge by urine, or which are faid to remove obftructions in the urinary paffages.

They are fuppofed to lubricate or foften the fibres which compofe the urinary glands and canals, and, by their attenuating and deterfive properties, rarify and thin vifcous or thick humours, fo as to render them fic to pafs through thefe canals, which they could 


\section{OB S E R V A T O NS}

could not do in a vifcid ftate; but, whichfoever of thefe ways they operate, it is well known that they are of fingular ufe in promoting the difcharge by urine, by which difeafes are not only frequently carricd off; but actually cured with expedition; and, in many cafes where purging medicines are prefcribed, diuretics would be much more preferable, as they may be ufed with greater fafety, more efpecially when it is confidered that the chief effects of either of thefe prefcriptions tend only to leffen the quantity of fluids in the body. Hence it will appear how falutary and beneficial medicines of this kind are to horfes in a great variety of cafes, but more particularly in thofe where any obftuction has taken place in the urinary veffels, attended with difficulty in ftaleing, a complaint which horfes are very fubject to, owing to a variety of circumftances. From this confideration, is will likewife be obvious how neceffary it is to allow horfes, which are upon a journey or travelling long ftages, 
to ftand fill at times, in order to let them make water; from a neglect of this kind, many horfes are killed; for, when the bladder has been overful, and diftended beyond its natural dimenfions, it turns paralytic, and lofes the power of contracting itfelf again for fome time, fo as to expel the urine immediately; hence dangerous fymptoms enfue, which, if not fpeedily relieved, prove fatal. Befides, when the urine is too long retained in the bladder, it is not only reabforbed or taken up again into the mafs of fluids, but, by ftagnating, it becomes thicker, the more watery parts being carried off firt by abforption, the more grofs and earthy parts remaining behind, and the tendency which thefe particles have to concrete may promote the formation of gravel, \&xc.

Diuretic medicines are moft frequently adminiftered in the form of balls, but, in fome circumftances, they may be given in the form of powders in the food. Nitre 
is not only an alterative, but it acts as a powerful diuretic to horfes, and, in fome cafes, may be given from one to four ounces a-day, according as. circumftances may require.

To coarfe horfes, or thofe of robuft. ftrong conftitutions, from two to four ounces of yellow rofin in powder may be put into their food, and repeated for two or three times, at proper intervals, according as it is found to operate in cafes of fwelled legs, greafy heels, \&c.; and it ought always to be obferved, that, when diuretic - medicines are given, the horfe fhould be indulged with plenty of water to drink during the time they are operating.

The cafes which require diriretic medicines, and which occur moft frequently, are when any difficulty is obferved in a horfe's making water, or when liable to frequent attacks of the Atrangury, or fuppreffion of urine, when the urine appears 
too thick, turbid, or difcoloured, whether it be red, yellow, or black; when there are fymptoms of any latent diforder, attended with a dulnefs or heavinefs in the horfe's looks, a ftaring dufty like coat, local fwellings on any part of the body, as on the belly, Theath, or legs"; running fores about the latter, commonly called the greafe, \&c.; in cafes where there are eruptions or pultules on the furface of the fkin, or when the horfe appears itchy, and frequently rubbing himfelf againft the ftall, \&x.; or in rubbing one leg againt the other, although no eruption appears on the fikin; in running thrufhes, cracks, or ulcers about the heels; in baldnefs, or lefing the hair on different parts of the body; in moft cafes where a courfe of diuretic medicines are prefcribed, bleeding will be neceffary before they are given. Regular exercife muft by no means be omitted, even during the time they are operating. The ufe of diuretics fhould not be continued too long 
328 OBSERVATIONS, \&c.

long at one time, as they weaken the body confiderably, and, as foon as the diforder for which they were given is removed or abated, they fhould be left off. 


\section{C $\quad H \quad A$ P. XIV。}

\section{OBSERVATIONS ON GIVING ME-}

DICINES AS PRESERVATIVES OR

\section{PREVENTATIVES.}

L A VING formerly nade a few re-

11 marks on the caution that is neceffary in giving médicines at certain times of ficknefs or difeafe; I thall now make a very fhort obfervation relating to the praca tice of giving horles medicines whilft they are in health, by way of preventing difeafes; a practice which, probably, has originated from a fimilar cuftom in ufe amongtt the human fpecies, in taking medicines as prefervatives or preventatives, without any knowledge of their medical $\mathrm{Tt}$ qualities, 


\section{$33^{\circ}$ OBSER VATIONS ON}

qualities, only becaufe the practice has the fanction of cuftom.

If a man or a horfe is in a fate of health, what more is required, or how can they be made better; health is the moft proper fiate of an animal body, and it is not in the power of medicine either to make if better, or to preferve it in the fame fate. A good medicine given feafonably, when there is an appearance of fome latent diforder, or fome derangement in the body, which would, in a fhort time, occafion its breaking out, may prevent it from taking place, by carrying it off. The fame medicine given in a fate of health, will produce an alteration in the fyftem, by increafing or diminifhing fome of the natural fecretions, or difurbing the animal functions; or, even allowing that it did not produce any of thefe changes, fill it leaves the body jutt as liable to the impreffions of difeafe as before. Befides, the cultom of giving medicines too frequently is a bad one; 
one; they become' habitual to the conftitution, which renders them totally inefficacious, when neceffary, or, at leaft, their effects are greatly impaired. This is but too vifible in many of the human fpecies, who indulge themfelves in the pernicious cuftom of drinking drams; hence, what in certain cafes would prove a cordial, lofes its effeet upon them. And there are but too many examples of people who have contracted the habit of taking medicines under the titles of ftomachic cordial, \&cc. \&cc. who have injured their health, and impaired their conftitutions, though otherwife naturally ftrong. Many arguments might be drawn from the analogy that fubfints between the human body and that of a horfe, to how the impropriety of the too frequent or injudicious exhibition of medicines to horfes whilf they are in health, and the pernicious effects which arife from this practice, can hardly efcape the notice of any but thofe who are blinded with prejudice. 


\section{OBSERVATIONS ON}

The medicines which are commonly adminiftered to horfes, by way of prefervatives or preventatives, are generally compofed of hot powders, aromatics, fpices, $\& c$. together with a number of other ingredients of the like qualities, under the denomination of cordials, \&c.; thefe are faid to heat and invigorate the ftomach, and thereby promote digeftion. But, if a horfe is otherwife in health, this defireable end is brought about in a much more natural way, by a moderate wholefome diet, and rcgular labour or exercife, or, in other words, by proportioning the food to the labour or exercife which the horfe undergoes.

There are likewife more powerful, and indeed more efficacious medicines, that are too frequently given to horfes in health, under the title of alteratives, which prove of great benefit, when properly prefcribed, in difeafe; although, at the fame time, it pught to be obferved, that they fhould ne- 
ver be given but when there is an appearance of fome latent diforder.

By alteratives are underftood the giving of certain medicines, which are faid to change the humours or juices of an animal body from a morbid or difeafed ftate to that of health; they have no immediate fenfible effect, but gain gradually on the conftitution, and are followed (if the vifcera are found) with the moft falutary effects, by promoting the natural fecretions which had been retarded or obftructed in their progrefs through the pores of the fkin: But, in this cafe, a difeafe is implied, and, of courfe, fuch things may be neceffary.

The medicines given under the denomination of alteratives, are antimony in its different preparations, mercury, fulphur, aloes, and falts. The former of thefe, efpecially the coarfer kinds, are generally given too frequently, in too great quantities, and in too grofs a ftate, which fometimes 


\section{OBSERVATIONS ON}

times brings on great ficknefs, or violent purging; and, in fome conftitutions, in place of promoting the cuticular fecretions, \&xc. they occafion a great heat and drynefs of the fkin, which is frequently fucceeded with a number of hard lumps, or with blotches, on'different parts of the body. Sulphur not only opens the body gently, but it readily makes its way through the pores of the fkin, and, therefore, it ought to be ufed with caution, as horfes are very apt to catch cold upon the too liberal ufe. of it, which may occafion a worfe complaint than it was intended to remove. Aloes given in fmall quantities, by way of an alterative, and too frequently repeated, as is fometimes the cafe, weakens the ftomach and bowels, fo as to bring on a lax, or what is called a warhy habit of body; it ought therefore to be prefcribed with caution to delicate horfes, and only given to coarfe robuft horfes, who are of a full habit of body, and newly taken from late 
grafs, or that have been accultomed to foul feeding, as grains, boiled chaff, \&c.

Salts, efpecially fal nitre, fal prunel, or common falt, are the beft and fafeft alteratives that can be given to horfes; they feem to agree with their conftitution, with this advantage, that they require no cloathing nor confinement during their operation, nor is the free ufe of them attended with any of the above difadvantages. But, at the fame time, it would be abfurd to prefcribe them without fome apparent caufe. Nitre is of great fervice in all inflammatory camplaints; it not only allays the great heat of the blood, which is common on thefe occafions, but it is an antidote againft putrifaction, to which the fluids of an animal body, in the end of thefe complaints, are greatly difpofed; it likewife promotes the natural fecretions, particularly that of urine, and is one of the beft and the fafeft medicines that can be given to horfes on fuch occafions. Common falt given to horfes, 


\section{$33^{6}$ OBSERVATIONS ON}

horfes, which do not appear to thrive when there are no fymptoms of an inflammatory difeafe, has a very good effect; it promotes digeftion, and the natural fecretions; it makes them take on flefh and coat well.

I would not be underftood to prohibit the moderate ufe of antimony as an alterative; I have only hinted at the bad confequences on giving the coarfer kind ill prepared, and frequently as injudicioully prefcribed. The antimony that is coarfe and black like gun-powder, fhould always be rejected. The beft antimony is ponderous, and compofed of long thining ftreakes like needles; it ought always to be levigated into the finet powder. 


\section{I A P. XV. \\ O B S E R V A T I O N}

O N

\section{MOULTING OR CASTING THE HAIR.}

H ROM a variety of circumftances obfervable about horfes towards the end of autumn and beginning of winter, it would appear, that fome particular change feems to take place in their conftitutions, which, at the fame time, is attended with a degree of faintnefs or weaknefs peculiar to that feafon. This may arife from a variety of caufes combined together; but the principal one, I apprehend, may proceed from that of moulting; for, although horfes in general do not caft their coats of hair at

$$
\mathrm{Uu} \text {. this }
$$


this feafon as they do in the fpring, yet, as a confiderable change takes place on the thicknefs and length of their hair at this period, it may properly be called their moulting feafon. The Count de Buffon, in his third volume, page 379 , fays, That " horfes of all colours, like molt animals " covered with hair, moult or calt their " hair every year, commonly in the fpring, " and fometimes in the autumn; as they " are then weaker than at any other period, " they require more care, and Thould be " more plentifully fed." As this obfervation of the Count's is in the general, and not limited to any particular climate or country, I fhall juft offer a few hints on the appearances which attend the moulting of horfes in this country, with the difeafes that prevail at this period.

It would be tedious to particularize the various fituations in which horfes may be kept, fed, and worked, \&cc. and to rake notice of their cafes feparately, and the difeafes 
difeafes that may follow on the difference of treatment they may be expofed to; the hints that are here offered may fuffice at prefent, as they may lead to farther difcoveries and improvement in the knowledge of the difeafes of horfes at this period.

As thofe horfes that are kept in warm ftables, and well fed through the winter. are hearty and vigorous in the fpring, when the feafon is gradually turning milder and warmer, their moulting at this feafon is not attended with that faintnefs, \&c. to which they are liable on their moulting towards the end of autumn. The reafon of this is obvious; the food of horfes in the fpring is dry, and free from all fuperfuous moifture, of courfe, it then produces richer and better nourifhment; hence, they are more lively, active, and vigorous; to which caufe may likewife be added the change of the feafon which then takes place, and which is more agreeable to their conftitutions, 
tions, and contributes greatly to chear and enliven them.

But, towards the end of autumn, it is very different with the generality of horfes, and even with thofe that are kept in the beft manner, but more efpecially with thofe who have been fed with new hav, new grain, or with the late grafs, and, at the fame time, are compelled to undergo fevere labour, or active exercifes; fuch food, at this feafon, abounding too much with water, produces lefs nourithment, and fills the veffels with what may be called a fuperfluity of watery fluids; this caufe alone will produce a general laxity of the mufcular fibres of the whole body; and, in this lat cafe, it increafes that languor and weaknefs which fo generally prevail during the time of moulting.

It is obferved, that thofe horfes who are kept in warm tables, and well fed, moult carly in the fpring; thofe that run abroad 
at grafs moult much later. But, if the former thould be expofed to cold winds or rain for any length of time together, by being turned out to pafture, or from their being in any hape expofed to cold weather, after they have once moulted, or caft their winter coat, that their hair will then grow thicker and longer, the fame as it does in the beginning of winter, and continue fo till the feafon turns milder, or that they are kept in warm ftables; in this cafe, fuch horfes may be faid to have moulted twice in the fpring.

The coldnefs, chillinefs, and moifture of the weather, which commonly prevails at this feafon in Britain, may likewife be added as another caufe which contributes to increafe this general diforder by occafioning a conftriction of the cuticular pores of the fkin; for it is obferved, at this period, that the hair of the generality of horfes ftares or ftands on end, (according to the ftable phrafe;) at the fame time, their fkin commonly 


\section{O B S E R V. A T I O N S}

monly feels dry and hard, or what is called bide-bound; and notwithltanding they, for the moft part, fweat moft profufely when they are put to any hard labour, or active exercifes, merely through weaknefs, and the laxity that then prevails in their conftitutions; yet that natural infenfible perfpiration, as it is called, which always takes place in a healthy ftate through the pores of the fkin, and which occafions or produces that hining, gloffy, and fmooth appearance on the fkin and hair, feems at this period to be almoft fuipended; in fuch a fituation and circumftances, they are difpofed, upon any irregularity in the management of them, to fall into difeafes of various kinds, more efpecially thofe, which proceed from obftructed perfpiration; from this general conftriction of the cuticular pores of the fkin, that fluid which ought to pafs off by infenfible perfpiration, is retained in the body; hence, the quantity of fuids in the veffels being increafed, thefe, together 
iogether with the general relaxed ftate of the mufcular fibres through the whole fyftem, derange the circulation; hence proceed thofe fwellings of the legs, \&c. fo common at this feafon, and which is frequently attended with running fores, or what is called greafy heels, \&c. \&c.

Horles who have got the early fpringgrafs, and afterwards are kept on hay, with a good allowance of grain, and daily accuftomed to moderate excrcifes, fuffer no material injury from moulting in the autumn, farther than their being more liable to catch cold at that time, from the alternate changes they are expofed to, viz. being kept in warm ftables, and, perhaps, in body cloaths, and fuddenly expofed to the chillinefs and moifture of the weather when they go abroad, and before their coats of hair have grown fufficiently thick to refift the cold.

Horfes, 
Horfes, who run at grafs through the fummer, and whofe bodies are fat and full of fluids, if expofed to active or laborious exercifes, are liable to many difeafes about the time of moulting, as the interval from the time they are taken from grafs, and the moulting, is too fhort to admit of their bodies being brought into that particular habit neceffary to enable them to perform thefe exercifes with fafety to themfelves; they fall into that languor, \&c. peculiar to this feafon; and, if fuffered to ftand in the ftable too much at reft, the habit of body they are in difpores them to fevers, diforders of the lungs, fwelling of the legs, glands about the throat and jaws, and running fores about the former, neither are they able to undergo common exercifes, without being more than ordinary fatigued and jaded.

Thofe horfes who run at grafs through the fummer and autumn, are ftill in a worfe fituation, they are not only more liable to the 
the difeafes above mentioned, from the very lax habit of body they are in at this time, but lefs fit for active exercifes of any kind, and require a longer time, even with the utmoft care and attention, to bring their bodies into that ftate in which they may undergo active exercifes with impunity. This period, in particular, proves critical with them, and, if laborious exercifes are perfevered in, they generally fall a victim to difeafe.

It very unluckily happens, that, in the fituations above mentioned, the means commonly ufed to render the bodies of horfes fit for active exercifes, or to carry off the appearance of difeafe, as fwelling of the legs, \&c. are evacuations of every kind, as bleeding, purging, rowels, diuretics, \&c. \&c.; at the fame time, thefe prefcriptions through impatience of the keeper or owner, are hurried on with too great a precipitancy, that would even affect a horfe in the foundeft ftate, and moft hardy habit of body, at any feafon, and reduce him to $\mathrm{X} \times$

great 
great weaknefs; the moulting comes on, which ftill adds to it: In thefe circumftances, the conftitution receives fuch a thock, as even that of a horfe cannot refint it; hence many of them fall a facrifice to this treatment, and, if they fhould furvive, they are attacked with fome lingering chronic diforder, which renders them a burthen and expence to their owners.

The end of autumn likewife proves very fevere on thofe horfes whofe flefh and firength are exhaufted from continued hard labour, or violent exercifes, as pofting, \&c. through the fummer and autumn; when the moulting comes on in this low fpiritlefs ftare of body, it carries off great numbers of them, that by proper care in moderating their labour, together with good nurfing, and feeding them with rich boiled food at this time, their lives might be preferved. Such foft nourining food becomes the more neceffary for horfes of this defcription at this particular period, in order to fupport them 
them under the moulting, as the ferous or watery parts of their fluids have been drained off by the violent perfpiration they have been expofed to, their mufcular fibres are then too rigid, and the blood too thick, for circulating fo freely as it ought to do thro' the fine capillary velfels; hence they are difpofed to fall into thofe diforders which proceed from this caufe.

Many of thofe horfes that are thought to be wore out from polting, \&xc. at the end of autumn, when they come to be fed with boiled food, or with potatoes or carrots, and continued fo through the winter, recover furprifingly. This laft mentioned food recovers their Alesh; it renews their fluids in general, and promotes all the natural fecretions; it operates on them nearly in the fame manner as the fpring grafs; it purges them gently on the firft ufe of it, and corrects the whole habit. On changing their food to that which is hard and dry, as oats and beans, and increafing their exercife 
ercife gradually towards the fpring, they foon become fit for the moft active exercifes, without any previous preparation from medicine, \&c.

This feafon likewife proves deftructive to aged horfes; when the green food is exhaufted, they are then obliged to feed on hard dry food; in fome, the digeftive powers may not only be weaker, but the teeth, at the fame time, may be defective, in not breaking down the hard food fo minutely. as it ought to be, in order to render it fit for digeftion, and the nourifhment of the body. Cafes of this kind have occurred in my practice, from which I conclude, that horfes are fometimes fubject to difeafe in their teeth, refembling that of the toothach in the human body, of which I thall give the following inftance. About the period above mentioned, a diftiller fent me an aged horfe, in order to infpect his mouth; the accounts I received of him were, that he feemed much inclined to eat dry 
dry food, fuch as hay, oats, \&rc. but that he no fooner filled his mouth with the former, and attempted to chew it thoroughly, than he let it drop out; he then took up a frefh quantity, which, after a few turns in his mouth, he dropt in the fame manner as the former, without being able to chew it fo fmall as to fwallow it; the oats, \&c. which he had eat, were paffed whole; in fuch circumftances, his body was confiderably emaciated from the want of nourifhment, as the only fupport he had had for fome time, was from grains and other dregs about the diftillery, which he fwallowed in the ftate they were given him. On infpecting the horfe's mouth, I obferved a part of the outter cheek-tooth, for grinders, as they are commonly called in horfes), on one fide of the upper jaw, overgrown, at the fame time projecting over the under tooth, and fo long, that it reached the gum on the under jaw; hence, when the horfe attempted to chew his food, this overgrown tooth fretted or wounded

the 
the jaw below it; from this laft circumftance, it may be inferred, that the pain arifing therefrom marle the horfe give up the attempt of chewing his food, as related above.

After this excrefcence on the tooth was broke off, the horfe eat very heartily of whatever kind of dry food he could come at, he recovered his flefh and ftrength, and became as ufeful to his mafter as formerly. On infpecting the part of the tooth that was broke off ${ }^{*}$, it was obferved to be hollow longitudinally, it likewife had a large hole tranfverfely through the enamel, which admitted the thick end of a hen's wing feather; at the fame time, it had all the appearances that a rotten tooth has, when drawn for the tooth-ach in the human body. From the cafe now men. tioned, it will be obvious how neceffary it is to infpect the mouths of horfes when they do not feed well, as even middle aged horfes are fomecimes troubled with fuch tharp

* This tooth I have ftill by me. 
Tharp excrefcences on the teeth; when they rife on the outfide of the jaw, they wound the cheek in maftication or chewing; when on the infide, which is more rarely to be met with, they wound the tongue; when they project beyond the end of the teeth in the oppofite jaw, as mentioned above, they not only wound the oppofite jaw, but their length prevents the teeth or grinders from coming fo clofe together as they ought to do, in order to break down the food minutely, fo as to render it fit for digettion, to be converted into nourifhment. In books of farriery, thefe excrefcences are termed wolves teeth. It is a pity a good old fervant hould be loft through the infirmities of age, when his complaint may be fo far paliated, as to prolong his fervices; yet many good aged horfes are loft from not attending to fuch circumftances as have been now mentioned; for, alchough horfes in fuch fituations can make fhift to live on green fucculent food, whilt it is good, and which does not require much chewing, and, 
at the fame time, perform their ufual labour, yet, when they come to be fed with. hard dry food towards the end of autumn, it occafions a very material change; their lofs of flefh, \&cc. foon difcovers that there is fome defect, either in the digeftive powers, or in the food not being properly broke down; hence, from the want of nourifhment to fupport them under the natural faintners, \&c. which prevail in the conftitution of horfes during the time of moulting, it is obferved, that more aged horfes die at this time than at any other period.

As the diforders which commonly prevail at this time amongt horfes, proceed in a great meafure from catching cold, together with the ficklinefs attending the moulting, horfes are differently affected, according to circumftances of habit of body, and the treatment they may be expofed to; fome are affected with colds in the head, attended with inflammation and fwelling of the glands about the throat and jaws, which 
too frequently, from want of proper care, terminate in the glanders; hence this diforder is frequent at this feafon: Some horfes are affected with coughs, and other diforders of the lungs. Rheumatifm is likewife common in different parts of the body, particularly in the neck, which is called the chords. Epidemical difeafes frequently originate at this period, and continue with more or lefs violence through the winter, and fometimes till towards the fpring. Fever is likewife common, together with a variety of other complaints, which would be tedious to mention. A!l thefe diforclers, as I have formerly oblerved, are forwarded from the above circumftances, together with horfes breathing, a heated foul air in their ftables, and their bodies expofed fuddenly to the chillnefs of the weather, before their coats of hair have grown fufficiently thick to refint the cold, \&x. for it is oblerved in thofe horfes who run abroad in the ficlds day and nighr, that they moult much fooner in the feafon; by which means they are fufficiently gruardY y

ed 


\section{O, BSER VATIONS}

ed againft the feverity of the weather when it becomes cold and damp; neither is it obferved that they are fo liable to be affected with thofe epidemical difeafes which prevail amongt horfes that are kept in too warm ftables. This fickly difpofition amongt horfes continues with more or lefs violence till fuch time as the weather turns more favourable and dry, or that the froft fets in. It commonly commences, if the weather is moift, cold, and damp, about the middle of October, and continues till towards the middle of December : After which, if it is favourable, horfes generally turn 'more lively and vigorous, and acquire their ufual fpirit, and healthy appearance, \&c.

From the hints now offered, it may be obferved, that as horfes are generally more weakly at the time of moulting towards the end of autumn than at any other feafon, their exercifes or labour, when circumftances will admit, hould be moderate.

Their 
Their feeding thould be increafed in order to ftrengthen and fupport them during this period. It ought likewife to be of the very beft quality, as old hay, old grain, that is, of the preceding year's growth; and if the grain that is given them was broke down in a mill, it would prove more nourifhing than in any other way it could be given them. New hay, or new grain of the fame year's produce, ought to be avoided, as it is extremely hurtful to horfes, who muft undergo fevere labour, or active exercifes, of which I have formerly taken notice of. Good rubbing and frequent dreffing are likewife of great benefit.

All evacuations, fuch as bleeding, purging, rowels, \&c. ought to be adminiftered with caution, as fuch prefcriptions contribute greatly to increafe that natural weaknefs, \&c. formerly mentioned, which prevails in the conftitution of horfes at this period. At the fame time it is to be underfood, that horfes are not by any means 


\section{6, OB SER V A T I ONS}

to ftand too much at reft in the ftable. Frefh air, with moderate exercife, when the weather will permit, being abfolutely neceffary to promote their health; neither is the proper ufe of the above prefcriptions to be neglected when they are thought neceflary, and prefcribed with judgement. All the precautions formerly mentioned, with refpect to their ftables, ought to be attended to, that they are kept clean, well ventilated, and kept moderately warm. Body-cloaths, however neceffary they may be thought for keeping their coats of hair fine, fmooth, and clean in the ftable, ought to be difpenfed with, as horfes cannot with propriety be rode with them; they muft therefore be fripped the moment they are to go abroad, even although they fhould happen to be in a ftrong perfpiration at the time; by which means they are liable to catch cold, \&c. And furely the the healch of a horfe is of much more confideration to his proprietor than the looks 


\section{ON M OULTING.}

or appearance of his coat of hair, efpecially when it is confidered, that good rubbing and frequent dreffing will produce the fame effect on the appearance of the hair. At the fame time that this operation will in a great meafure prevent the confequences above mentioned, of rendering horfes fo very liable to catch cold. One fingle rug or theet is fufficient covering for horfes whilft in the ftable: More proves hurtful. 



\section{C $\mathrm{H}$ A P. $\mathrm{XVI}$}

\section{O B S E R V A T I O N S}

$$
\text { O N }
$$

\section{$\begin{array}{llllllll}L & A & M & E & N & E & S & S \text {. }\end{array}$}

$7 \mathrm{HE}$ fteps of a horfe in a found ftate

1 are equal and uniform; a certain harmony fubfifting in the motion of the whole body and limbs, any deviation from this harmony, or defect in moving the legs, is termed lamenefs.

Various are the caufes which may occafion lamenefs, and, frequently, a combination of caufes may take place at one and the fame time in different parts of the fame limb; 
limb; for inftance, a prick with a nail in the foot, and a ftrain in the tendons of the legs, the ligaments of the joints, or in the fhoulders, happen frequently together; for, as the pain arifing from the nail in the quick caufes the horfe to trip and Atumble in riding, an exertion to fave the pained foot may, and indeed frequently does, occafion the ftraining of the ligaments of the joints, or the tenuions, \&xc. of the legs; and thus a complication of the caures of lamenefs is produced. The fame effects are likewife produced from excrefcences growing upon the bones of the legs, which occafion pain; an exertion of the horfe to fave the pained limb may occafion the ftraining fome of the mufcles in the fhoulders, \&c. Here it may be neceffary to make a remark on what is commonly, though very erroneoufly, called a fhoulder flip; this phrafe is much in ufe, and may be fuppofed to imply a diflocation or a feparation of the fcapula or thoulder-blade from the ribs, a circumftance that never can 


\section{ON L A M E N E S S. . 36 I}

happen to this bone, from the nature of its junction with the ribs; for the fcapula or fhoulder-bone is not fixed to the body by any articulation or joint, but by appofition, that is, laid alongft the outfide of the ribs, and there faftened by the mufcles, \&c. which lie both on the infide and outfide of the fhoulder-bone; hence, therefore, it is evident, that the mufcles and tendons of the fhoulders may be overAtretched or Atrained, but the bone itfelf cannot flip out of its place without a force fufficient to deftroy the texture of the mufcles, \&c. which form the junction with the ribs; the ligament which furrounds the articulation where the humerus joins with the fcapula, at the point of the fhoulder, is no doubt liable to be injured from ftrains, \&x. in common with other joints of the body; but I never knew or heard of one inftance of its being diflocated in a horfe, although it is poffible that it may happen. Hence, therefore, the term of fhoulder-

$$
\mathrm{Z} z \text {. }
$$


flip is improper, and only tends to millead the young and unexperienced.

Lamenefs frequently proceeds from tumors growing upon the bones of the legs, or on thofe immediately connecled with them; thefe are commonly termed in horfes fplents, fpavins, osflets, ringbones, \&cc, and are diftinguifhed or named from the particular part of the limb on which they grow. But, as thefe bony excrefcences, (or exoftofes, as they are called in the human body), are not limited to particular parts of the legs, but they grow on every bone of the body, and fometimes are concealed in fuch fituations, that it is impoffible they can be difcovered, although their effects in caufing lamenefs, when connected with the parts that are conducive to motion, are very apparent; inftances of which might be met with almoft every day, if horfes were more frequently diffected. Thus, a houlder-bone, which I had carefully preferved, and which is now in the poffeffion of the Right 


\section{ON L A M ENESS. $3^{6} 3$}

Right Honourable the Earl of Pembroke, has an exoftores of this kind, about the fize of a large nut, on the thinnelt and molt tranfparent part of the bone on its infide, which is placed next to the ribs; the horfe was lame for feveral years before his dearh, but the caufe of his lamenefs could never be difcovered till after diffection; this bony excrefcence was fo fituated as to prefs upon the middle of the fub-fcapulary mufcle, and could not fail to impede its action, and occafion lamenefs.

Something of the fame nature as thefe exoftofes likewife takes place on the fmall bones of the joints, efpecially in thofe of the hind-legs; the offeous or bony matter proceeding from fome morbid caufe, forming a number of fmall tumors between the joints, and cementing or joining two or more of thefe bones together, which, by impeding the action of the joint, occations lamenefs. 


\section{OBSER VATIONS}

Many people flatter themfelves that they can take off moft of thefe bony excrefcences, by bliftering, \&c. even after they have acquired their utmon folidity; but thore who are acquainted with the anatomical ftructure of the parts, the folidity and broad bafis of thefe bony tumors, together with the firm connection they have with the bone on which they grow, will readily fee the impracticability of this method fucceeding. It is true, in fome cafes, where thefe tumors have a narrow bafe, they may be chopt off with a chiffel; but, at the fame time, it will be evident, that this operation mult, in many cafes, be attended with confequences much more detrimental to the horfe than the fplent, \&c. would be in its fuileft growth; befides, a caries in the legbone may follow from this operation, and the cicatrix that remains will disfigure the horfe more than the excrefcence would have done in its full extent; many fplents of an uncommon large fize are daily feen on horfes legs, yet they go quite found. Hence, therefore, 


\section{O N L A M E N E S S. $3 \sigma_{5}$}

therefore, it is obvious, that it is not the fize or largenefs of a fplent that caufes lamenefs, after it has grown to its full exrent, but its interference with fome of the other parts that are fubfervient to motion of the leg, where, by its connection, it impedes their motion, and caufes lamenefs.

It likewife frequently happens, that thefe excrefcences grow up between the two fmall bones on the back part of the forclegs, and immediately under the tendons, the grooves or hollows that are there formed on the furface of the excrefcence, whilt it is in its foft ftate, by the friction of the tendons, evidently fhow that they have been impeded in their motion, which will produce lamenefs. In this fituation, it becomes impoffible to apply any remedy whatever to remove this excrefcence; befides, it frequently happens that the legbones, in fuch cafes, are confiderably enlarged, for which there is no cure; this will be farther evident on infpecting the 


\section{O B S E R V T I O N S}

bare leg-bones, that may be found almoft in every field where dead horfes are laid; a number of fuch bones $I$ have now in my poffeffion.

Van Swieten, in his fourth volume of commentaries, page 426 . has the following remark on the effeets thefe excrefcences produce in the human body on their firft rifing, and which is applicable to the prefent purpofe in horfes: "But," fays he, " as cxof" tofes, (that is, bony excrefcences), riling " on the outfide of the bones, mult necef" farily diftend by degrees the incumbent " periofteum, very troublefome and lafting " pains will fometimes follow from thence, " and fuch as are exceeding tharp; but " yet will ceafe the fooner, if the exolto"fes be pointed." The fame author mentions a cafe of one of thefe exoftofes, from M. Petit, which grew upon the leg-bone with a tharp point, and rofe above the furface of the bone the length of four geometrical lines, which, in the beginning, was 


\section{O N L A M E N E S S. $\quad 367$}

attended with very tharp pains, that gradually decreafed, and at laft went entirely off, leaving the bony tumor quite indolent.

That the fame effect is produced by thefe excrefcences growing on the leg-bones of horfes, called fplents, is very evident from their firtt beginning to rife on the outfide of the bone, they diftend or overftretch the periofteum which covers the bone; this creates pain, which is followed with lamenefs in horfes; but, when this membrane is either divided, ruptured, or becomes benumbed by the diftenfion it has undergone, the pain arifing from it ceafes, and, unlefs the excrefcence communicates with fome other bone, or preffes on fome of the parts that are conducive to motion, as the tendons, \&c. the lamenefs goes off, although the tumor on the bone remains in its full extent.

Lamenefs likewife proceeds from rheumatic pains in different parts of the body, which 


\section{OBSER VATIONS}

which frequently change from one place to another, and from cramps, fpafms, fciatica, \&x. all of which produce lamenefs; the true feat of which, in fome cafes, cannot be afcertained with any degree of certainty. Other caufes of lamenefs are more eafily difcovered from their external appearance, or the fymptoms which attend them, as a fwelling of the parts affected, attended with pain to the animal upon touching them; of this kind are ftrains or fprains, whether of the ligaments of the joints, or the mufcles and tendons of the legs and thoulders.

Lamenefs likewife proceeds from blows, occafioning contufions or bruifes, or from wounds and punctures, from watery or running fores about the legs or heels, under every denomination whatever, as in thefe cafes the legs are more or lefs fwelled and inflamed, of courfe they are ftiff and unfit for action. 


\section{O N L A M E N E S S. 369}

Lamenefs likewife proceeds from long and continued violent exercife, which occafions too great a wafte of the fynovia or oily liquor which lubricates the joints; hence they become ftiff, and, on the horfe's moving, make a crackling noife. It is likewife produced from a variety of other caufes, which are confined to the hoofs, as pricks from nails in thoeing, wounds in the hoofs from nails picked up in the freets, glafs, fharp pointed bones, \&x. which penetrate into the quick, from injudicious thoeing, and paring the hoofs to excefs, or fuffering them to grow too large and long at the toes, by which the feet grow benumbed, a partial contraction taking place at the coronet and heels, or a contraction of the whole hoof, which is commonly known by the' name of hoofbound. This laft difeafe is greatly forwarded by keeping the horfe's legs and hoofs too hot and likewife too dry, by means of a great quantity of litter, and, perhaps, hot dung at all times under them.

$$
3 \mathrm{~A} \quad \text { The }
$$




\section{OBSER VATIONS}

The practice of the Arabians, formerly mentioned, ought, in this refpect, to be adopted, which is, wafhing the legs of their horfes frequently through the day with cold water; and, although it be not exprefsly mentioned by the Count de Buffon, from whom the paffage alluded to is quoted, yet it may be inferred, that the hoofs, at the fame time, are moiftened by the water. This kind of treatment is natural to horfes hoofs; at the fame time, it not only keeps the legs cool, but it contributes to brace and frengthen the mufcular and tendinous fibres, and prevents fwellings, \&rc. in them. How differently treated are the Britifh horfes in this refpect? no fuch precautions are ever intentionally ufed to them, but directly the contrary; it may literally be faid, that they are compelled at all times (when in the ftable) to ftand on a hotbed; at the fame time, their hoofs are bafted with greafe, oil, $\operatorname{tar}$, or turpentine, things perfectly foreign, and of a direct oppolite quality to the intention of applying them; by which means, the generalit: 
O N L A M E N E S. 37 E

generality of fine horfes, that are much kept in ftables, fooner or later, become cripples.

Lamenefs likewife proceeds from corns, Junning thrufhes, from gravel infinuating it felf between the thoe and the fole of the foot, efpecially in weak hoofs, or by forming a lodgment there, it at laft penetrates into the quick which is called graveling.

There is likewife another kind of laneners peculiar to the hind-quarters, and which occafions a fudden jerking of the legs upwardis on moving; by fome it is called fring-halt; and by others click-fpavin. This complaint feems to be a particular affection of the nerves of the legs, which caufes this kind of involuntary motion, for which no certain method of cure has as yet been difcovered.

From all thefe, and a variety of other caufes, lamenefs is produced, the true feat of which, in many cafes, cannot be difco- 
vered by any external appearances; hence, practitioners ought to be very cautious in giving their opinions of the caufes of lamenefs, before they pofitively determine on the particular feat of the difeafe, or the caufe which produces it, without their having a fufficient or a vifible proof to fupport their opinion, and be enabled, from the nature of the cafe, to prognofticate the event, or the fuccefs, in performing the cure; for how frequently has it happened, from want of this precaution, together with a too fuperficial infpection of the parts, and too hafty a determination as to the feat or caure of lamenefs, that applications have been made to the found parts, whilft the real caufe has foon afterwards thown itfelf to be elfewhere, perhaps in the hoof, to the thame and confufion of the practitioner. Therefore, unlefs the caure of a horfe's lamenefs is perfeetly evident, it will be prudent to examine at all times the foot of the lame limb firtt with care and attention; and, if it hould ftill appear doubtful, 


\section{O N L A M E N E S S. 373}

ful, to infpect it next day a fecond time, and even a third time may be needful, rather than give too hafty or precipitate a determination with refpect to the feat of a horfe's lamenefs; for the foot is always to be fufpected, efpecially after a horfe has been new fhoed, or has had his thoes faftened, or when the thoe lies too flat, and preffes upon the fole, or when the thoe is made too narrow or too ftrait for the hoof, or if there is a corn in the foot. A horfe may be lame from a nail, although it be not drove immediately into the quick, by its thicknefs preffing on the foft parts, or from its being bent inwards upon the quick, or, when drove too near, it will raife a fmall portion of the hoof, its own breadth, and force it upon the quick; and this laft caufe is the reafon why horfes are a longer time lame, after fuch accidents, than when a nail is drove immediately into the quick. A wound by a nail in the flefhy part of the foot, if timeoufly difcovered, and properly sreated, fuppurates kindly, and foon heals 
up; but a thin fplinter, (as mentioned above), when raifed from the hoof by a nail, and forced on the quick, has more lafting effects, the horfe will be the longer lame; it may be compared to a particle of fand or gravel in a man's thoe, that is conftantly pinching him, with this difference, that, in the former, it cannot be fo eafily or ro foon removed.

From what has been faid, it will be evident, that no certain rules can be laid down for difcovering the true feat of lamenefs, in a horfe, from the motion of the body; notwithftanding, a great deal has been faid on this fubject, by fome people who have pretended to this difcovery; for, when any of the parts which are neceffary to the motion of the body are injured, the adjacent parts will be affected more or lefs, and thus, by a kind of fympathy, the whole limb, \&c. will be affected; thus, a prick with a nail in the foot, will caufe an inflammation of the whole leg; the thooting 


\section{ON L A M E N E S. 373}

ing pains, in thefe cafes, may affeet the mufcles of the fhoulders, fo as to obftruct their motion, and, upon touching or pinching thefe parts, the horfe will flinch, and fhow a fenfe of pain in them, and a fiffnefs in moving forward, or frdewife, that will be very apt to miflead the unwary, and make them conclude that the caufe of lamenefs is centered entirely in the fhoulder, when, in fact, thefe are only fymptoms which proceed from the fhooting pains occafioned by the nail in the foot. There are few people, perhaps, who have not experienced fomething like this in themfelves, from cuts, punctures, boils, \&zc. in the extremities of the fingers, or toes, which frequently occafion the molt acute pains in the arms and fhoulders, $8 x$.

The caution above mentioned will appear ftill more neceary, when it is confrdered that the bony excrefcences, as formenly defcribed, will excite the moft acute pains whillt they are growing, by their extending 


\section{OB S R V A T IO N S}

tending or ftretching the membrane which covers the bone, and which is always attended more or lefs with fome degree of inflammation on the part, although, in fome cafes, their fituation cannot be perceived. And, if I may be allowed to reafon from analogy, the pain that is produced from fplents, fpavins, \&c. in horfes, whilft they are growing, may be compared, in fome degree, to the pain of teething in children, which continues till fuch time as the periofteum or membrane which covers the jawbone is divided or cut by the new tooth.

I have formerly hinted that horfes are likewife fubject to fpafms in the mufcles, and to cramps, \&cc. the real feat of which, or part affected, cannot eafily by afcertained in horfes from any external appearances; but our own experience of fome of the like complaints, and deep pains, will in fome meafure make us fenfible how painful fuch complaints may likewife be in 
horfes, and, of courfe, when they are put in motion, will occafion lamenefs.

Another caufe of. lamenefs ftill remains to be taken notice of, which proceeds from ill-made faddles, or from thofe that are not properly fitted to the back. This is a confideration of importance, both to the eafe of the horfe and the rider's fafety; for it frequently happens, that both fuffer from inattention to this article; for, if the faddle-trees are tog wide, and the faddle without a crupper, it moves too far forward, upon the fhoulder-blades; by which means, the weight of the rider, together with the points of the faddle-trees, confining the motion of the fhoulder-bones, impedes their action; this caules the horfe to ftumble, and frequently to come down; at the fame time, the cartilaginous ends of the fhoulderbones, mufcles, \&cc. are crufhed and bruifed; hence large fwellings are produced on the fhoulders or withers, which terminate in fitulous ulcers, and which, from the fituation 


\section{8 OBSER VATIONS}

of the parts, are very difficult to cure, unlees they are cautioufly and judicioufly managed. The other extreme of having too narrow faddle-trees thould likewife be carefully guarded againft, as they bruife the fkin, \&cc, and occafion thofe hard lumps called fitfafts or warbles, which mult be extirpated with the knife, and, on that account, render the horfe's back tender for a long time.

A faddle that is well fitted fhould prefs equally on every part of the back, the middle or ridge of the fpine excepted, without touching, preffing, or even coming near the fhoulder-blades, which ought by no means to be interrupted in their motion; the faddle pannel oppofite to the hollows that are on each fide of the fpine fhould be bolftered and well fitted up on each fide, which will prevent it from moving too far forward on the fhoulder-blades, even althọ" no crupper is ufed. 


\section{O N L A M E N E S S. 379}

I find, that what I have recommended in a former treatife, (on Jhoeing and difeafes of the feer, with refpect to the management of the hoofs of horfes, has been greatly mifunderftood, and that feveral people have cxpected cures from it, which I never promifed; and, upon its not fucceeding to their withes, have condenmed the practice in general. Some have had boots made for their horfes legs, which they filled with water, in order to keep them cool and moift at all times; others have had the pavement in the ftall taken up under the horfes fore-feet, in order to make a hole, which they filled with clay and water; and all this with a view to reftore foundnets, \&xc. to lame and battered horfes. I would here beg leave to obferve, that, although I have always recommended coolnefs and a certain degree of moifture, as moft natural to the legs and hoofs of horfes, by way of preventing difeafes in thefe parts, yet I never once faid that fuch means will cure difeafes there, when 
380 OBSERVATIONS, \&c.

when they have once taken place. It is very obvious, that the legs and hoofs of horfes in a natural fate, that is, running at grafs, are more expofed to coolnẹfs and moifure than to the oppofite extreme of heat; when kept in the former fituation, they are always found to be in the beft ftate both with refpect to the quality of the hoofs, firmnefs of the mufcular fibres of the legs, and foundnefs, \&xc.; but, when they are kept too hot, and, at the fame time, greafed and oiled, the pores of the hoof are thut up, the natural perfpiration is obfructed; hence they become parched, dry, hard, and brittle, and greatly difpofed to contract, or grow narrow in their dimenfions, which affect the foft internal parts within the hoof, and hence produce lamenefs. Befides, great heat, as I have formerly obferved, when applied to the legs and hoofs, occafions an accumulation of blood to them; hence a fulnefs and diftenfron of the veffels within the hoofs, and fwelling in the legs. On the contrary, a moderate 


\section{ON L A MENESS. $\quad 3 S I$}

moderate degree of coolnefs, repels this fulnefs of the veffels, braces the mufcular fibres of the legs, \&c. which keeps them fine and clean limbed, and free from any difpofition to fwelling, \&c. 



\author{
G H A P. XVII \\ O B S E R V A T I O N S \\ O N

\section{BEATING OR ILL-TREATING H O R S E S.}

ELF-prefervation is natural to horfes $\omega$ as well as to other animals; they therefore endeavour to avoid or fhun every thing that to them has the appearance of danger. This they do either from natural inftinct, from what may be called in them memory, if I may be allowed to ufe that expreffion, or from the impreffion of fear or pain they have felt on former occafions, when particular objects prefent them- 
themfelves to their view, or on hearing cers tain founds. Thus fear of pain will reftrain a dog from taking a piece of meat out of a man's hand, if he has been beat on a former occafion for attempting it. A fprightly horfe will be greatly agitated by fear from hearing the crack of a whip, or upon its being held up to him, becaufe he has fuffered pain from it formerly.

The reafon why horfes are generally rendered vicious, is mal-treatment of fome kind or other on their being frift handled; and in the breaking; the effects of which remain longer with forme than with others; according to their tempers or difpofitions; for they poffels thefe peculiarities as well as mankind, of which there are confiderable variety, and which are not neceffary here to particularize, as the method to be obferved with them in general is the fame. For if we wih to have them docile and tractable, we will fucceed much better by familiarity and careffes and gentle ufage;

than 
B E A TING HOR SES. 385

than by force and chaftifement. We ought, in this refpect, to take a leffon from the Arabians, whom I had occafion formerly to quote, and whofe horfes, it is to be obferved, are remarkably tractable and docile, and from whom the finet horfes in $\mathrm{Eu}-$ rope are defcended. Buffon fays, in vol. III. page 368 . "That as the Arabs live in "tents, thefe tents ferve them likewife for "Atables. The mare and her foal, the " hurband and his wife and children, fleep " together promifcuouly. The infants " often lie on the body, or on the neck of "the mare or foal, without receiving any " injury from thefe animals, which feem " afraid to move for fear of hurting them. "Thefe mares are fo accultomed to fo" ciety, that they fubmit to every-kind of "familiarity. The Arabs never beat their " mares, but treat them gently, and talk " and reafon with them. They are fo "careful of them as to allow them always " to walk, and never fpur them, unlefs the " occafion be very urgent. Hence, when" ever the creatures perceive the rider's 


\section{OBSERVATIONS ON}

"heel make an approach to their fides, "they inftantly fet off with incredible "fwiftnels, and leap hedges and ditches as "nimbly as ftags. If their rider chances "to fall, they are fo well trained, that they "ftop hort, even in the molt rapid gal"lop."

It has been obferved, that the tempers and difpofitions of horfes differ as much as in the human fpecies, and which ought to be particularly ftudied and artended to by thofe who go about them, and more fo in the perfon who breaks them, whofe province it is to form their manners and difpofitions together with that of their actions; at the fame time he is to correct them. from vicious habits, in the doing of which the greateft caution is neceffary : But chaftifement with feverity is always to be avoided.

We frequently meet with horfes who pave been ill ured in the breaking, that fcar 


\section{B E A TING HORSES. 387}

fear or bogle at almoft every object they meet with on the road. This, together with other caufes formerly mentioned, may proceed from the impreffion of fear, of whatever it may be called, which remains with them from being beat on fuch occafions, or on feeing fuch objects formerly. The animal, for ought we can fay, knows nothing to the contrary, but that it is the object he fees before him that inflicts the punifhment he feels, or apprehends is to follow, from the prefence of fuch an object before him, and hence endeavours to fly from or to thun it. Chaftifement, in fuch cafes, always increafes the animal's fears, and makes him worfe. But foothing words, and ftroaking his neck, \&c. gently, will pacify him, and reconcile him to the object that fcars him. He fhould likewife be fuffered to ftand ftill iill fuch time as his fear abates; at the fame time he will naturally ufe another of his fenfes to fatisfy his fears, which is that of hearing. If there be nothing to alarm that fenfe, his fear foon fubfides. The conftant habit 


\section{OBSERVATIONS ON}

habit of gentle ufage towards horfes, efpecially on fuch occafions, will banifh this timidity entirely from them. It is the fame with horfes in a variety of other refpects: Thus a fprightly horfe, once ill ufed, on his being firt thoed, will be afraid of a farrier ever afterwards; and the fight of a fmith's forge will always put him in a tremor.

The fenfe of hearing is very acute in horfes. I have known many of them diftinguifh when the farrier was prefent, who thoed them, and thow all the fymptoms of fear on hearing his voice only. It will therefore be the intereft of every farrier to avoid or to prevent the ufing or treating horfes ill on their firft being fhoed; for, although he fhould have a little extra trouble on thefe occafions, (and which he ought to be paid for) it is of no confideration when compared to the conftant trouble and danger in thoeing fuch horfes afterwards. 


\section{B E A T ING HORSES. 389}

As horfes thus readily know the voice of individuals, they foon learn to diftinguifh the tone of foothing, or that of anger, in every language where they happen to be fituated; and it will be found, that where horfes are accuftomed to be directed by the ear, that is, by words fpoken familiarly to them, that they are by far more tractable and pliant than where the whip is always ufed.

The obfervation with refpect to horfes that fcar or bogle at objects on the road, ought particularly to be attended to, as it is frequently followed with fatal confequences to their riders, and is fometimes hurtful to themíelves, as the fudden or violent exertions made on thefe occafions have fometimes produced incurable lamenefs.

I would likewife offer one advice to fuch as are bad riders, or who are not much accuftomed to it, which is, never to wear fpurs, for this reafon, as they are not acquainted with the proper method of frtting in the faddle. They grafp the

horfe's 


\section{OBSER VATIONS ON}

horfe's fides and belly tight with their legs and heels; at the fame time they turn out their toes. From this pofition, thê fpurs, at every jolt of the horfe, are forced into his fides. Hence the horfe will, as he has been taught, exert himfelf to the utmoft of his fpeed, and run off with his rider. The horfe, at the fame time, will naturally bound and kick, till he frees himfelf from the fpurs that fo cruelly torment him.

It is much the fame with timorous riders on the apprehenfion of any danger. They may be faid to communicate the impreffion of fear to the horfe by their fuddenly grafping his fides with their legs and heels, in order to keep themfelves firmly feated in the faddle. The horfe, naturally expecting the fpurs, immediately fets off at full fpeed.

Many horfes, from a variety of caufes, are apt to trip and fumble when travelling on the road. The whip and fpurs are too frequently applied by way of chaftifing them 


\section{B EA TING HORSES. 391}

them for this fault. Hence thefe horfes, who are much addicted to tripping or fumbling, foon become fenfible of what they are to expect from a repetition of this blunder; which no fooner happens, than, in order to avoid the punifhment they dread, they exert themfelves to the utmoft of their power to recover their feet, and fuddenly fpring forwards or fideways, to the great danger of unhorfing the rider. It likewife frequently happens, that in their attempts to recover themfelves from the firit tumble, that through fear, \&c. they often fail in their endeavours, and tumble headlong.

I have hinted above, that there are a variety of caules which contribute to make even the fureft footed horfe trip and ftumble at times; and, in the cafes of others, which, when duly confidered, ought to fcreen them from chaftifement they do not merit. 


\section{OBSER VATIONS ON}

It has been frequently hinted, that if a faddle comes too far forward on the thoulders, that this circumftance, together with the weight of the rider, prevents the free action of the thoulder-blades, of courfe the horfe muft unavoidably trip and ftumble. Every thing about the feet that makes the horfe go uneafy will likewife operate to produce the fame effect as weak hoofs, whether naturally fo, or occafioned by bad management. Too ftrait, or too heavy, thick, illformed fhoes, the nails drove too near the quick, difeafes in the feet, as corns, running thrufhes, hoof-bound, cracks in the heels, \&c. to which may be added the fuffering the hoofs to grow too long toward the toe, by which means the horfe's toe ftrikes the ground before he has made a full ftep, whether in walking or trotting, of courfe he will trip and frike the ftones that lies in his way, and drive the loofe ones in every direction around him.

Horfes 
B EA TING HOR S S. 393

Horfes likewife fumble from debility or weaknefs; this may either proceed from a natural weaknefs of body, or from fatigue, o: when overloaded by too heavy a rider in proportion to their ftrength, or faintnefs from low diet, or poor keeping; and I have frequently remarked of hearing more complaints of horfes fumbling about the end of autumn, than at any other feafon of the year, which I have always attributed to the natural weaknefs which prevails in their bodies at that period, when they are moulting, and more efpecially in thofe horfes who are kept on low poor feeding, which adds to it. 



\section{G H A P. XVIII.}

O B S E R V A T I O N S

O M

TRIMMING HORSES EARS.

NY obfervations on this head will be H thought fuperfluous and trifling by many people, who think this operation not only ornamental, but ufeful and even neceffary to horfes. But as the plan I have adopted, which is to treat on whatever is hurtful or beneficial to horfes, I hope that will apologize for the obfervations I am about to make.

The ears of horfes, like other animals, are covered on the infide with a thort down, 


\section{$39^{\circ}$ OBSERVATIONS ON}

down, intermixed with long hairs, which line the external cavity of the ear; the ufe of which feems defigned by nature to prevent harh founds from making too great an impreffion upon the brain, and likewife to prevent the cold air, rain, duft, flies, \&c. from annoying the internal ear.

The means commonly ufed to remove this down, \&x. is by the fciffars, the flame of a candle, or that of a burning torch. Both the latter are cruel and barbarous, and caufe a deal of pain to the animal, not only from the blifters that fometimes sife on the ears after this manner of finging them, but likewife from the means that are ured to make horfes nand with patience to undiergo the operation, that is a twitch * on the nofe; and perhaps if he is troublefome to the operator, one put on the other ear.

* An infrument that fqueczes the nofe. 


\section{TRIMMING HORSES EARS. 397}

It is to be obferved, that horfes are very much guided or directed by the fenfe of hearing. This is obvious in thofe that hear diftinctly, (for many of them, particularly the fineft kind, as they only are liable to this kind of treatment, have the fenfe of hearing confiderab!y blunted, if not rendered quite deaf from the above operation,) from the motion of their ears, and the direction they give them to whatever quarter any founds come from, the attention they pay to what paffes around them, or to what is fpoke to them.

As this operation is generally firft performed on young horfes at the time they are breaking, it is the more hurtful, as the uncommon founds, which are entirely new to them, and to which they are then more expofed on the road or in ftreets, muft make the greater impreflion on the fenfe of hearing; fuch as the rattling of carriages, drums, \&cc. and perhaps it may be owing to the above caufe only that many horfes 


\section{OBSERVATIONS ON}

horfes are timorous to approach, or to pafs carriages, and remain fo ever afterwards.

Another difadvantage which attends this operation upon the ears of horfes, is, that they will not go on chearfully, when travelling, in oppofition to the wind, more efpecially if it rains; for as the wind and raingets freeaccefs into the ears, they are continually lhaking their heads and endeavouring to turn from it ; and thofe who are of a more impatient temper, will wheel fuddenly round, in order to avoid what gives them fo much uneafinefs. They are then faid to be reftive; the whip and fpurs are applied by way of chaftifement for a fuppofed fault only.

From what has been faid, it will be obvious, that, from the conftant practice of taking away the natural covering from the infide of the ears, that the internal ear muft be expofed to be confiderably injured, particularly from cold, duft, \&c. which blunts the fenfe of hearing, and perhaps 


\section{TRIMMING HORSES EARS. 399}

caufes deafnefs; for it is obferved in thofe horfes who have been much ufed to this treatment, that they lofe that lively, active motion of the ears, and appear dull and inattentive to what paffes around them, and even to the voice of their keeper.

What has been juft now obferved with refpect to the trimming the infide of horfes ears, may be applied to the practice of cropping, or rather cutting horfes ears, almoft clofs to the fcull, as it produces the fame effects on the fenfe of hearing; befides another difadvantage attending it, which is the difficulty of keeping a collar or bridle on their heads. 

. C If A P. XIX.

OBSER VATIONS

$\ddot{0} \mathrm{~N}$

FRICTION, OR DRESSING HORSES。

HAVE hitherto mentioned currying. 1 dreffing, and cleaning of horfes, in $a$ curfory manner. In this place it will be proper to enlarge more fully on the advantages that arife from it. - As exercife acts as an affiftant to the heart in promoting the circulation of the fluids, in like manner friction, on the furface of the body, by means of the curry comb and bruh, contributes to forward the circulating fluids there, and promotes that infenfible perfpiration through the cưticular pores of the $3 \mathrm{E}$ Nkin, 
fkin, which is fo conducive to the health of horfes.

The general intention of currying and brufhing horfes that are kept in ftables, it would appear, from the manner of performing it, is with a view only of taking away the duft and dirt that may be collected on the hair. But, when confidered in a more extenfive point of view, it will be found, when properly performed, to be a very beneficial operation to horfes, as they naturally perfpire much through the pores of the $\mathrm{kkin}$. When this operation is neglected, or flightly performed, the perfpirable matter hardens in the pores, it remains lodged at the roots of the hair, and has the appearance of a whitifh or brownifh duft, and fometimes like fmall fcales, which, for the moft part, creates an itching; the fkin, at the fame time, generally appears dry and hard, the hair ftares or ftands on end, (in place of lying fmooth and fhining), which 
which always denotes a confriction of the cuticular pores of the fkin.

Van Swieten, in his commentaries, obferves on friction to the human body, "Which*," he fays, "is in a manner the " alternate preflur and relaxation of the " parts of the body, gentle friction preffes " the veins only, whereas a ftronger preffes "alfo the arteries. By preffing the veins, " it accelerates the motion of the venal "blood towards the heart; and, by this " means, the motion of the heart is quick" ened, and, of courfe, the blood is pro" pelled with a greater velocity through " all the veffels. The vital powers may be " increafed therefore by friction to any de"gree, without any foreign addition to " the body; for a burning fever may be " kindled by friction in the coldeft hydro" pical perfon. In thofe bodies where " none of the vifcera deftined to form the "chyle,

* Vol. I. p. 67. 
" chyle, difcharge their office through a " Itate of inactivity, the rubbing the abdo" men with coarfe woolen cloths in a morn" ing fafting, has wrought wonderful ef"fects. And, for this reafon, the ancients "fet a high value upon frictions, both as " a prefervative of heaith, and ferviceable " in the cure of many difeafes." The fame author farther obferves, that "if a "horfe be fuffered to ftand in the ftable " without drefling, in a few days he will "become ufelefs*; but, if his $\mathrm{kkin}$ be " curried daily with an iron comb, and " rubbed with a bruh, he will continue " active for many years." And, in page 376 . he obferves the great ufe of frictions in refolving obftructions: "I have feen," fays. he, " an indurated parotid gland, af" ter many very good applications have "failed, refolved by being wivell rubbed " with woollen cloths for an hour together, "twice a-day, after having been expofed "to the vapour of warm water and vinegar. - He probably means unfit for active exercifes. 


\section{ON FRICTION. 405}

"gar. The like alfo has been feen in the " glands of the neck; when they have been "Atrumous:"

Columella likewife obferves, that "* the " bodies of cattle ought to be rubbed down " daily, as well as the bodies of men; and " oftentimes it does them more good to " have their backs well rubbed down, than ". their bellies filled with large quantities of "provender."

It was cuftomary with the ancients to advife the ufe of baths and frictions, after long.journeys, to the human body; and this cuftom fill prevails in Afra.

From what has been oblerved on friction or rubbing to the human body, it will be evident how much benefit may be derived to horfes from good rubbing and dreffing, as frequently as poffible; but more efpecially when they are cold and chilly, after being over-

De Re Ruftica, lib. vi. cap. 30. p. 597. 
over-heated, or from being fuffered to ftand in the cold air, tied at the ftable-door; friction becomes then the more neceffary, as it produces a gentle heat and warmth all over the furface of the body, and prevents ftagnation of the fluids in the veffels on the furface, and promotes a free perfirition through the cutaneous pores of the fkin.

Notwithftanding the great advantages that may be derived to horfes when in health by friction, or rubbing their bodies, yet there are cafes of difeafe in which it may prove hurtful on certain parts, as in fwellings of the legs, attended with inflammation, where rubbing with the hands is frequently recommended, or when there is a difcharge of hharp ichorous matter from the pores, or in cracks in the heels, attended with great pain, or in wounds or punctures; as all thefe cafes are attended with more or lefs inflammation, friction then proves hurtful on thefe parts; as the heat there is already confiderable, friction will add to it, and, 
and, of courfe, increafe the diforder; befides, as the veffels, in fuch cafes, are too full and diftended with blood, the force that is applied in rubbing the legs renders them liable to be ruptured.

Wafhing horfes with cold water, in order to clean them, by throwing whole pailfuls on their bodies when they are over-heated, immediately after polting, \&c. which, I am informed, is now become fafhionable on the poft roads; and, it is faid, that no bad confequences follow from it, of which I have great doubt. If they are well rubbed down immediately after fuch exercifes, there is no need for wafhing them with cold water, and then rubbing them afterwards, as the latter operation is fufficient to clean them, without running any hazard of warhing them with cold water, as cooling the body too fuddenly always conftringes and fhuts up the cuticular pores, and prevents that perfpiration which is found fo effentially neceffary for promoting the 


\section{OBSER V A T IONS}

the health of men, and of thole animals who perfpire through the pores of the fkin; and, it is probable, that the only thing that prevents immediate bad confequences following from this manner of treatment, is, that fuch horfes are very foon afterwards put to active exercifes again by pofting, \&c. by which the ftrong perfpiration they are fo foon put into carries off the bad confequences that might have been expected from it; for not only daily experience, (the fingle inftance of the prefent practice above mentioned excepted), but the experience of paft ages have demonftrated the bad confequences that commonly follow from the too fudden application of cold, whether it be water or air, to the human or animal body, when over-heated; for, although the conftitution of the animal body be fuch, that at times it can withftand many bocks, alterations, and irregularities; yet prudence points out the danger that may follow, and which ought at all times to be avoided. No doubt there may be exceptions to general rules, and, in this in-

ftance 
ftance of wafhing horfes, it is not to be depended on, as too fudden tranfitions cannot fail, in certain circumftances, or habit of body, to produce fome kind or degree of diforder in the conftitution, when difeafe will be the confequence; inftances of which will readily occur to every one, where both men and horfes have undergone very fudden tranfitions from cold to heat, and from heat to cold, where fome have efcaped any bad confequences from it, whilf, at the fame time, it has proved fatal to others; hence, therefore; it will be prudent to ayoid the wafhing of horfes, when they are over-heated, with cold water, more efpecially in cold chilly weather, as it anfwers no good purpofe, and in which there is danger to be apprehended. For the fame reafon, wafhing the dirt off horfes legs, belly, and thighs, with cold water, immediaicly after they have performed a ftage and have been over-heated, hould likewife be avoided till they are cool, well rubbed afterwards, and thoroughly dry; but which is very feldom put in practice.

$$
3 \text { I C.HAP. }
$$





\title{
Q H A P. XX.
}

\section{O B S E R A T I O N S}

\author{
O $\mathrm{N}$ TH E
}

\section{MANAGEMENT OF HORSES WHEN TRAVELLING.}

HE frequent applications that have

1 been made to me for directions concerning the management of horfes, previous to, or when on a journey, induces me to give my readers a few thort obfervations on that fubject.

It ought always to be remembered, that, when a horfe is intended for a journey of any length, and the profpect of continuing it for fome time, that he be properly prepared 
pared for it, by good feeding, and that he has been in the habitual practice of regular and daily exercife; for, without a due proportion of the latter, no horfe can be in a proper condition for travelling, or undergoing any fatigue, without danger of being laid up by fome acute difeafe; for which reafon, it will be obvious, that a horfe which is too fat, or full of Alen, or that has been kept long on foft feeding, or newly from the hands of a dealer, or running late at grafs, or that has been accuftomed to ftand much at re?t in the ftable, or thofe that are too low of flem, and are wore out or exhaufted by former fatigue, from difeafe, or from old age, are unfit for this purpofe; neither are too young horfes fit for a journey, efpecially when about cafting their foal teeth, or before their ftrength is confirmed, and their bodies feafoned by the habit of labour or exercifes. On the other hand, a horfe that is rather meagre than fat, and whofe flefh is firm from good feeding, andin the habitual practice of undergoing 


\section{ON TRAVELIING. $\quad 413$}

dergoing active exercifes or labour, has always the beft chance of performing a long journey with eafe to himfelf, and with fatisfaction to his owner.

For the eafe of the horfe, and fafety of the rider, it is proper to attend particularly to the faddle, that it fir the horfe's back properly, that is, it muft neither be too wide in the trees, to come forward on the fhoulder-blades, nor too narrow, fo as to pinch and break off or bruife the fkin; and that the bolftering or ftuffing in the pannel is adapted to the hollow fpaces on each fide of the fpine or ridge of the back; that it lie fmooth and equal on every part, the fpine excepted, which it ought not to touch or come near in the leaft, neither on the fore or back part. If it is thus properly fitted, there will be no occafion for a crupper, unlefs it may be the choice of the rider. The rider mult likewife take notice, when on the road, that the ftuffing in the faddle pannel does not become too thin, which 


\section{$4 I$ OBSERVATION}

which it will be apt to do, and, if needful, to have it repaired.

Before a horfe fets out on a journey, it will be prudent to have him thoed fome days before hand, in cafe any accident thould happen by driving the nails too near, \&c. There is another advantage attending this caution, which is, the thoes become firmer feated on the hoofs, and the clenches and nails rufted, which contributes greatly to keep them firm in their place. If the horfe goes too near, fo as to cut his legs, either before or behind, that mut be provided againft in the thoeing.

It is cultomary to water horfes in the morning, before they are fed; but it will be found of more advantage to water them after feeding, as it then more properly dilutes the food that is taken into the ftomach; at the fame time it wathes the mouth and throat, and prevents or reftrains the too fudden return of thirft or defire for wa-

ters 


\section{ON TRAVELLING. 4 I 5}

ter, which occafions an inclination in horfes of ftopping at every rivulet that comes in their way on the road. But; as horfes that ftand in a warm ftable thro' the night, and, perhaps, feeding greedily on hay, are difpofed to drink too much water, when led to a watering trough, it will be proper to prevent them from drinking too much, by giving them water in a pail by meafure; about half a pailful at once will be fufficient. On their firf fetting out on the road, they ought not to be too fuddenly hurried on, as the ftomach and bowels are then too full; as this fulnefs goes off, they will naturally mend their paces of themfelves; towards the end of the ftage, their motion may be reftrained by degrees, and brought in as cool as poflible; after they are thoroughly cool and well dreffed, they fhould then be fed and watered as above. The fame rules may be obferved at the end of every ftage. At night, their legs, below the knee, and the hoofs, may be wafhed with water, and well rubbed afterwards, 


\section{O.B S E R V T I O N S}

till the legs are thoroughly dry, when they may be fed and indulged with more water given them at once than they have had through the day: It ought always to be obferved, that, when horfes come to the end of a ftage, if they are very warm, that they be walked about gently till they. cool gradually; and never to wan their legs, or any part of their bodies, till they are cool. In hot weather, when the roads are dry and dufty, the wafhing of horfes legs proves very refrefhing; when the roads are dirty and wet, it is the readieft method of cleaning them, but they ought always to be well rubbed afterwards.

It may be needful to remind young tra- vellers, that they have their horfes thoes infpected at every ftage, and, whatever is amifs about them, or the clenches 'of the nails, rectified; likewife to obferve that the faddle has kept its proper place, in order to prevent its injuring the back or coming forward on the fhoulder-blades. 
It frequently liappens; that the fkin of horfes who have not been accuftomed to perform long journeys becomes fcalded by the friction of the, girths, and likewife on the under part of the brealt, between the fore legs; where the Ikin is loofe and full of wrinkles; this proceeds entirely from neglect; in not cleaning the fand and dirt from thefe parts; but fuffering it to cloat amongit the hair, it collects in lumps, and; by the continued friction in the horfe's moving, it produces the above effect, which is attended with pain to the animal, and caufes a contracted ftep in his going; and when it is not taken notice of in proper time, the parts become inflamed and fwell ed, which proves a great hindrance to the horfe's travelling; when the hair is fretted off by the girths, they thould be wathed clean from the fand and dirt, and dried 'thoroughly before a fire, after the horfe is done up for the night; at the fame time; it will be proper to caufe the fand and gravel to be picked out from below the Thoes,

$3 \mathrm{G} \quad$ and 


\section{OBSERVATIONS}

and to wafh out the fmaller particles of fand that are apt to lo: ge there, as in weak hoofs it frequently occifions laments. One great advantage that arifes to the honts trom being frequently walhed and moiftened with water, efpecially in dry warm weather is, that it keeps them cool, a fate which is moft natural to them, and which is much more beneficial than all the ftopping and greafing that at prefent is fo much in ufe. But, as this fimple procefs of wafhing the hoofs with water only, diminifhes the oftler's fees, at the fame time that it creates more labour and trouble, he ought by no means to be a fufferer; the owner will, in the end, be a gainer by the exchange.

It is likewife proper to obferve, that the faddle girths be not drawn too tight, efpecially on the belly; if the fore or point girths on the breaft be drawn tolerably tight, that will be fufficient of itfelf, if the faddle iits properly to keep it in its place. The girths on the belly, however tight they may 


\section{ON TRAVELLING. 419}

may be drawn, foon flacken as the bowels empty, and they only ferve to give pain to the animal, by confining the vifcera, and occalion a difficulty of breathing on the horfe's firft fetting out, when the belly is diftended with food; befides, in round barrelled or round bellied horfes, efpecially if the belly is big, the back-girths, the tighter they are drawn, contribute to purh the faddle forwards on the fhoulders, in fpite of every means that can be devifed to keep it in its proper place.

Road-horfes, on long ftages, at any baiting place, about the middle of the ftage, mould get a little oatmeal mixed in about half a pail of water, to refrefh them; this not only quenches their thirft, by warhing their mouths, \&c. when the roads are dufty, but it invigorates them to perform the remainder of the ftage; the oatmeal prevents any bad confequences that might arife to them from giving cold water when they are heated, 
heared, efpecially in fuch a fmall quantity at once:

It frequently happens on bye-roads, or little frequented inns, and baiting places, efpecially towards the end of harvett, that horfes are fed with green oats in the theaf, newly taken from the field, from want of other feeding; this is extremely hurtful to them, as it occafions faintifhnefs, \&c. and frequently produces a diarrhoea or fcouring, attended with great weaknefs. If porfible, in fuch fituations, it would be prudent to get oatmeal for them, and mix it with a fmall quantity of water, only as much as is fufficient to moiften the meal, fo as to prevent it from blowing away by their breath in feeding: It would be the means of faving the life of many a good horfe, that otherwife falls a facrifice in fuch cafes from this kind of green feeding. When the oats are too new and foftinh, oatmeal hould always be got for them, if poffible, in their ftead, and given as above directed. 


\section{ON TRA VELLING. $\quad 421$}

directed. Bread, of different kinds, is likewife a good fubftitute in place of new or bad grain, efpecially the coarfe wheaten bread, formerly fo much ufed to horfes, and known by the name of horfe-bread. But, whatever kind can be got, if they will not eat it by itfelf, it may be rubbed down between the hands, or beat in a trough, and mixed with oatmeal, this will make very good feeding for horfes, and which moft of them will eat. A little extra trouble and care, in fuch cafes, ought not to be grudged for the benefit of fo ufeful and valuable creatures, on fuch emergencies.

Horfes on a journey, from the ftrong perfpiration they undergo, and the conftant feeding on dry food, are apt to become too coltive; this ought to be guarded againft, by giving them occafionally a manh of fcalded bran, boiled barley, or malt, either by themfelves, or mixed in their oats, by way of a double feed. When a horfe thows an inclination to ftale on the road, he fhould 


\section{OBSER V A T IONS}

always be allowed to ftand ftill for that purpofe; and, if he has any difficulty in in Ataleing, an ounce of nitre may be given himin his food for a few nights following. It is of confequence to attend to this difcharge, and alfo that by flool, as inattention to either of them frequently proves the fource of many diforders.

Before I conclude this chapter on travelling, I would beg leave to prefer a petition in favour of the poor animal who is the fubject of this treatife, and which is, the allowing him a little more time to perform the tank required of him; 15 minutes more than what is allowed at prefent to perform a ftage of as many miles, would fave the lives of a number of horfes in Great Britain ycarly, befides the numbers that are lamed, and otherwife rendered ufelefs by fuch feverity.

As it is not foreign to the prefent fubject, I hall here mention one obfervation

on 


\section{ON TRAVELLIN G. 423}

on thoeing horfes, which had efcaped me when treating on that head in my former publication.

When the roads, \&c. are covered with ice, it becomes neceffary to have the heels of the thoes turned up, and frequently tharpened, in order to prevent horfes from flipping and falling. As this cannot be done without the frequent moving of the Thoes, which breaks and deftroys the cruft of the hoofs where the nails are drove, to prevent this, I have always recommended to thofe who were willing, to be at the expence, to have fteel points fcrewed into the heels or quarters of each fhoe, which might be taken out and put in occafionally.

The method of doing this properly, is firt to have the fhoes fitted to the thape of the hoof, then to make a fmall round hole in the extremity of. each heel, or in the quarters, about three eighths of an inch in diameter, or more, in proportion to the breadth 


\section{OBSERVATIONS}

breadth and fize of the fhoe; in each of thefe holes a fcrew is to be made; the fteel points are likewife to have a ferew on them, exactly fitted to that in the hoes. Care muft be taken that the fcrew on the points is no longer, when they are forewed into the fhoe, than the thicknefs of the latter. The fteel points are to be made fharp; they may either be made fquare, triangular, or chiffel pointed, as may be moft agreeable; the height of the point above the fhoe fhould not exceed half an inch for a faddle horfe; they may be made higher for a draught horfe. The key,or handle that is neceffary to fcrew them in and out occafionally, is made in the thape of the capital letter $T$, and of a fufficient fize and ftrength; at the botrom of the handle, a focket or cavity muft be made, properly adapted to the hape of the fteel point, and fo deep as to receive the whole head of the point that is above the thoe. In order to prevent the forew from breaking at the neck, it will be neceffary to make it of a gradual taper; the fame 


\section{ON TRAVELLING. $42 \xi$}

is likewife to be obferved of the female fcrew that receives it, that is, the hole muft be wider on the upper part of the thoe than the under part; the tharp points may be tempered or hardened, in order to prevent them from growing too foon blunt; but, when they become blunt, they may be tharpened as at firft. Thefe points Thould be unfcrewed when the horfe is put into the ftable, as the ftones will do them more injury in a few minutes than a day's riding on ice. A draught horfe thould have one point on each thoe, as that gives them firmer footing in drawing on ice; but, for a faddle horfe, when they are put there, they are apt to make him trip and fumble.

When the thoes are provided with thefe points, a horfe will travel on ice with the greateft fecurity and fteadinefs, much more fo than on caufeway or turnpike roads, as the weight of the horfe preffes them down in the ice at every ftep he makes.

$$
\text { E I N I S. }
$$




\section{E $\quad R \quad R \quad A \quad T A$.}

Page 35 line 1. for contractive read contractile. 67. laft line, for weighs read weigh. 109. line 12. for putrifaction read putrefaction. 126. 148. I. for are read is.

3. dele cuticular.

239. 19. for defluctions read defluxions. 282. I. for ditto read ditto. 268. I6. for was read vere.

312. $\quad 5$. and 6. for nafuea read naufea: 335. I3. for camplaints read complaints. 335. I 6 . for putrifaction read putrefaction. 34x. 19. dele cuticular. 342. 19. dele cuticular. 349. 7 . for outter read outer: 

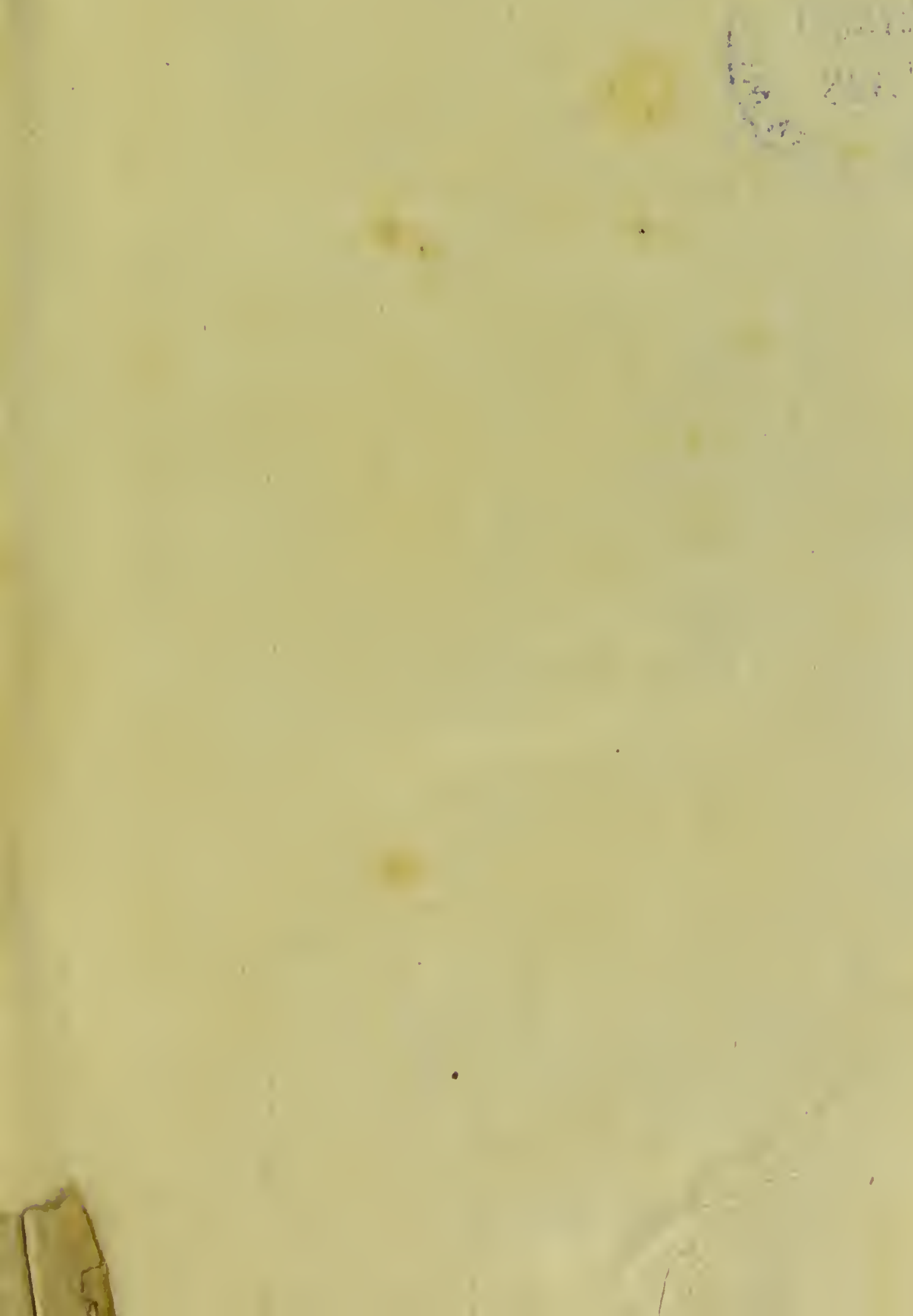


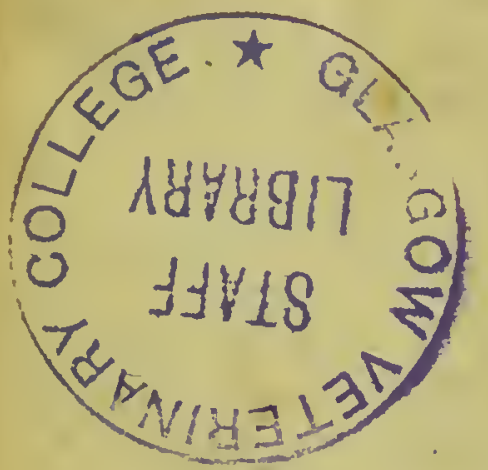



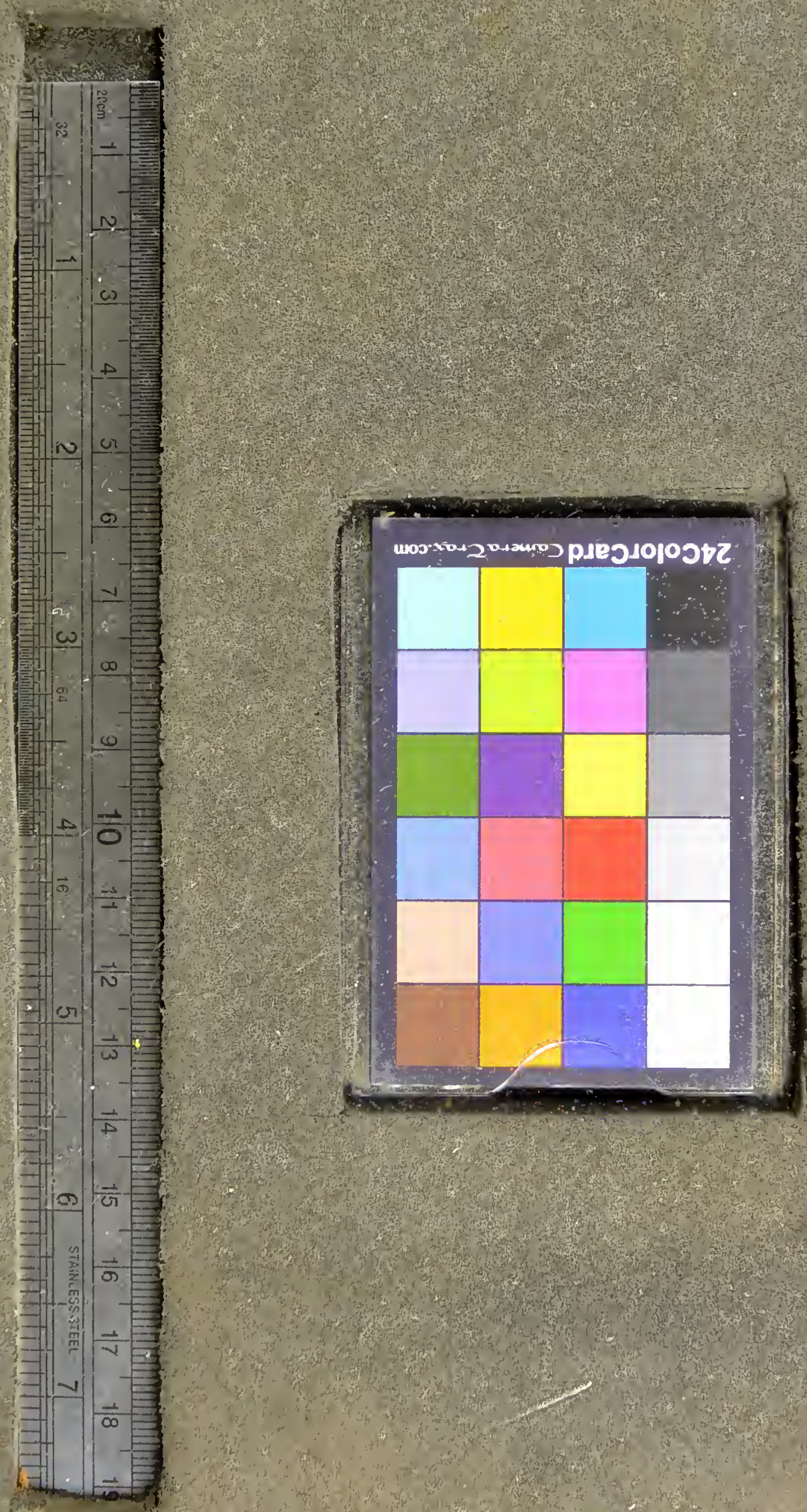